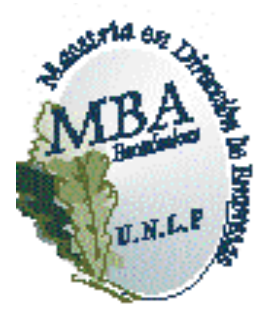

Universidad Nacional de La Plata

Facultad de Ciencias Económicas

Maestría en Dirección de Empresas

\title{
Evolución del Mercado de Seguros de Vida en Argentina
}

\author{
Restricciones para el Crecimiento
}

Trabajo final para optar al título de Magíster

- Autor: Ricardo Bautista Penna

Licenciado en Administración

- Edición: Novena (Cursada en años 2006 y 2007)

- Director de Tesis: Dr. Daniel A. Lauría

\section{La Plata}

Noviembre de 2010 



\section{Índice}

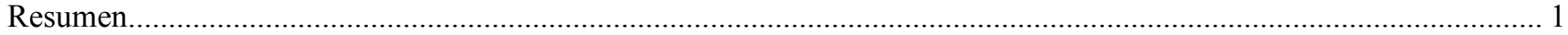

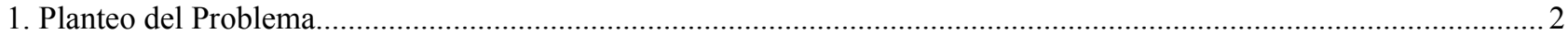

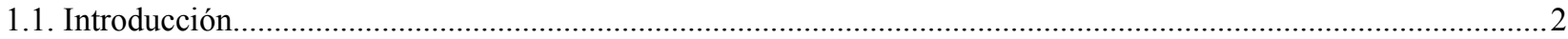

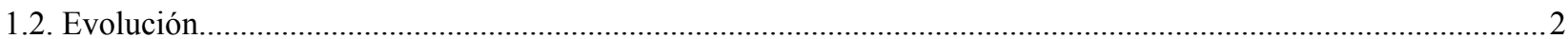

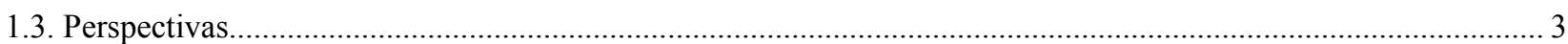

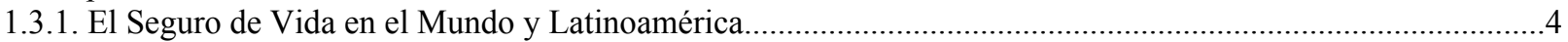

1.3.2. El Control y Mercado de los Seguros de Vida en la República Argentina ....................................................6

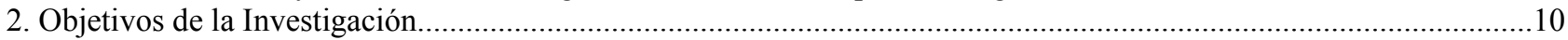

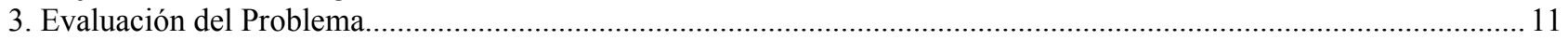

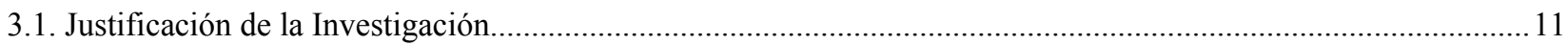

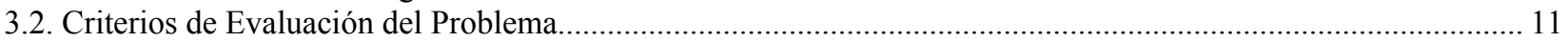

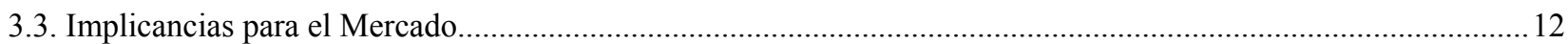

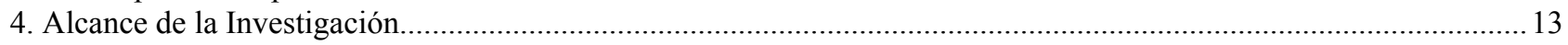

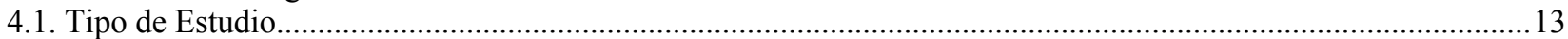

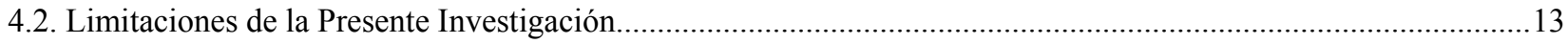

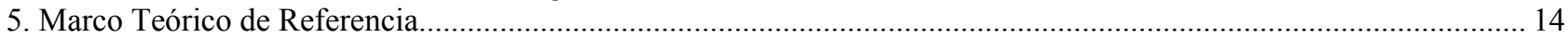

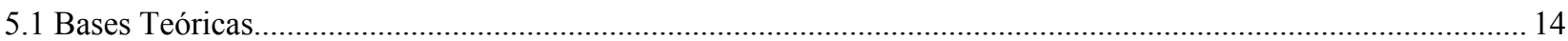

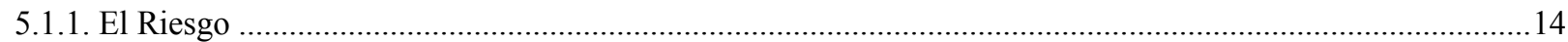

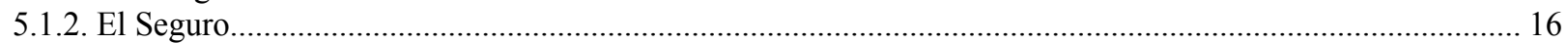

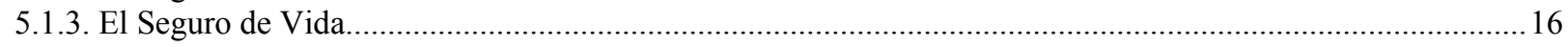

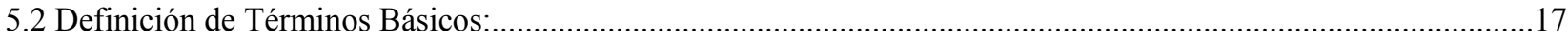

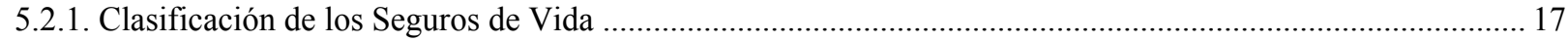

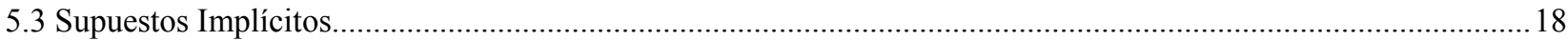

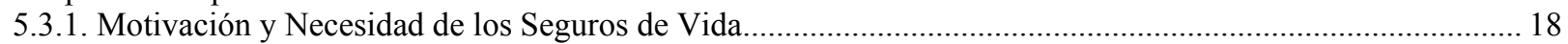

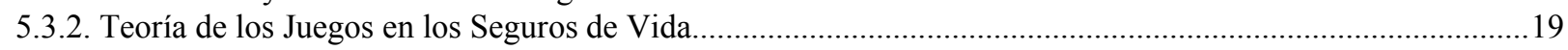

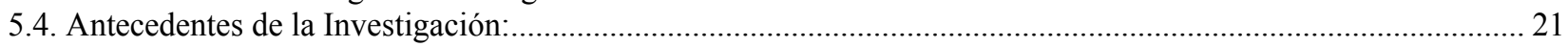

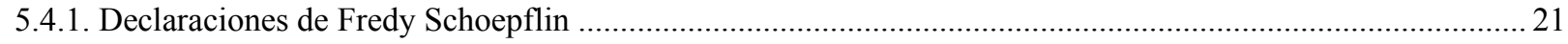

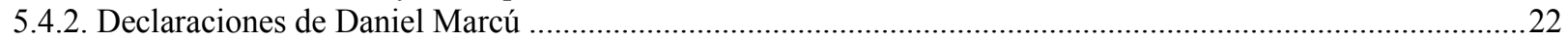

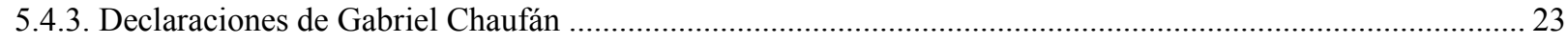

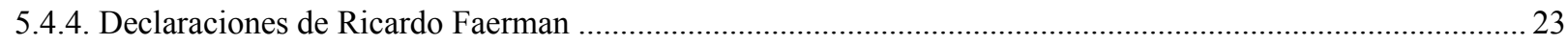

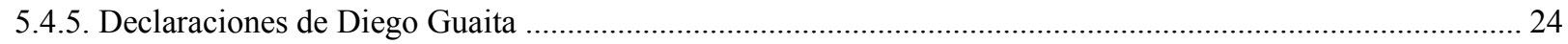

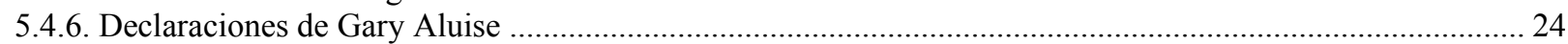

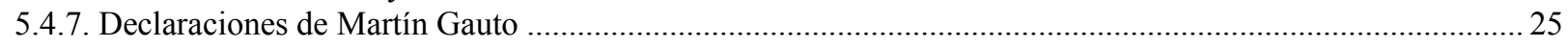

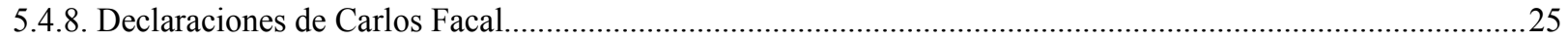

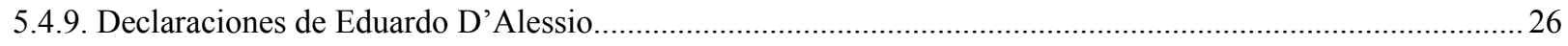

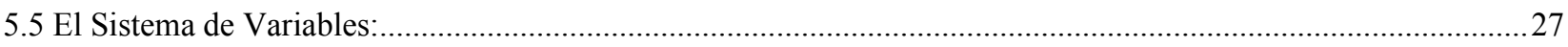

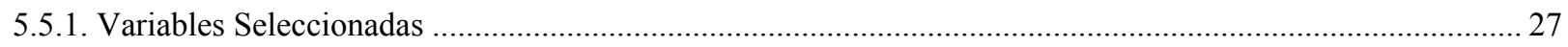

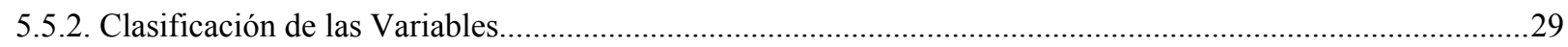

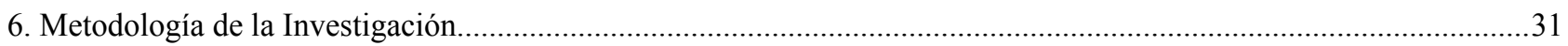

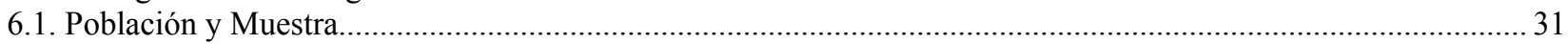

6.2. Tipo de Investigación................................................................................................................................. 32

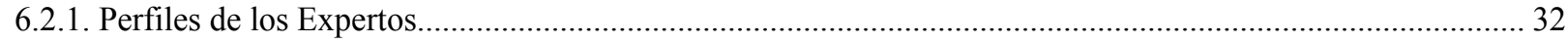

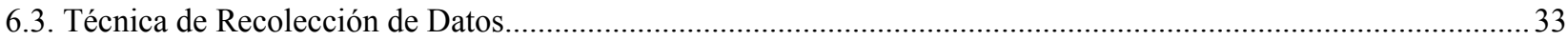

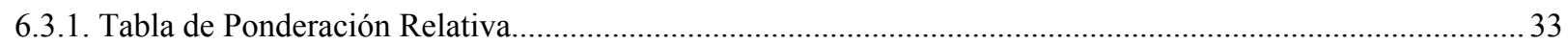

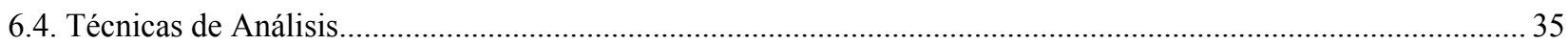

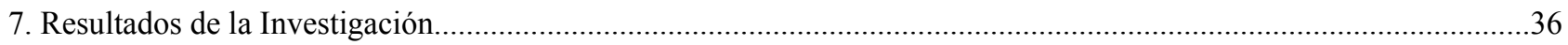

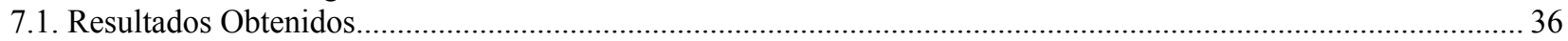

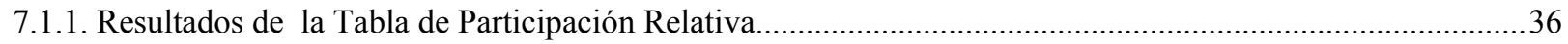

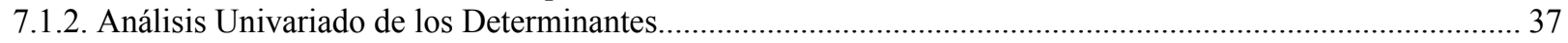

7.1.3. Tabla a Doble Entrada de Puntajes Promedio de los Determinantes................................................................40

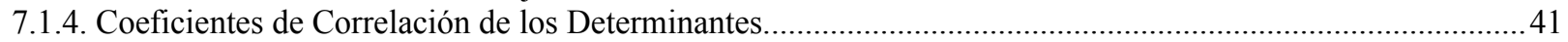

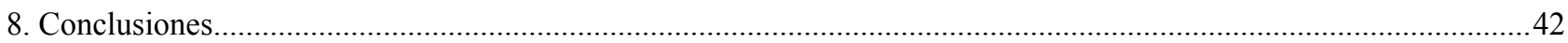

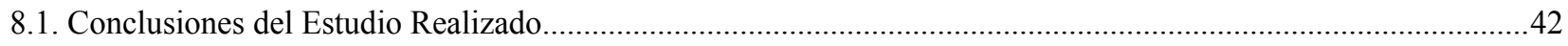

Lic. Ricardo B. Penna $\quad$ MBA - UNLP 9 Edición Página $\mathrm{N}^{\circ} \mathrm{I}$ 
8.1.1. Clasificación de los Determinantes Conforme con el Tipo de Condicionamiento............................................43

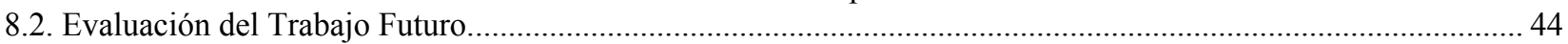

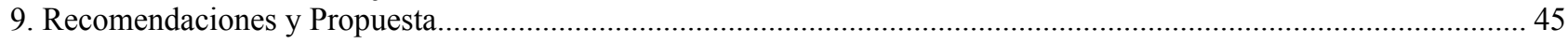

9.1. Propuesta de Valor

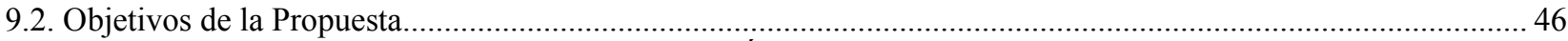

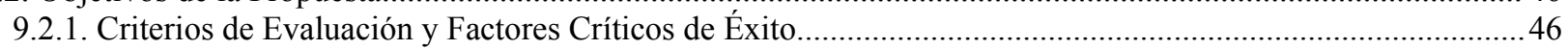

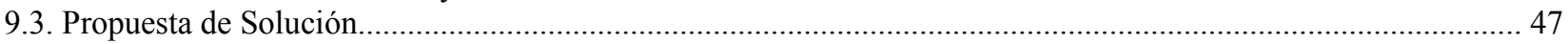

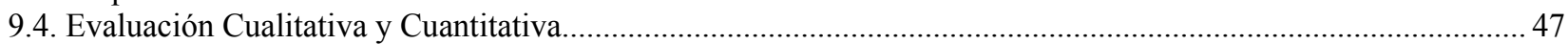

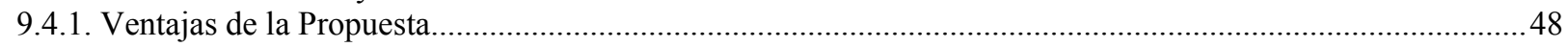

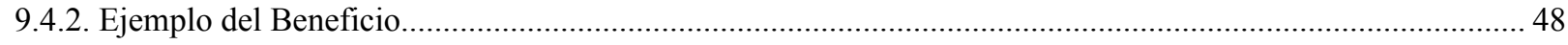

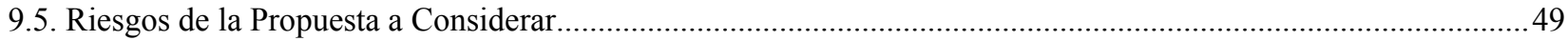

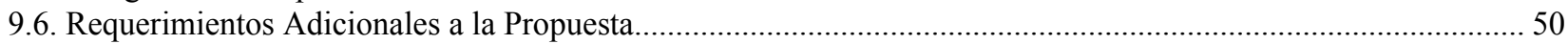

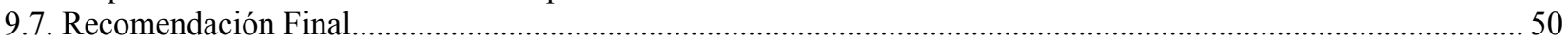

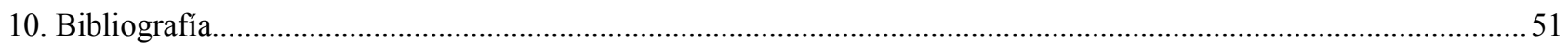

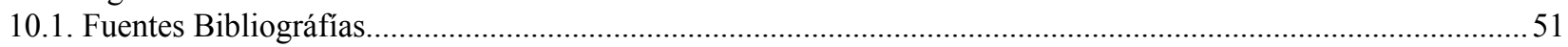

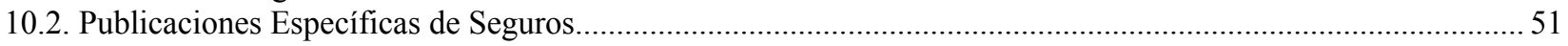

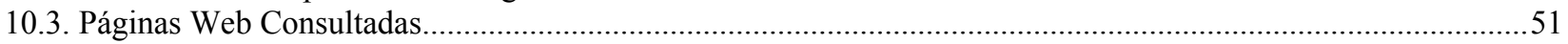

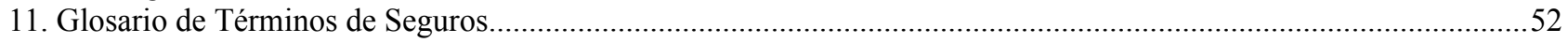

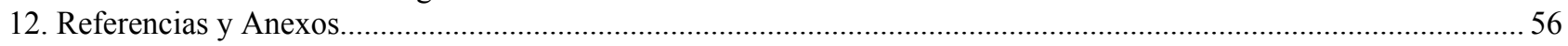

12.1. Tablas del Estudio sobre la Relación de la Población y el Seguro de Vida.............................................................56

12.1.1. Encuestas sobre el Proyectos y Ahorros Familiares...............................................................................56

12.1.2. Encuestas sobre Información y Contratación de Seguros de Vida............................................................56

12.1.3. Encuestas sobre Intereses y Motivación a los de Seguros de Vida............................................................ 57

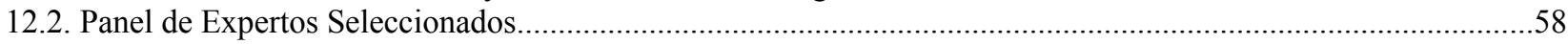

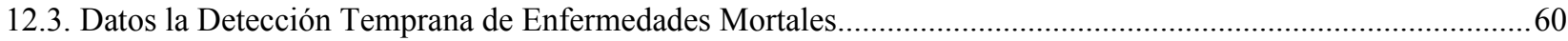

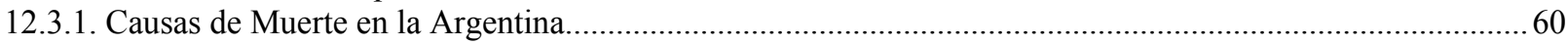

12.3.2. Opiniones Especializadas sobre la Detección Temprana de Enfermedades..................................................60

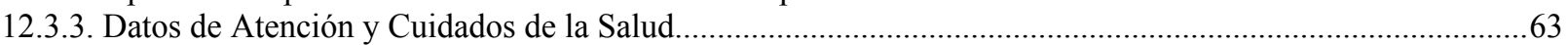

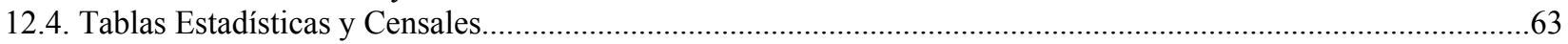

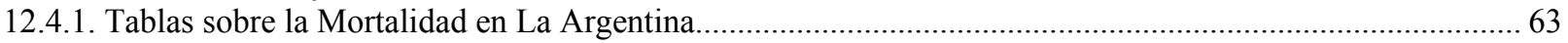

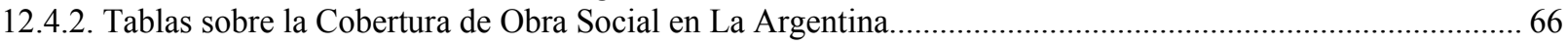

12.4.3. Tablas sobre la realización de Estudios de Prevención para la Salud............................................................67

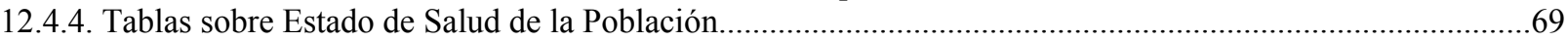




\section{Resumen}

El presente trabajo trata sobre los fundamentos, causas y/o determinantes de la actual evolución de los seguros de vida individual en la República Argentina y las perspectivas para el futuro del sector.

En este sentido, luego de definir la problemática planteada, sus implicancias y las comparaciones con lo que ocurre en otras regiones, se introduce tanto en la temática de la gestión del riesgo en las empresas como en la administración de los seguros en general, conformando el marco teórico del estudio, para luego abordar las particularidades del mercado de los seguros de vida (su clasificación y características).

Cabe destacar que si bien se abordan los temas anteriormente mencionados desde lo general a lo particular, se profundiza en los aspectos teóricos a fin de proporcionar los fundamentos y herramientas tendientes a permitir determinar las restricciones para el desarrollo de los seguros de vida individual de contratación voluntaria en la argentina y a la vez indagar sobre las características y relaciones de condicionamientos que tales limitantes ejercen sobre la evolución del sector.

En forma adicional y con base en las conclusiones del estudio se exploraron las vías de superación a la problemática que se plantea, finalizando en la elaboración de una propuesta para la eventual evolución del mercado de los seguros de vida en la República Argentina. 


\section{Planteo del Problema}

\subsection{Introducción}

Es de destacar que la industria del seguro de vida individual voluntario en la República Argentina ha disminuido durante los últimos años luego de la salida de la convertibilidad, principalmente los que poseían un componente de ahorro, lo cuál era característico de los productos que ofrecían las aseguradoras de origen extranjero y dónde las pólizas que inicialmente se comercializaron en moneda extranjera, fueron "pesificados" (es decir, convertidos al tipo de cambio US $\$ 1,00=\$ 1,40)$.

Este hecho generó una reducción del sector para luego solo recuperarse hasta un nivel mínimo de estancamiento y sin que ningún producto o aseguradora en particular lograra romper con el nivel del $18 \%$ de penetración que posee actualmente el seguro de vida individual voluntario dentro de la población económicamente activa.

A su vez, los asegurados que gozaban de buena salud son los que más rápidamente abandonaron el mercado, quedando con la cobertura aquellos que poseían alguna patología, lo cual atenta contra los márgenes de utilidades que la industria posee y que a su vez no pueden ajustarse por inflación a diferencia de lo que ocurre en otros sectores del seguro en los que las tarifas aumentan conforme se incrementa el valor de los bienes asegurados (autos, casas, etc.).

Cabe señalar que para estimar una suma asegurada en vida, generalmente se proyectan los ingresos de las personas entre tres y cinco años y contrariamente a los seguros de daños patrimoniales, la actualización de los capitales asegurados no se realiza en forma "automática" como contrapartida de los aumentos generales de los precios, sino que debe hacerse voluntariamente.

\subsection{Evolución}

A nivel mercado de seguros, la evolución y relevancia del problema planteado se puede percibir al detallar la prima emitida en el total del mercado argentino de seguros (valuada a valores constantes al 30 de Junio de los últimos diez años), comparando los importes de los seguros por daños patrimoniales comparada con la evolución del mismo concepto en los seguros de vida individual:

\begin{tabular}{|c|r|r|}
\hline Primas de Seguros & Patrimoniales & \multicolumn{1}{|c|}{ Vida Individual } \\
\hline 2000 & 13.781 .890 .161 & 1.193 .839 .184 \\
\hline 2001 & 14.503 .149 .406 & 1.493 .749 .419 \\
\hline 2002 & 12.500 .385 .828 & 1.138 .300 .413 \\
\hline 2003 & 10.421 .080 .518 & 736.430 .493 \\
\hline 2004 & 11.437 .686 .852 & 616.838 .877 \\
\hline 2005 & 12.020 .417 .576 & 458.956 .588 \\
\hline 2006 & 13.537 .439 .573 & 522.547 .385 \\
\hline 2007 & 15.521 .292 .886 & 627.382 .969 \\
\hline 2008 & 17.985 .574 .370 & 664.702 .068 \\
\hline 2009 & 21.395 .801 .147 & 749.590 .490 \\
\hline Evolución 2009/2000 & $\mathbf{5 5 , 2 5 \%}$ & $\mathbf{- 3 7 , 2 1 \%}$ \\
\hline
\end{tabular}


Las cifras provenientes del anexo II de la Comunicación $\mathrm{N}^{\circ} 2.336$ de la Superintendencia de Seguros de la Nación, expresadas en pesos de Junio de 2009 y publicados en Junio de 2010, reflejan la diferencia asimétrica de las primas de ambos tipos de seguros, dado que mientras los seguros por daños patrimoniales aumentaron en más de un $55 \%$, lo producido por los seguros de vida individual se redujeron en más de un $37 \%$.

También, del mismo cuadro se puede analizar la participación de la prima emitida por los seguros de vida individual con relación a las primas totales de todo tipo de seguros (patrimoniales y de las personas) en el mercado argentino:

\begin{tabular}{|c|r|r|r|}
\hline Primas de Seguros & Primas Totales & Primas Vida Individual & Participación \\
\hline 2000 & 22.187 .809 .993 & 1.193 .839 .184 & $\mathbf{5 , 3 8 \%}$ \\
\hline 2001 & 23.968 .077 .712 & 1.493 .749 .419 & $\mathbf{6 , 2 3 \%}$ \\
\hline 2002 & 19.595 .880 .374 & 1.138 .300 .413 & $\mathbf{5 , 8 1 \%}$ \\
\hline 2003 & 15.151 .575 .597 & 736.430 .493 & $\mathbf{4 , 8 6 \%}$ \\
\hline 2004 & 16.750 .082 .127 & 616.838 .877 & $\mathbf{3 , 6 8 \%}$ \\
\hline 2005 & 18.706 .446 .497 & 458.956 .588 & $\mathbf{2 , 4 5 \%}$ \\
\hline 2006 & 19.843 .833 .248 & 522.547 .385 & $\mathbf{2 , 6 3 \%}$ \\
\hline 2007 & 22.771 .030 .974 & 627.382 .969 & $\mathbf{2 , 7 6 \%}$ \\
\hline 2008 & 25.262 .407 .572 & 664.702 .068 & $\mathbf{2 , 6 3 \%}$ \\
\hline 2009 & 27.610 .870 .117 & 749.590 .490 & $\mathbf{2 , 7 1 \%}$ \\
\hline
\end{tabular}

En el cuadro anterior se observa una pérdida de 2,67 puntos de los seguros de vida sobre el total, lo cuál implica que en los últimos 10 años la participación relativa de los seguros de vida individual se redujo a la mitad, sin que hasta la fecha exista un estudio serio que determine los determinantes de este efecto y la ponderación de los mismos en cuanto a la responsabilidad de cada factor en esta reducción.

\subsection{Perspectivas}

En el trabajo realizado en Junio y Julio de 2009 por la consultora D'Alessio IROL para la Asociación de Aseguradoras de Vida y Retiro (Ver el anexo 12.1. Tablas del Estudio sobre la relación de la población y el seguro de Vida), el $17 \%$ de los consultados seguramente adquiriría un seguro de vida, mientras que el $30 \%$ probablemente lo contrataría.

A su vez, la misma población también fue consultada sobre si contratarían un seguro de vida con una motivación adicional, como un incentivo fiscal, y las respuestas ascendieron al $34 \%$ de los que seguramente lo contratarían y al $45 \%$ los que probablemente lo adquirirían.

Por otra parte, la Encuesta Permanentes de Hogares, establece que las finalidades de gastos los principales para la población económicamente activa se destina a: alimentación y bebidas $(33,40 \%)$, transporte y comunicaciones $(15,20 \%)$ y la adquisición de propiedades, combustible agua y electricidad como favoritos; quedando solo un $6,10 \%$ para gastar en bienes y servicios varios entre los cuales se encuentra el seguro de vida. 


\begin{tabular}{|l|r|}
\hline \multicolumn{1}{|c|}{ Finalidad del gasto } & Total del país \% \\
\hline Total gasto de consumo & 100 \\
\hline Alimentos y bebidas & 33.40 \\
\hline Indumentaria y calzado & 8.30 \\
\hline Propiedades, combustible, agua, electricidad & 10.80 \\
\hline Equipamiento y mantenimiento del hogar & 7.20 \\
\hline Salud & 7.60 \\
\hline Transporte y comunicaciones & 15.20 \\
\hline Esparcimiento & 8.20 \\
\hline Enseñanza & 3.10 \\
\hline Bienes y servicios varios & 6.10 \\
\hline
\end{tabular}

Fuente $\cdot$ Cuestionario Permanente de Hocaares

Si bien las encuestas señalan la existencia de una propensión por parte de la población a adquirir productos con coberturas de vida, dicha tendencia queda en la mera intención al verificar los indicadores del sector, a la vez que no haya sido establecido fehacientemente las causas.

\subsubsection{El Seguro de Vida en el Mundo y Latinoamérica}

Una de los primeros cuestionamientos que el lector puede hacerse es inquirir sobre la generalidad o no de este comportamiento y si lo que ocurre con la población asegurable de vida en la argentina es similar a lo que ocurre en otros lugares del mundo.

En este sentido, se destaca un bajo grado comparativo de penetración de los seguros de vida en los hogares de la república Argentina, ya que mientras que en países desarrollados como Japón o Estados Unidos el seguro de vida tiene una penetración en los hogares del $88 \%$ y el $80 \%$ respectivamente; en la Argentina solo llega al 18\%. A su vez, en nuestro país el 54\% declara poseer algún tipo de cobertura de vida, debiéndose esta diferencia a los seguros cuya contratación no es optativa, relacionado con la seguridad social y los seguros obligatorios instituidos por leyes, decretos o convenios colectivos de trabajo.

\begin{tabular}{|c|c|c|c|}
\hline País & Estados Unidos & Japón & Argentina \\
\hline Población & 300.000 .000 & 127.000 .000 & 39.000 .000 \\
\hline Productores de Vida registrados & 5.400 .000 & 2.500 .000 & 26.000 \\
\hline Cantidad Productores de Vida Per Cápita & 1 cada 55 & 1 cada 50 & 1 cada 1.500 \\
\hline Penetración de los Seguros de Vida en los Hogares & $80 \%$ & $88 \%$ & $18 \%$ \\
\hline
\end{tabular}

Otro factor que a nivel comparativo puede señalarse es el de la cantidad de agentes comerciales, ya que mientras que en los países desarrollados se encuentra un asesor especialista en seguros de vida cada 50 o 55 habitantes; en la Republica Argentina hay registrados uno cada 1.500. De todas formas este factor no se puede asociar en forma directa con la causa de la penetración descripta, ya que puede identificarse como consecuencia de la misma, (dado que todo Productor Asesor de Seguros matriculado en la Superintendencia de Seguros de la Nación 
habilitado para comercializar seguros patrimoniales, puede a su vez asesorar y vender seguros de vida), siendo este un análisis que excede al alcance de la presente investigación.

Por su parte, el Seguro de Vida en Latinoamérica no ha alcanzado la difusión que dicha cobertura posee en Europa y en los Estados Unidos. Por ejemplo, que en Estados Unidos la prima de Seguros de Vida por habitante/año, alcanza a US\$2.000 mientras que, en el conjunto de Latinoamérica llega sólo a US\$ 69 en promedio (conforme a datos del año 2009).

Si bien se señala que en Latinoamérica en general la existencia de una menor cultura del ahorro, abundamiento del trabajo informal y la vigencia de sistemas de Seguridad Social extendidos en la región, se destaca el ejemplo del Brasil, que ha establecido estímulos tributarios, beneficios fiscales y acción promotora de los bancos, logrando mejorar la difusión de la cobertura de vida. Por su parte Chile también ha establecido beneficios tributarios, desregulaciones y adecuada red de distribución y en México se ha desarrollado la difusión de microseguros de Vida, promoviendo la concientización popular de los beneficios de contratar las coberturas de Vida.

A modo de ejemplo, se trasladan los indicadores en base a datos del año 2007 para la región, en la que se destaca el comparativamente bajo grado de penetración de los seguros de vida en la República Argentina.

\begin{tabular}{|l|r|r|r|r|r|}
\hline Datos Anuales 2007 & $\begin{array}{c}\text { Población } \\
\text { (en Millones } \\
\text { de } \\
\text { Personas) }\end{array}$ & $\begin{array}{c}\text { Primas } \\
\text { Emitidas Vida } \\
\text { Individual y } \\
\text { Colectivo }\end{array}$ & $\begin{array}{l}\text { Prima de Vida } \\
\text { Promedio por } \\
\text { Habitante }\end{array}$ & $\begin{array}{c}\text { Prima } \\
\text { Emitida } \\
\text { Total }\end{array}$ & $\begin{array}{c}\text { \% de } \\
\text { Vida }\end{array}$ \\
\hline Brasil & 192,6 & $10.818 €$ & $56 €$ & $22.109 €$ & $49 \%$ \\
\hline México & 106,4 & $5.137 €$ & $48 €$ & $12.655 €$ & $41 \%$ \\
\hline Panamá & 3,3 & $132 €$ & $40 €$ & $441 €$ & $30 \%$ \\
\hline Chile & 16,6 & $1.040 €$ & $63 €$ & $4.084 €$ & $25 \%$ \\
\hline Honduras & 7,2 & $44 €$ & $6 €$ & $179 €$ & $25 \%$ \\
\hline El Salvador & 7,1 & $52 €$ & $7 €$ & $286 €$ & $18 \%$ \\
\hline Guatemala & 13,3 & $50 €$ & $4 €$ & $280 €$ & $18 \%$ \\
\hline Colombia & 46,1 & $523 €$ & $11 €$ & $2.994 €$ & $17 \%$ \\
\hline Perú & 27,9 & $139 €$ & $5 €$ & $862 €$ & $16 \%$ \\
\hline Bolivia & 9,8 & $18 €$ & $2 €$ & $113 €$ & $16 \%$ \\
\hline Ecuador & 13,6 & $77 €$ & $6 €$ & $493 €$ & $16 \%$ \\
\hline Nicaragua & 5,6 & $11 €$ & $2 €$ & $72 €$ & $15 \%$ \\
\hline Uruguay & 3,3 & $34 €$ & $10 €$ & $280 €$ & $12 \%$ \\
\hline Argentina & 39,4 & $562 €$ & $14 €$ & $4.682 €$ & $12 \%$ \\
\hline República Dominicana & 9,7 & $45 €$ & $5 €$ & $429 €$ & $10 \%$ \\
\hline Puerto Rico & 4 & $676 €$ & $169 €$ & $6.794 €$ & $10 \%$ \\
\hline Paraguay & 6,1 & $6 €$ & $1 €$ & $72 €$ & $8 \%$ \\
\hline Costa Rica & 4,5 & $12 €$ & $3 €$ & $357 €$ & $3 \%$ \\
\hline Venezuela & 27,5 & $130 €$ & $5 €$ & $5.207 €$ & $2 \%$ \\
\hline Total & 544 & $19.505 €$ & $36 €$ & $62.389 €$ & $31 \%$ \\
\hline
\end{tabular}

Fuente: Fundación Mapfre

Los datos (que se encuentran en euros, dada que la Fundación que los recabó tiene su casa matriz en España), hacen referencia a los seguros de vida de contratación optativa por parte de los interesados (dejando de lado las coberturas obligatorias), y se aprecia un grado de 
penetración del $12 \%$ en la población económicamente activa total para la República Argentina, ubicándose muy por debajo de los porcentajes de Brasil, México e incluso Chile.

Por otra parte, aún con primas en Euros muy inferiores, países como El salvador, Bolivia y Perú logran un mayor grado de conciencia por parte de la población a la hora de la contratación optativa de estas coberturas que el obtenido en la argentina.

\subsubsection{El Control y Mercado de los Seguros de Vida en la República Argentina}

En forma previa a analizar las particularidades del negocio de los Seguros de Vida, composición del sector y función del organismo de contralor, se debe destacar lo siguiente:

El órgano de contralor de la actividad aseguradora en la Argentina es la Superintendencia de Seguros de la Nación (SSN), conformando desde 1938 un organismo público descentralizado dependiente del Ministerio de Economía y Producción, cumpliendo funciones como supervisor y fiscalizador de las entidades de seguros y reaseguros en la República Argentina; siendo su principal misión la de controlar las actividades de evaluación e inspección de los operadores del mercado para garantizar el cumplimiento de las legislaciones y regulaciones vigentes.

El mercado argentino de compañías aseguradoras que intervienen en el ramo vida individual, se encuentra compuesto por 35 empresas, de las cuales 21 comercializan el riesgo vida en forma exclusiva (en un total de 178 compañías en el total del mercado asegurador), con un promedio de 144 empleados por aseguradora, según datos de la SSN al 30/06/2009.

Es de destacar que existe una cámara de las empresas aseguradoras de vida y retiro, denominada Asociación de Aseguradoras de Vida y Retiro de la República Argentina (AVIRA), la cual intermedia con el organismo de contralor, procurando defender los intereses de la industria; por lo que por lo general las aseguradoras elevan sus requerimientos y necesidades a través de esta cámara con el objeto de lograr mayor capacidad de negociación.

Es importante señalar que todo producto, cláusula o cobertura que una aseguradora quiera comercializar debe se previamente aprobada por la SSN, siendo que dichos planes presentados podrán ser utilizados por cualquier aseguradora (que acompañe las notas técnicas actuariales pertinentes), luego de un plazo de 6 meses.

Conforme al informe estadístico en base a datos del cierre del ejercicio del mercado asegurador (01/07/2008 al 30/06/2009), publicado por la Superintendencia de Seguros de la Nación, la que se detalla más abajo es la composición de la producción total (primas emitidas netas de anulación y de cesión a los reaseguradores), y las participaciones parciales de cada sector dentro de su categoría y con relación al total del mercado asegurador.

Es válido señalar que se han excluido del análisis a los ramos Vida Previsional y Rentas Vitalicias, por tratarse de operatorias que no cuentan con plena vigencia y que pueden distorsionar la evaluación global. 


\begin{tabular}{|l|r|r|r|}
\hline \multicolumn{1}{|c|}{ Ramos } & Primas Emitidas \$ & Participación Parcial & Participación Total \\
\hline Salud & 35.318 .838 & $1,01 \%$ & $0,17 \%$ \\
\hline Vida Individual & 257.304 .865 & $7,36 \%$ & $1,21 \%$ \\
\hline Vida Colectivo & 3.022 .590 .629 & $86,43 \%$ & $14,19 \%$ \\
\hline Vida Obligatorio & 9.615 .803 & $0,27 \%$ & $0,05 \%$ \\
\hline Sepelio Individual & 27.285 .626 & $0,78 \%$ & $0,13 \%$ \\
\hline Sepelio Colectivo & 145.098 .322 & $4,15 \%$ & $0,68 \%$ \\
\hline Sub-Total Seguros de Vida & 3.497 .214 .083 & $100,00 \%$ & $16,42 \%$ \\
\hline Accidentes Personales Individuales & 250.983 .773 & $49,43 \%$ & $1,18 \%$ \\
\hline Accidentes Personales Colectivos & 256.731 .376 & $50,57 \%$ & $1,21 \%$ \\
\hline Sub-Total Accidentes Personales & 507.715 .149 & $100,00 \%$ & $2,38 \%$ \\
\hline Retiro Individual & 38.767 .675 & $16,04 \%$ & $0,18 \%$ \\
\hline Retiro Colectivo & 202.945 .761 & $83,96 \%$ & $0,95 \%$ \\
\hline Sub-Total Seguros de Retiro & 241.713 .436 & $100,00 \%$ & $1,13 \%$ \\
\hline Sub-Total Seguros de Personas & 4.246 .642 .668 & $19,94 \%$ & $19,94 \%$ \\
\hline Total del Mercado & $\mathbf{2 1 . 2 9 6 . 8 8 8 . 5 7 4}$ & $\mathbf{1 0 0 , 0 0 \%}$ & $\mathbf{1 0 0 , 0 0 \%}$ \\
\hline
\end{tabular}

Fuente: Superintendencia de Seguros de la Nación

La mayor participación la posee el ramo Vida Colectivo, dónde por lo general las empresas toman la coberturas para sus empleados (también comprende los de saldo deudor y coberturas de continuidad de estudios), como beneficios diversos e impositivos; en los que resulta poco frecuente el consentimiento efectivo del asegurado y el pago del mismo, corre frecuentemente a cargo del contratante.

En cuanto al Seguro Social Colectivo de Vida Obligatorio (que proviene del Decreto 1567/74) se trata de un seguro social de contratación obligatoria para todos los empleadores con trabajadores en relación de dependencia, funcionando este seguro con una caja compensadora en el que las aseguradoras cobran las primas y abonan los siniestros y luego de quedarse con una comisión, remiten el diferencial resultante a la Superintendencia de Seguros de la Nación.

La particularidad de los seguros de Accidentes Personales es que amparan a los trabajadores autónomos o a los que se encuentran fuera de la economía formal y que por estos hechos no poseen la cobertura de las Aseguradoras de Riesgos del Trabajo (ART).

Por su parte, tanto las coberturas de Salud, Sepelio como las de Retiro provienen de la necesidad de los asegurados de suplir y/o complementar sus necesidades que quedan insatisfechas por los sistemas de seguridad social.

Por todo lo antedicho, se destaca que el ramo Vida Individual es el único dónde el asegurado contrata directa y libremente la cobertura procurando ampararse de los riesgos que por enfermedad o accidente le pudieran acontecer. Esta área de negocio representa algo más del $7 \%$ del total de los seguros de vida y solo supera el $1 \%$ del total del mercado de los seguros en la República Argentina.

Con el objeto de analizar la rentabilidad de cada sector, se detallan los datos de los siniestros abonados (también se trata de los devengados, netos de traslados a los 
reaseguradotes, se detallan los montos pagados por cada área de negocio y la participación total dentro del mercado asegurador en general. A su vez se le anexa una columna indicando la siniestralidad en cada caso (Siniestros Pagados / Prima Emitida).

\begin{tabular}{|l|r|r|r|}
\hline \multicolumn{1}{|c|}{ Ramos } & \multicolumn{1}{c|}{ Siniestros \$ } & \multicolumn{1}{c|}{ Participación Total } & \multicolumn{1}{c|}{ Siniestralidad } \\
\hline Salud & -15.263 .156 & $0,11 \%$ & $43,22 \%$ \\
\hline Vida Individual & -139.482 .357 & $1,01 \%$ & $54,21 \%$ \\
\hline Vida Colectivo & -928.381 .338 & $6,70 \%$ & $30,71 \%$ \\
\hline Vida Obligatorio & -1.430 .484 & $0,01 \%$ & $14,88 \%$ \\
\hline Sepelio Individual & -8.456 .093 & $0,06 \%$ & $30,99 \%$ \\
\hline Sepelio Colectivo & -57.097 .397 & $0,41 \%$ & $39,35 \%$ \\
\hline Sub-Total Seguros de Vida & -1.150 .110 .825 & $8,30 \%$ & $32,89 \%$ \\
\hline Accidentes Personales Individuales & -67.925 .412 & $0,49 \%$ & $27,06 \%$ \\
\hline Accidentes Personales Colectivos & -58.630 .680 & $0,42 \%$ & $22,84 \%$ \\
\hline Sub-Total Accidentes Personales & -126.556 .092 & $0,91 \%$ & $24,93 \%$ \\
\hline Retiro Individual & -153.372 .375 & $1,11 \%$ & $395,62 \%$ \\
\hline Retiro Colectivo & -260.682 .337 & $1,88 \%$ & $128,45 \%$ \\
\hline Sub-Total Seguros de Retiro & -414.054 .712 & $2,99 \%$ & $171,30 \%$ \\
\hline Sub-Total Seguros de Personas & -1.690 .721 .629 & $12,21 \%$ & $39,81 \%$ \\
\hline Total del Mercado & -13.850 .300 .976 & $\mathbf{1 0 0 , 0 0 \%}$ & $\mathbf{6 5 , 0 3 \%}$ \\
\hline
\end{tabular}

Fuente: Superintendencia de Seguros de la Nación

El seguro de vida individual, a pesar de ser el único en que la contratación es totalmente voluntaria y depende exclusivamente del interés asegurable del solicitante, con el consiguiente agravante que puede prestarse a la antiselección, la mayor siniestralidad no resulta comparativamente desproporcionada al resto de las coberturas que comprenden los riesgos de enfermedad y/o accidente y por debajo del mercado asegurador en general.

Asimismo se destaca que por ser el que mayor siniestralidad posee dentro de este subgrupo, para las empresas aseguradoras intervinientes en este ramo, resulta de vital importancia maximizar los recaudos en cuanto a la selección de los riesgos a asumir a la vez que se procura desarrollar su producción.

En cuanto a las empresas que intervienen en el mercado de los seguros de vida individual, conforme a los datos estadísticos publicados en el anexo II de la Comunicación SSN N 2520 de fecha 03/018/2010 con datos correspondientes al 31/10/2010, se observa su composición en el siguiente cuadro: 
VIDA INDIVIDUAL

\begin{tabular}{|c|c|c|c|c|}
\hline \multirow[b]{2}{*}{$\begin{array}{l}\text { Or- } \\
\text { denN.J. }\end{array}$} & \multirow{2}{*}{\multicolumn{2}{|c|}{$1^{2}$ Trim 10}} & \multicolumn{2}{|c|}{$\begin{array}{c}\text { Comparacton } \\
4^{\circ} \mathrm{Trlm} \text {. 09 }\end{array}$} \\
\hline & & & \begin{tabular}{|c} 
Var. \\
$\%$
\end{tabular} & $\begin{array}{l}\text { Uble. } \\
\text { Anter. }\end{array}$ \\
\hline 1 E ZURICH INTERNATIONAL LIFE & 24,75 & 24,7 & $-6,7$ & 1 \\
\hline 2 A PRUDENTIAL & 14,52 & 39,3 & $-3,8$ & 2 \\
\hline 3 A UDERAR & 14,13 & 53,4 & 27,2 & 4 \\
\hline 4 A HSBC VDA & 13,95 & 67,3 & 4,6 & 3 \\
\hline 5 A FED. PATRONAL & 6,12 & 73,5 & 21,4 & 5 \\
\hline 6 A EQUITATIVA DEL PLATA & 4,03 & 77,5 & 5,7 & 6 \\
\hline 7 A PARANA & 3,53 & 81,0 & 4,7 & 7 \\
\hline 8 A PRONINCIA VIDA & 3,22 & 84,2 & 9,5 & 8 \\
\hline 9 A METUFE VIDA & 2,97 & 87,2 & 1,7 & 9 \\
\hline 10 A NACION & 2,39 & 89,6 & & 14 \\
\hline 11 A ALICO GENERALES & 2.24 & 91,8 & $-7,3$ & 10 \\
\hline 12 A CNP & 2,19 & $\$ 4,0$ & 7,1 & 11 \\
\hline 13 A SMG VIDA & 1,97 & $S 6,0$ & 9,9 & 12 \\
\hline 14 A BINARIA VIDA & 1,40 & 97,4 & 16,2 & 13 \\
\hline 15 A GALICIA & 0,70 & S8,1 & $-0,7$ & 15 \\
\hline 16 A SEGUNDA PERSONAS & 0,30 & 98,4 & $-29,4$ & 16 \\
\hline 17 A ARGENTINA SALUD Y VIDA & 0.27 & S6,7 & $-10,9$ & 18 \\
\hline 18 A CAJA GENERALES & 0.25 & 98,9 & $-14,9$ & 19 \\
\hline 19 C SAN CRISTOBAL & 0.23 & 59,2 & 5,2 & 21 \\
\hline 20 A INSTITUTO SALTA & 0.22 & 99,4 & $-40,4$ & 17 \\
\hline 21 C SANCOR & 0.21 & 59,6 & 7,0 & 22 \\
\hline 22 A MAPFRE VIDA & 0,16 & 99,7 & $-42,0$ & 20 \\
\hline 23 A MERCANTIL ANDINA & 0,05 & 59,8 & $-5,0$ & 23 \\
\hline 24 A HOLANDO SUDAMERICANA & 0,03 & 59,8 & -6.2 & 25 \\
\hline 25 A ASSURANT & 0,03 & 99,8 & $-7,6$ & 24 \\
\hline 26 A ZURICH & 0,03 & 99,9 & $-5,7$ & 26 \\
\hline 27 A IAM & 0,02 & 59,9 & 33,5 & 28 \\
\hline 28 A CONERCIO & 0,01 & 59,9 & $-6,1$ & 30 \\
\hline 29 A INDEPENDENCIA & 0,01 & 59,9 & $-16,5$ & 31 \\
\hline 30 A GENERALI CORPORATE & 0,01 & 59,9 & $-36,0$ & 29 \\
\hline 31 C BERNARDINO RIVADAVIA & 0,01 & 59,9 & 4,9 & 32 \\
\hline 32 A BOSTON & 0,01 & 100,0 & 9,0 & 33 \\
\hline 33 A SMSV & 0,01 & 100,0 & $-1,0$ & 34 \\
\hline 34 C RIO URUGUAY & 0,01 & 100,0 & $-51,8$ & 27 \\
\hline 35 O INST. ENTRE RIOS & 0,01 & 100,0 & $-19,2$ & 35 \\
\hline
\end{tabular}

Del cuadro anterior, se observa el cumplimiento del modelo de Pareto (80-20), ya que de las 35 empresas intervinientes en ese mercado, las primeras 7 (es decir el 20\% del total), conforman el $81 \%$ del total del mercado (24,75\% la primera; $14,52 \%$ la segunda; $14,13 \%$ la tercera; $13,95 \%$ la cuarta; $6,12 \%$ la quinta; $4,03 \%$ la sexta y $3,53 \%$ la séptima), quedando el $19 \%$ restante a repartirse entre las 28 empresas restantes, según datos de la SSN, sobre la prima emitida en el trimestre cerrado al 31/03/2010. 


\section{Objetivos de la Investigación}

La presente investigación tiene como objetivos:

- Determinar las restricciones existentes para el crecimiento de los seguros de vida de la República Argentina, y

- Establecer la incidencia porcentual que le es atribuible a cada una de estas en cuanto a su participación relativa como limitantes a la evolución del mencionado sector. 


\section{Evaluación del Problema}

\subsection{Justificación de la Investigación}

La problemática de no contar con la cobertura que otorgan los seguros de vida conlleva implicancias sociales que afectan tanto a las familias como núcleo de la sociedad. Más allá de los fines lucrativos que atañe a todo el mercado de los seguros en general, las razones que originan y justifican el estudio superan los meros beneficios económicos, ya que los seguros de vida en particular, al amparar el riesgo de fallecimiento, cumplan con el rol social más importante de toda la actividad aseguradora, dado que el riesgo más desastroso para la estabilidad económica de los hogares, es el de la muerte prematura del jefe de familia y su consiguiente interrupción abrupta de la fuente de generación de recursos como sustento de su economía.

Asimismo, al determinar las restricciones existentes y procurar establecer las vías de superación de dichos limitantes, para el Estado repercutirá en una menor presión presupuestaria en cuanto a los recursos a afectar en seguridad social, educación, salud, etc. A su vez, las empresas aseguradoras en general y las de seguros de vida en particular (por sus características que la facultan a realizar inversiones a largo plazo), representan impulsores para la economía del país, tomando inversiones de bonos soberanos, obligaciones negociables, entre otras inversiones de bajo riesgo, que promueven el desarrollo económico del país.

Es por lo anteriormente planteado que es posible enunciar que el objeto de la presente investigación supera las necesidades de un sector o mercado en particular, para interesar a la sociedad en su conjunto.

\subsection{Criterios de Evaluación del Problema}

Al analizar la posible evolución del mercado de los seguros de vida, lejos de proyectar el pasado, se debe considerar hacia dónde se dirige "naturalmente" el sector. En este sentido se considera pertinente recurrir al modelo de "la selección natural o supervivencia de los más aptos" que el naturalista inglés Charles Darwin trata el sexto capítulo de su obra "El Origen de la Especies", en el cuál afirma que todo organismo que sea perjudicial para el conjunto será destruido rigurosamente, teniendo más posibilidades de sobrevivir los que posean cualquier ventaja por sobre los demás, por más ligera que sea.

El paralelismo con el mundo empresarial y del mercado de los seguros de vida es comprensible y asimilable; ¿Por qué habrían de sobrevivir industrias que solo se interesen por sus propios beneficios económicos? Ante el servicio más intangible que una empresa o industria pueda proporcionar (como lo es un seguro de vida, dónde en principio la prestación principal que pueda realizar de la aseguradora nunca será percibida por quién efectivamente contrató la cobertura), ¿Qué deben tener en cuenta los actores intervinientes en este sector para lograr que las personas sacrifiquen "consumo inmediato" destinando recursos para el ahorro y la previsión?

El Seguro es una industria que, por su propia naturaleza debe contribuir al desarrollo social y económico de los países y de sus habitantes, generando riqueza y puestos de trabajo, fomentando el ahorro y trabajando por la solidaridad. El sector asegurador en general y en 
particular las empresas intervinientes en el mercado de los seguros de vida deben inspirarse en un sentido de servicio a la sociedad, de acuerdo con la función y la responsabilidad que corresponde a las empresas en el progreso de la misma.

Un modelo de responsabilidad social que sea efectivo, debe percibirse por los actos de una empresa o mercado, debiendo formar parte de la propia gestión en cada caso. Por ello, generar acciones procurando atender las cuestiones relacionadas con la responsabilidad social, es a la vez un compromiso voluntario y una actitud estratégica ya que el desarrollo de las actividades empresariales desde un comportamiento ético, transparente y contribuyendo a la satisfacción de las necesidades presentes y futuras de la sociedad, resulta la manera más clara y segura de procurar la consecución de los objetivos empresariales.

En consecuencia, al analizar las perspectivas sobre la posible evolución del mercado de los seguros de vida, se debe mencionar lo siguiente:

- El mismo se desarrollará en un contexto dónde las empresas o sectores que solo atiendan sus objetivos de lucro, descuidando los intereses comunes de la sociedad, no tendrán lugar en el futuro inmediato;

- Desde el sector privado se debe procurar ofrecer productos y servicios que promuevan el bienestar general, sin desatender los objetivos empresariales;

- Las acciones tendientes a desarrollar una industria del seguro de vida como sistema social sostenible en el largo plazo, debe procurar una rentabilidad que sostenga los resultados técnicos propios del negocio;

- El protagonismo de las aseguradoras de vida en cuanto a la atención de los intereses y necesidades de la sociedad, les repercutirán en forma positiva tanto en lo social como en lo comercial.

\subsection{Implicancias para el Mercado}

El hecho que hasta el momento no se hayan determinado en forma fehaciente las causas que determinan la evolución de los seguros voluntarios de vida, ha hecho que no se produzca el desarrollo de estos seguros.

El resultado final que se pretende lograr, representa un aporte de nuevos conocimientos sobre la realidad para el sector que comercializa el riesgo vida y que a la vez el mismo pueda ser empleado como herramienta para superar tales restricciones.

En este sentido se destaca la orientación hacia la aplicación del conocimiento generado que contiene la presente investigación, toda vez que los fines hacia los cuales puedan ser volcados los resultados obtenidos, como por ejemplo la mejora en el aprovechamiento de los recursos que el mercado emplea para su propia evolución, serían de uso directo y de aplicación en el corto plazo. 


\section{Alcance de la Investigación}

\subsection{Tipo de Estudio}

El estudio es de carácter explicativo, por cuanto se centra en identificar los condicionantes al fenómeno observado el cual consiste en la evolución de los seguros de vida en el ámbito de la República Argentina.

Asimismo el estudio comprende un carácter descriptivo toda vez que analiza sobre la naturaleza y manifestación del evento que representa la contratación (o no), de un seguro de vida.

A su vez tiene características de una investigación exploratoria, dado que procura familiarizar al lector con un tema frecuentemente desconocido, o al menos escasamente estudiado con seriedad, el cual puede representar el punto de partida para posteriores estudios con diferente grado de profundidad.

\subsection{Limitaciones de la Presente Investigación}

Teniendo en cuenta la necesidad de restringir la amplitud del presente trabajo, la investigación se enfoca en los limitantes al seguro de vida individual de contratación voluntaria en la República Argentina.

A su vez, se hace énfasis en la cobertura de vida (la que ampara el riesgo de fallecimiento ya sea por enfermedad o como consecuencia de un accidente), si bien muchos de los condicionantes que puedan establecerse, ejercerán influencia en otro tipo de coberturas (invalidez, enfermedades graves, etc.), así como también en otro tipos de seguros de vida (con ahorro, colectivos y/o retiro).

Es por ello que se aborda este análisis desde la perspectiva de la cobertura que posee el seguro de vida (cubrir las eventualidades de fallecimiento, invalidez, enfermedades graves, etc.) y no desde el componente de ahorro que algunos productos poseen y que pertenecen más al mercado financiero que al de seguros. 


\section{Marco Teórico de Referencia}

El marco teórico del presente estudio está conformado por las bases teóricas, estudios y antecedentes en general que posee relación con la problemática abordada.

\subsection{Bases Teóricas}

Con el objeto de proveer un sistema acumulativo de conocimientos organizados. Se consignan a continuación el significado y las relaciones del tema en estudio con otras áreas del conocimiento. Por ello abarcando desde lo general hasta lo particular conforman la base teórica del presente estudio: el riesgo, los seguros en general y los seguros de vida en particular con el objeto de proporcionar un dominio conceptual y brindar el ámbito de aplicación general, intermedio y específico respectivamente.

\subsubsection{El Riesgo}

El Riesgo es una medida de hasta qué punto puede desviarse o no un resultado de su valor esperado o deseado.

En un sentido estricto se puede diferenciar dos estadios principales que se encuentran entra la certeza total y la ignorancia absoluta, siendo ellos el riesgo y la incertidumbre, dependiendo si se conocen la existencia de probabilidades matemáticas de ocurrencia o solo se puede inferir una probabilidad subjetiva, respectivamente.

Es por ello que en materia de seguros, al contar con estadísticas, probabilidades matemáticas, tablas de mortalidad, etc. se afirma que la probabilidad de que ocurra un siniestro es un riesgo.

A su vez, en la terminología aseguradora, se emplea este concepto para expresar indistintamente dos ideas diferentes: de un lado, riesgos como objeto asegurado; de otro, riesgos como posibles acontecimientos, cuya aparición real o existencia se previene y garantiza en la póliza. Este último criterio es el técnicamente correcto y, en tal sentido, se habla del riesgo de incendio o muerte, para aludir a la posibilidad de que el objeto o la persona asegurada sufran un daño material o fallecimiento respectivamente; o se habla de riesgo de mayor o menor gravedad, para referirse a la probabilidad más o menos grande de que el siniestro pueda ocurrir.

Una empresa puede adoptar diferentes posturas frente a los riesgos que se presenten en el desarrollo de su actividad principal y que frecuentemente no se encuentran relacionados con la esencia de su negocio en sí.

Por ejemplo: una empresa cuyo negocio sea la explotación agrícola y que exporte su producción, debe ocuparse de los riesgos que atañen a la productividad por quintal, a la selección de la semilla adecuada y a la ubicación de su producto en el mercado adecuado, entre otras actividades, pero puede no querer asumir el riesgo de cambios en el precio del dólar. Se entiende que no debería hacerlo, ya que realizar pronósticos sobre la evolución de la paridad cambiaria, no forma parte del negocio de esa organización. 
Las diferentes actitudes que puede asumir una empresa frente a los riesgos que se le presenten, se pueden agrupar en estas cuatro alternativas:
1. Ignorarlo
2. Asumirlo
3. Transferirlo a Terceros
4. Gestionarlo

Brevemente, se puede describir cada una de ellas:

\section{Ignorarlo}

No hay mucho para decir con relación a esta alternativa. Simplemente no se identifica el riesgo por incapacidad o negligencia, "esperando que nada ocurra". Cuando se concreta el riesgo en estas situaciones donde el evento no fue considerado, los malos administradores expresan "no lo vimos venir", "tuvimos mala suerte", etc.

Otra forma de "Ignorar los Riesgos" es identificarlos pero no documentarlos y/o no medir el impacto o las consecuencias en el caso en que se produzca. Al ocurrir el evento previsto suele ser aún peor, quedando la sensación de "lo sabíamos, pero no hicimos nada".

\section{Asumirlo}

Toda medida que no impida la ocurrencia del evento previsto, pero que tenga por objetivo reducir el posible daño eventual puede categorizarse en esta alternativa, en la que se está consciente del riesgo y se mejorar la capacidad para hacerle frente y/o minimizar el impacto.

También se puede incluir a la disuasión dentro de esta categoría ya que lo que se procura al adoptar esta actitud, es la disminución de la frecuencia del evento. Por ejemplo, ante la amenaza del sabotaje o robo, se puede incluir medidas de seguridad como cámaras que no detendrán el daño pero tenderán a que menos personas intenten hacer daño. En el ámbito de los seguros es frecuente observar en estacionamientos de hipermercados y shoppings la presencia de carteles indicando que los propietarios del establecimiento no se hacen responsables por el robo o los daños que puedan sufrir las unidades que allí se dejan, con el objeto de disuadir a los propietarios de los vehículos a que realicen los reclamos que les corresponden.

\section{Transferirlo a Terceros}

Un riesgo puede ser transferido a terceros principalmente utilizando dos instrumentos. El primero es valerse de un derivado financiero (opciones de compra, opciones de venta, swaps, etc.) que permitan cubrirse ante la eventualidad. La otra alternativa es contratar un seguro específico que provea amparo ante un riesgo específico.

\section{Gestionarlo}

El riesgo no es azaroso, puede calcularse o estimarse, lo que facilita la toma de decisiones previendo que las mismas pueden tener mayor o menor riesgo.

Gestionar el Riesgo consiste en encontrar la combinación de actividades que permita aspirar a un balance entre el Resultado Esperado, la Variabilidad y la Libertad de Acción, siendo que dicho balance debe estar en función de la capacidad de la empresa para asumir esos riesgos.

Según Wideman (1992) para gestionar el riesgo se deben seguir 4 etapas: $1^{\circ}$ Identificar el riesgo; $2^{\circ}$ Evaluarlo, midiendo el Impacto y probabilidad de ocurrencia; $3^{\circ}$ Planificar la Respuesta, 
considerando las posibles medidas de contingencia a tomar en base a un análisis de costo beneficio; y $4^{\circ}$ Documentar lo anterior e implementación del plan elegido.

Por su parte, el diseño de una estrategia de administración del riesgo implica atender tres cuestiones: Identificar fuentes potenciales de riesgo; anticipar la probabilidad de ocurrencia de ciertas situaciones y sus consecuencias; y tomar acciones de modo de obtener la combinación preferida de retorno esperado, variabilidad y libertad de acción.

Al hablar de las empresas de seguros, la esencia del negocio consiste principalmente en gestionar correctamente los riesgos que han sido transferidos desde las personas y de otras empresas. A su vez, cuando una Compañía de seguros opta por volver a transferir todo o una parte del riesgo que le delegaron, recurre a una empresa de reaseguros.

\subsubsection{El Seguro}

El seguro es un mecanismo económico el cual se sustenta en la agrupación de un número considerable de asegurados sujetos a un riesgo similar, que contribuyen con el importe de sus primas para construir un fondo común con el cual luego se hará frente a las obligaciones resarcitorias nacidas de los siniestros acaecidos a los asegurados que integran el grupo aportante (principio de mutualidad). De este modo se distribuye entre todos y por un importe ínfimo, en relación con el monto de cada daño posible, el peso económico de los riesgos que los afectan.

Los seguros son componentes de la cobertura del riesgo, ya que transfieren los riesgos a las compañías aseguradoras, de una manera planeada de tal modo que la adversidad queda cubierta y funda la confianza de los inversionistas más renuentes al riesgo. La compañía de seguro conserva la prima si el individuo no realiza ningún reclamo. Un seguro reparte el riesgo entre los empresarios que lo cubren. Al repartir el riesgo entre los empresarios que lo cubren se logra minimizarlo.

Cuando una Compañía de seguros vende pólizas a varios individuos que enfrentan riesgos no perfectamente correlacionados, el riesgo total del portafolio será menor que le promedio de las pólizas individuales. La probabilidad de que todos los asegurados en el pool sufran una pérdida es extremadamente baja de modo que el asegurador diversifica riesgos no sistémicos.

Teniendo en cuenta que los asegurados conforman un gran grupo de personas, la compañía aseguradora pagará menos dinero del que ingresa. Si esto no fuese de esta manera, el negocio no sería sustentable.

Frecuentemente la indemnización de un seguro especifica que el damnificado obtendrá el dinero si y solo si ciertos hechos ocurren, si estos hechos no ocurren, no obtiene dinero alguno. Las expectativas de cobro serán mucho menores a los pagos salvo que logre obtener una póliza con las utilidades a su favor, lo cual no ocurre ya que comprar un seguro tiene un valor negativo.

\subsubsection{El Seguro de Vida}

El objetivo básico de un seguro de vida es el de prever y proveer hoy para el mañana neutralizando los riesgos mediante el pago de una prima conforme a la probabilidad de ocurrencia 
de los mismos. El riesgo más desastroso para la estabilidad económica del hogar, es el de la muerte prematura del jefe de familia.

El propósito del Seguro de Vida es otorgar una indemnización a los beneficiarios en caso de fallecimiento de la persona asegurada. Este beneficio consiste en una suma de dinero llamada Capital Asegurado que puede pagarse de una sola vez o en forma de una renta financiera. Los destinatarios de esta suma de dinero son los beneficiarios designados en la póliza (familiares del Asegurado, sus socios, sus acreedores, etc.) o en su defecto los herederos legales.

En definitiva, el Seguro de Vida da una seguridad económica a los beneficiarios cuya estabilidad financiera puede verse amenazada ante la muerte del Asegurado.

Para determinar qué tipo de Seguro de Vida contratar se deben analizar las necesidades de la familia en caso de fallecimiento del generador de ingresos.

También existe el Seguro de Vida "con Ahorro" en el cual se involucra además la posibilidad de que el asegurado se haga de un "fondo" en caso de sobrevivencia a un determinado período de tiempo.

El Seguro de Vida y/o el Seguro de Vida con ahorro tienen por objeto:

- Proveer ingresos al cónyuge e hijos por un plazo determinado.

- Proveer ingresos para la educación de los hijos.

- Cancelar saldos de deuda (hipotecarios, prendarios, crediticios o personales)

- Pagar las deudas finales del Asegurado, tal como servicios médicos, fúnebres, etc.

- Proveer un fondo para una futura jubilación.

La motivación de la contratación de un Seguro de Vida dependerá de:

- La edad de la persona asegurada

- La cantidad de personas que tenga a su cargo y de la calidad de vida que desee dejarles a ellos

- La conservación de los ingresos

\subsection{Definición de Términos Básicos:}

Considerando que los conceptos empleados en la presente investigación de uso específico en el mercado de los seguros de vida, se entiende merecen ser detallados en un glosario particular (el cuál se encuentra luego de la bibliografía), con el objeto de proporcionar una mayor claridad en la información recopilada, se procede a mencionar dentro del presente apartado la clasificación de los seguros de vida.

\subsubsection{Clasificación de los Seguros de Vida}

Los seguros de vida se pueden clasificar en función a varias variables. Las más características son: 


\section{a) Según su duración}

Seguros Temporarios o Seguros de Vida Entera: en el Seguro de Vida entera se cubre la muerte del Asegurado durante toda su vida, mientras que en el Seguro Temporario la cobertura sólo la otorga durante un determinado plazo de tiempo preestablecido en la póliza.

\section{b) Según la cantidad de asegurados cubiertos en la póliza}

Seguros Individuales, Seguros Colectivos, Seguros de Varias Cabezas: en los Seguros Individuales se cubre la muerte de un solo Asegurado, en los Seguros Colectivos se cubre en forma independiente, con una sola póliza, a un determinado número de personas y los seguros de varias cabezas cubren a más de un Asegurado pero se establece que la suma asegurada se abonará en caso de que fallezca el primero o el último del grupo de Asegurados.

\section{c) Según tengan o no componente de Ahorro}

Seguros de Vida Tradicionales (sin Ahorro) y Seguros de Vida con Ahorro: en los Seguros Tradicionales al fallecimiento del asegurado el asegurador abona a los beneficiarios el Capital Asegurado. En los Seguros de vida con Ahorro el asegurado va acumulando un fondo propio en la compañía de seguros; si el asegurado fallece antes de vencer el contrato, el asegurador le abona el Capital Asegurado a los beneficiarios y si sobrevive, el asegurado recibe el fondo acumulado (que también puede adquirir la forma de una renta periódica).

\subsection{Supuestos Implícitos}

Teniendo en cuenta que la ciencia se basa en ciertos supuestos que se toman como ciertos sin necesidad de una demostración empírica, la presente investigación recurrirá a supuestos relacionados tanto con la necesidad de las coberturas de vida, como con la motivación y el comportamiento que las personas en condiciones de tomar un seguro de vida.

\subsubsection{Motivación y Necesidad de los Seguros de Vida}

Al tratar el tema de la motivación se referirá al estímulo que mueve a una persona para realizar determinadas acciones y persistir en ellas para lograr un objetivo. Por ello la Motivación, en pocas palabras, es la voluntad para hacer un esfuerzo que tendrá como resultado alcanzar las metas propuestas, siendo que la base de toda motivación es el deseo y la obtención de lo que se desea es por lo general un sinónimo de felicidad.

Existen varias teorías sobre la jerarquía de necesidades y la motivación, dentro de las cuales la de Abraham Maslow mantiene su influencia en todos los ámbitos de aplicación. Maslow representó la jerarquía de necesidades a través de una pirámide que consta de cinco niveles. Según Maslow las necesidades más altas ocupan nuestra atención solamente una vez que se han satisfecho las necesidades inferiores de la pirámide. La necesidad de crecimiento hace que se busque colmar los estratos superiores de la pirámide. 


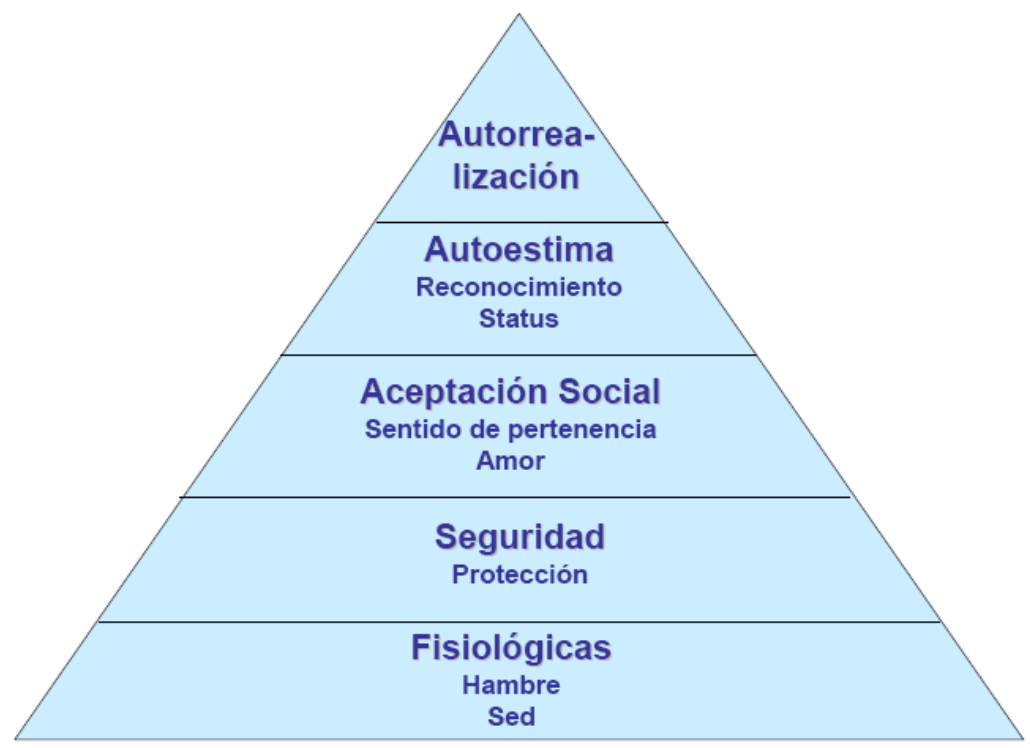

La necesidad de contar con un seguro de vida, pertenece al rango de las necesidades de seguridad, en el cuál, todos tienen tendencia a la estabilidad, a organizar y estructurar nuestro entorno y de ahí que se busquen mínimos que brinden seguridad, por lo que "a priori" no resulta fácil explicar la alta resistencia a contratar un seguro de vida, perteneciendo esta necesidad al segundo rango de mayor importancia según la categorización de Maslow, relegando a la aceptación social, a la autoestima y a la autorrealización en el orden de prioridades a satisfacer; por lo que el seguro de vida debería primar a la hora de elegir dónde destinar los recursos.

\subsubsection{Teoría de los Juegos en los Seguros de Vida}

La Teoría de Juegos analiza las decisiones de asignación óptima y decisión bajo riesgo y rentabilidad entre dos o más agentes que compiten y cuyas decisiones les afectan a todos, fundando una especulación racionada y menos riesgosa. Cuando un agente "especula" es porque creé saber qué va a pasar mañana y esa información la utiliza para tomar una decisión. La economía de la incertidumbre plantea la medición del riesgo y su cobertura para amparar la toma de decisiones de las empresas de manera que permita inversiones más seguras, asimilando un riesgo estimado.

Como ya se ha mencionado, en la evaluación del riesgo existe cierta cobertura que ofrecen las aseguradoras a las cuales se les transfiere el riesgo, así en un margen considerado de confianza, las adversidades son previstas en grado para amparar a los inversionistas que se aventuran a invertir bajo incertidumbre. Con esto se puede concebir la incertidumbre planeada, en el sentido de que queda cubierta por la contratación de un seguro.

En este sentido, los riesgos derivan de la adversidad de que lo esperado no se de cómo se desea. La cobertura de riesgo vía aseguradoras es un costo adicional de las inversiones que opera a favor de una menor rentabilidad a cambio de decisiones más seguras. No obstante existe riesgo moral cuando el seguro llega a ser tan oneroso a la persona renuente al riesgo que finalmente acaba por admitir el riesgo a cambio de evitar el pago del seguro, lo que incrementa la probabilidad de incrementar las pérdidas posibles. La cobertura es una fórmula de asimilación del 
riesgo de una empresa aseguradora en su toma de decisiones al adquirir un pasivo que contrataste el riesgo implícito en sus activos.

Asimismo es de destacar que existen algunos casos donde los fallos del mercado especulativo (regidos por el arbitraje) son muy graves lo que no permite su cobertura financiada por las empresas privadas, es así como el Estado es el encargado de ofrecer un seguro social que ampare esta situación, el cuál desempeña un papel importante pues otorga cobertura a inversiones que son necesarias no solo en el sentido privado sino también en el social que finalmente asume la sociedad en su conjunto.

Dentro del campo de la Teoría de los Juegos relacionado con los conceptos de "riesgo" e "incertidumbre", se debe considerar la tendencia de los individuos a no aceptar "juegos justos" (aquel en el que cuesta igual a su valor esperado, es decir un juego que tiene ganancia esperada es igual a cero). De ahí que la aversión al riesgo es generada por la existencia de utilidades marginales decrecientes especto al ingreso y es por ello que una persona neutral al riesgo (utilidad marginal constante) nunca comprará un seguro (o será indiferente entre comprarlo o no si la prima del seguro es cero), mientras que un amante del riesgo nunca contratará un seguro por que se reduciría su utilidad (es un caso en el que la utilidad marginal es creciente).

La selección adversa se presenta cuando existe información privada (que posee determinado individuo) antes de la realización de un contrato (por ejemplo: el verdadero estado de salud del asegurable). De tal forma que si una empresa aseguradora decide asumir un riesgo sin suscripción a cambio de una determinada prima "estándar" proveniente de las tablas de mortalidad normal, obtendrá como máximo asegurados cuya "calidad" de salud sea la del promedio de la población, (de la cuál se desprenden las tablas de mortalidad y la prima "normal") o cuyo estado de salud sea peor. Esto es así simplemente porque el asegurado conoce la calidad de su estado de salud que tiene y no lo va a asegurar a menos que perciba que la indemnización esperada sea superior al hecho de tener que rescindir el valor de la prima que hoy paga y por ello se le llama selección adversa.

Al analizar las motivaciones e incentivos para adquirir un seguro, se deben tener en cuenta las restricciones de Racionalidad Individual y la de Compatibilidad de Incentivos. La restricción de racionalidad individual establece que para que un agente participe en el contrato de seguro debe obtener una mayor utilidad que si decide no participar (en cuyo caso obtiene lo que se llama utilidad de reserva). Como el agente asegurado de tipo mayor salud es el que tiene mayor utilidad de reserva, si se cumple la restricción para el de mejor salud también se cumple para el de peor estado de salud. Es decir que si al asegurado que goza de muy buen salud percibe como conveniente contratar un seguro de vida, al asegurado que posee una patología lo cree conveniente aún más.

El problema fundamental se da con la restricción de compatibilidad de incentivos. Esta restricción lo que dice es que la utilidad que recibe un agente asegurable por aceptar una prima determinada haciéndose pasar por su propio estado de salud (es decir si se trata de una persona enferma que lo declare y que acepte abonar la prima de una persona enferma; y viceversa) es mayor que mintiendo y diciendo que se trata de una persona sana. En eso se basa la selección de riesgos de la aseguradora, en lograr que el tipo enfermo no se haga pasar por el sano (desalentando la mentira o "reticencia" mediante advertencias sobre que no se abonará la indemnización prevista en el caso en que el asegurado hubiera falseado su verdadero estado de salud). Obviamente la otra compatibilidad de incentivos no opera como restricción porque ninguna 
persona "sana" se querrá hacerse pasar por "enferma" y pagar más caro por su cobertura de seguro de vida.

En los seguros, también existe el Riesgo Moral ocurre cuando luego de firmado un contrato no hay posibilidad de verificar que el contrato procuró resguardar aquello que se aseguró. Por ejemplo, luego de contratado un seguro contra cristales por el valor total de los vidrios en su comercio, el asegurado no tendrá incentivos para adquirir una lámina protectora para los mismos.

En atención al riesgo moral, lo que hacen las compañía de seguros para evitar el riesgo moral es ofrecer seguros que no cubren la totalidad del siniestro, de tal forma que luego de firmado el contrato, independientemente de lo que ocurra con el estado de la naturaleza del objeto del seguro, el agente contratante del seguro tendrá incentivos para que el siniestro no ocurra, ya que tendrá que pagar una parte del siniestro. Por ello el valor de una póliza del seguro que tenga cobertura total resultará mucho más caro, ya que la empresa aseguradora es conciente de la existencia del riesgo moral.

En relación con las aseguradoras de vida, no es posible asegurar la "inmortalidad de alguien" y se asume generalmente (aunque las condiciones de póliza prevén exclusiones contra el suicidio), que una persona no desea conscientemente morir. Sin embargo, el riesgo moral se refleja por ejemplo, en el hecho que los asegurados de vida con coberturas de salud (enfermedades graves, renta por internación, etc.), paguen lo mismo siendo fumadores o no genera una situación de riesgo moral: ya que el fumador está asegurado en su tratamiento si enferma lo que genera que no tenga este estímulo para cuidarse. Esto genera que los que finalmente se ven perjudicados son los no fumadores ya que terminan pagando un seguro más elevado para compensar los mayores gastos que generan los fumadores al servicio de las coberturas de salud. Analizando este hecho, la solución debiera encaminarse en cobrar de manera diferencial, lo que mejorará la suscripción de los riesgos de la aseguradora limitando un problema de selección adversa que en el campo del mercado de seguros se conoce como "antiselección".

\subsection{Antecedentes de la Investigación:}

Con el objeto de realizar una revisión bibliográfica racional y actualizada (conforme a la realidad actual del sector), principalmente se recurrió a las opiniones de los referentes del sector, recabadas en artículos de publicaciones especializadas y/o correspondientes a declaraciones de los exponentes relevadas por los medios específicos del ámbito de los seguros, destacando los extractos pertinentes a la temática abordada.

\subsubsection{Declaraciones de Fredy Schoepflin Exposición: "Tendencias del Seguro de Vida y Pensiones"}

Durante la presentación $17^{\circ}$ Convención Nacional de Aseguradores en México DF, el 22 de Mayo de 2007, Fredy Schoepflin abordó el tema de las tendencias del seguro de vida y pensiones para América Latina, señalando cuáles serían las buenas perspectivas económicas sientan las bases para el crecimiento del sector en la región. 
El expositor destacó que "durante el año $2006\left(^{*}\right)$, el 90\% de las primas de América Latina se generaron en cinco países: Brasil (47\%), México (24\%), Chile (10\%), Argentina (6\%) y Colombia (3\%)" citando como fuente a los organismos de supervisión, Swiss Re Economic Research \& Consulting.

Seguidamente Fredy Schoepflin remarca que "en el año 2006, en América Latina, un tercio de las primas del seguro provinieron del seguro de vida", y enunció que "los factores que impactan positivamente en el desarrollo del seguro de vida, según la experiencia en América Latina son las ventajas fiscales, recuperación económica, y cambios legales; mientras que sucesos como la devaluación e hiperinflación, desalientan el desarrollo."

Como conclusión Fredy Schoepflin señaló que "el seguro de vida se beneficia de la estabilidad económica y de la privatización del seguro social, la creencia de los clientes en una conservación del valor real en caso de siniestro y la disminución de las tasas de inflación."

\subsubsection{Declaraciones de Daniel Marcú Exposición: "El Seguro de Vida en Tiempos de Turbulencia Financiera"}

El consultor Daniel Marcu inicia su ponencia en el Seminario Anual organizado por Zurich Argentina y desarrollado en Diciembre de 2008, aseverando que la crisis 2001/2002 no fue lo peor para la industria del seguro de vida como se pensaba, sino que la crisis financiera internacional iniciada a mediados de 2007 mostró "la mayor intranquilidad en el mundo" y es con este hecho donde "uno empieza a dudar de todos los mercados financieros y del ahorro."

El especialista se pregunta inicialmente sobre "¿De qué depende que ahorremos o no a largo plazo?", para luego citar las variables que a su juicio determinan el ahorro voluntario a largo plazo, entre las cuales enumera principalmente a: "la Propensión cultural al ahorro (vs. Hábitos de consumo), la Seguridad Jurídica, la Profundidad de los ciclos económicos, los Incentivos fiscales, la previsibilidad de ingresos vs. gastos, la Protección frente a la inflación", con una importancia media o moderada a: "Ios canales de distribución eficientes, la solvencia / credibilidad de los operadores" y de una importancia menor a: "los productos atractivos, la dimensión de la clase media registrada (empleo formal), la confianza en el estado benefactor, la existencia de brechas en la seguridad social y la propensión social para cubrirlas".

Posteriormente Marcu afirma que "el Estado debería ayudar y es tarea de las aseguradoras hacer el lobby que corresponda para que el Estado brinde mejores soportes fiscales, mejore los topes de deducibilidad y también dé movilidad automática. Es absurdo que en un país con inflación como el nuestro haya que rogar para que se ajusten los topes", continuó el especialista, para luego remarcar la necesidad de "controlar mucho más a los operadores off shore" algo que según el expositor "nunca se tuvo demasiado éxito."

Para terminar, Daniel Marcu destaca que para que sean exitosos, los productos del mercado "deben ser flexibles, transparentes y tendientes a atender necesidades futuras concretas", como por ejemplo procurar que la gente "tenga ingresos para financiar su propia salud" y finalmente "atender necesidades empresariales y sindicales de ahorro y protección para sus empleados y afiliados", concluye el expositor. 


\subsubsection{Declaraciones de Gabriel Chaufán Exposición: "Hay que Generar Conciencia Aseguradora"}

El por entonces presidente de la Asociación de Aseguradores de Vida y Retiro de la República Argentina (AVIRA), Gabriel Chaufan, llamó el marco del 1er Seminario Internacional sobre Seguros de Vida y Retiro 8Septioembre de 2008), organizado por la entidad a "generar conciencia aseguradora" en la sociedad argentina y a "derribar algunos mitos sobre los seguros para aprovechar las oportunidades que presenta hoy el mercado".

Chaufan remarcó que el gran objetivo es lograr que sectores cada vez más amplios de la población accedan a estas herramientas de protección, ahorro y planificación financiera. Pero advirtió que para ello es necesario crear conciencia aseguradora. "La planificación financiera es fundamental para la dinámica de una familia en el tiempo porque las contingencias existen y protegerse tardíamente es no protegerse”.

Además, destacó que hay ciertos mitos respecto a los seguros que hay que tumbar. Según el por entonces titular de AVIRA, mucha gente suele pensar que los seguros obligatorios ya cubren sus necesidades o que los seguros de vida y retiro son sólo para ricos o que son caros. Pero Chaufan aclara que "hay opciones que se adaptan a todas las necesidades. Cuanto más depende una persona de su salario para el bienestar de su familia, más importante es contar con cobertura".

También Chaufan, remarcó que hay cuatro pilares para el desarrollo del sector: "el primero es que exista una buena oferta de compañías, de productos y de redes de venta; el segundo, una distribución profesional amplia. Las otras dos patas son la conciencia aseguradora y los incentivos de rentabilidad, tanto de gestión como fiscales. En este último caso la desgravación y el diferimiento son fundamentales a la hora de motivar a la sociedad a posponer consumos a futuro".

Para finalizar, Chaufan destacó que como la apuesta de los seguros de vida y de retiro es a largo plazo la mayor parte de sus inversiones se vuelcan en herramientas financieras que contemplen esta característica. "Por ejemplo, el 53\% de las inversiones se asignan a títulos públicos, $18 \%$ a plazos fijo, $10 \%$ en fondos comunes de inversión, $5 \%$ en acciones y $14 \%$ en otros".

\subsubsection{Declaraciones de Ricardo Faerman}

Artículo: "Perspectivas de los Seguros de Vida en la Crisis"

El especialista en seguros Ricardo Faerman, que escribe frecuentemente en Buenafuente señala el 30 de Enero de 2009 que "la crisis financiera afectó a la industria hasta un límite tal que nadie es capaz de predecir que sucederá de aquí en adelante."

Faerman señala que "alguna vez todos estuvimos en el mismo bote, creíamos que el sistema financiero era uno solo y se componía de bancos, aseguradores, fondos de inversión y todo aquel que se colocara a si mismo como una diversificación del mismo y hoy aceptamos haber estado groseramente equivocados".

También señala que "con la crisis financiera internacional desencadenó que la situación de las aseguradores a nivel internacional se complicara hasta el punto que el Consejo de Aseguradores Americano pidió a la Asociación de Comisionados de Seguros un cambio en el 
modelo de calculo de reservas que las alivie de la imperiosa necesidad que muchas tenían respecto de conseguir más capital en un ámbito tan turbulento."

Posteriormente Faaerman se pregunta: “¿Y ahora qué? ¿Cómo vender ahorro de largo plazo en este contexto? ¿Cómo hablar de seguros de vida con ahorro, planificación para el retiro o rentas vitalicias?" Finalmente el analista sentencia que: "Ahora quizás el nudo se desate desde el regreso a los planes conservadores, con intereses garantizados y comisiones razonables que se vendían hasta el inicio de los ochenta, en el siglo pasado. Habrá que sufrir y la cosa será difícil, pero el agente de seguros será menos "asesor financiero" y más "asesor en seguros" sobre todo si quiere seguir en la profesión."

\subsubsection{Declaraciones de Diego Guaita}

\section{Exposición: "Los Seguros de Vida y Retiro como Complemento de la Seguridad Social”}

En el marco del 2do. Seminario Internacional de AVIRA (Agosto de 2009), Digo Guaita actuario y Director de la consultora internacional Towers Watson, planteó: "la necesidad de contar con un marco normativo que facilite y fomente el ahorro individual."

Luego de analizar la experiencia latinoamericana observando qué es lo que se hace en otros países de la región, evaluó Los diferentes productos existentes en el mercado en cuanto al grado de Disponibilidad Vs. Iliquidez, a la vez que consideró los productos de ahorro pro versus los que ofrecían "protección pura", señalando los beneficios de aquellos que se encuentran equilibrados entre estos factores como son los seguros de retiro y los de vida con ahorro.

Como mensaje final, el actuario Diego Guaita remató que "si bien existen aseguradoras que ya han desarrollado productos y adecuado sus sistemas, se debe crear un marco legal e impositivo adecuado que facilite y promueva el ahorro y la previsión." Rematando que "De esta manera lograremos múltiples beneficios para todos al lograr mayor estabilidad económica y financiera para la sociedad, una mejor protección de la familia y mantenimiento del nivel de vida para el trabajador, desvinculaciones menos traumáticas para las empresas y mejoras en las cuentas públicas para el gobierno", entre otros beneficios.

\subsubsection{Declaraciones de Gary Aluise}

\section{Artículo: "Vendamos a las Masas y Comamos con las Clases más Refinadas"}

Con 34 años de experiencia en la industria aseguradora, el Vicepresidente y Managing Director de operaciones internacionales de LIMRA (Life insurance marketing and Research Association) Gary Aluise, fue entrevistado por el diario "El Cronista" el Miércoles 26 de Agosto de 2009 y en la página 4 del suplemento de seguros se encuentra la nota de la cuál se extraen los siguientes fragmentos.

Inicialmente Aluise destaca que LIMRA es una marca que se dedica a la investigación del mercado en general desde hace 93 años y señala que "el mercado local es comparable a lo que ocurre en Europa y en Estados Unidos (dónde no se están cancelando los seguros de vida ya adquiridos, pero tampoco están contratando nuevos), a diferencia de lo que ocurre en Asia dónde está aislada." 
Aluise destaca que "a opinión pública internacional sobre las aseguradoras en la actualidad es buena, principalmente por haberse mantenido fuera de las primeras planas internacionales en los momentos más fuertes de la crisis."

Posteriormente remarca la necesidad de "capacitar mejor a los productores (de seguros) a la vez que hace falta crear nuevos canales comerciales para volver más eficiente la comercialización como clave para el desarrollo del mercado asegurador".

Finalmente al consultarle sobre por qué pensaba él que en la Argentina el seguro de vida tiene tan bajo grado de penetración en comparación con los parámetros internacionales, Aluise responde con una anécdota: "Hubo un muy famoso productor estadounidense que era miembro del MDRT, que se dedicaba únicamente a vender a las clases medias, y con su acento típico texano se expresó: - vendamos a las masas y comamos con las clases más refinadas."

\subsubsection{Declaraciones de Martín Gauto}

\section{Artículo: "Protección con trampa: los verdaderos riesgos del seguro Off Shore"}

En una nota realizada a Martín Gauto y publicada el 29 de Julio de 2009, presidente de AVIRA y número uno de Prudencial Seguros, la periodista Mónica Fernández de "El Cronista" consulta a este y otros funcionarios sobre la ilegalidad del seguro Off Shore. Al respecto Gauto señala "definitivamente, siempre es ilegal contratar un seguro fuera de la argentina".

Luego agrega: "Todos los seguros contratados en compañías no autorizadas a operar en la Argentina, independientemente del país donde estén localizadas (sean o no paraísos fiscales), son pólizas Off Shore y por tanto contratos ilegales, es decir prohibidos por la ley", remarca Gauto enfatizando el grado con el que las contratación de estas coberturas ilegales afectan al mercado nacional.

Para finalizar Martín Gauto asevera que "la calidad de ilegalidad no se evita con la declaración o reconocimiento" aclara, para luego sentenciar que "es más, la AFIP es uno de los organismos que interviene en el control de esta actividad ilegal, con lo cuál si alguien lo declarara tendría como consecuencia directa la aplicación de las multas a las partes intervinientes".

\subsubsection{Declaraciones de Carlos Facal}

Artículo: “¿Quién tiene la culpa que no se vendan seguros de vida?”

El Dr. Carlos Facal (abogado especialista en seguros de vida) expuso sus razones sobre por qué no se venden seguros de vida en Argentina, el día 25/09/2009 en el marco de la sexta edición del Foro Nacional del Seguro y posteriormente levantado por numerosos medios especializados, incluyendo Buenafuente.com de dónde se tomaron tales declaraciones.

En esa oportunidad, el Dr. Facal inició enumerando aquellas preguntas que son frecuentes y que se suelen hacer a la hora de explicar este problema. “¿Faltan incentivos impositivos? ¿La Culpa la tiene la venta off-shore? ¿Falta capacitación en la fuerza de ventas? ¿Los Argentinos no tienen necesidad de ahorrar?", cuestionó, para luego negar a su criterio que estos posibles 
impedimentos sean la verdadera razón, ya que según explicó el especialista, en el país no hay productos que respondan a lo que los argentinos necesitan.

"Yo quiero un asegurador que no se porte con sus clientes más desprotegidos como la ANSeS lo hace con sus jubilados, ni quiero que engañe a la gente o lucre con su desesperación o ignorancia, pero sobre todo quiero un asegurador que ponga a sus clientes antes que a sus accionistas" exclamó el especialista, quien agregó: "El cambio sin duda va a empezar ya cuando tengamos aseguradores; luego cuando tenga el país jueces rápidos, aunque va a ser difícil; cuando tengamos acciones de clase, que no nos obliguen a litigar eternamente para que valgan nuestros derechos (es decir, si el caso es el mismo para todos, sea de inmediata aplicación para todos los casos); cuando tengamos leyes que el Estado no sea el primero en desconocer".

Invitando a las aseguradoras a hacer una autocrítica, y frente a un auditorio que comenzaba a asentaba con la cabeza sus palabras, Facal aseguro que este es el cambio más rápido y próximo que se puede dar para salir a captar nuevos clientes, y es aquel que tiene que salir de las propias compañías. De cumplirse estas primeras medidas, Facal prevé que de esta manera ya se tenga mercados y moneda confiable "sin que lo hayamos buscado", y que se tengan que poner mayores regulaciones para que las compañías argentinas no tomen pólizas off-shore de habitantes de otro país con instituciones más débiles.

Con relación a la seguridad jurídica, el especialista afirmó que esta es la base de cualquier compromiso social. "Quizás para comenzar a resolver el problema, hay que comenzar por lo más próximo: aceptar las pérdidas, reconocer los contratos que existen de antes y empezar a construir algo para que la gente crea que pase lo que pase alguien va a estar ahí para cumplir".

"Cuando ha habido un shock que ha afectado la confianza, la mejor manera de recuperarla es mediante otro shock para que la gente vuelva a creer que a pesar de todo se va a cumplir siempre", sintetizó Facal para finalizar.

\subsubsection{Declaraciones de Eduardo D'Alessio \\ Estudio: "Relación entre la Población y el Seguro de Vida y Retiro"}

Corresponde a la presentación que D’Alessio realizó en el Seminario de AVIRA de Agosto de 2009, sobre el trabajo realizado durante los meses de Junio y Julio de 2009 por la consultora D'Alessio IROL (Certificación en encuestas online norma ISO 9001:2000) para la Asociación de Aseguradoras de Vida y Retiro (AVIRA) presentado en el marco del Seminario Anual 2009 de esta asociación. Realizado sobre una muestra de 1.667 casos, en un universo de personas de entre 25 y 54 años de nivel socioeconómico C1, C2, C3 y parte de D1, mediante la técnica Cuantitativa de Encuestas On Line RTRpc®, en todo el país (33\% Capital Federal, 33\% Gran Buenos Aires y 34\% Resto del País) y cuyos principales tablas de resultados de la investigación se encuentran en el anexo 12.1 titulado: "Tablas del Estudio sobre la Relación de la Población y el Seguro de Vida".

El mencionado Estudio se propuso principalmente: "Indagar si existe propensión al ahorro y aceptación de productos de protección financiera, determinar el perfil actual del potencial comprador/tenedor de un seguro de vida o retiro, saber qué conocimiento existe de ambos productos, especificar la tasa de penetración de ambos, detectar los atributos decisores de compra y marcar las oportunidades que existen para la industria". 
A partir de los casos estudiados, desde la consultora se concluye que existe una "brecha entre la expectativa y la realidad", dado que mientras un $95 \%$ considera que es importante o muy importante el ahorro para el hogar, solo un $23 \%$ de los hogares consultados ahorra.

Luego, al medir el nivel de confianza en las instituciones y servicios, se determina un bajo nivel comparativo a las aseguradoras con 4,1 puntos (en una escala del 1 al 10), ubicándolas junto a las empresas de telefonía y por debajo de los bancos privados $(4,7)$, empresas de agua y gas $(5,0)$ y de los bancos públicos y tarjetas de crédito $(5,3)$.

A partir de ese dato se buscó establecer sobre: “¿Qué elementos le generan confianza en una aseguradora?" y se identificaron los principales factores que afectan la confianza en el Pasado: "Antecedentes (años de trayectoria), prestigio y referencias de conocidos"; en el Presente: "Buena atención al cliente, poca burocracia, capacidad de respuesta y comunicación"; y para el futuro: "Cumplimiento en tiempo y forma ante posibles siniestros y responsabilidad a la hora de cumplir con lo pactado."

Con posterioridad se indagó sobre el conocimiento existente en los seguros de vida, del cual solo el $12 \%$ de los encuestados pudo proporcionar una definición apropiada.

Para finalizar el Estudio, la consultora D'Alessio IROL establece a "la confianza como condición necesaria" para el desarrollo de los seguros de vida y retiro en la argentina y como condiciones suficientes menciona a: "la Información desde las aseguradoras, a la accesibilidad de los productos (fácil comprensión, fácil ingreso) y a la necesidad de estímulos impositivos."

\subsection{El Sistema de Variables:}

\subsubsection{Variables Seleccionadas}

Teniendo en cuenta los antecedentes citados, los cuales representan las opiniones de los principales exponentes del sector en el mercado argentino de los seguros de vida y cuya información principal se detalla dentro del marco teórico, se han agrupado las variables intervinientes en nueve grupos a fin de poder evaluarlos y ponderar la participación relativa de los mismos como limitantes al crecimiento de los seguros de vida en el mercado argentino.

Seguidamente se detallan las nueve variables seleccionadas ordenados alfabéticamente:

1 - Complejidad de los Productos: Se refiere a que generalmente los productos de los seguros de vida son complejos para la comprensión del solicitante dado que, por ejemplo, los seguros de contratación individual que no posean componente de ahorro, deben modificar su costo o el capital al menos una vez al año. Los productos que se diseñan poseen diferentes plazos, formas de ajustes de la reserva matemática (en caso de existir), penalidades por rescate, etc. lo cuál resulta poco asimilable por parte del comprador que solo percibe la diferencia en los nombres del los productos, los cuales responden a cuestiones comerciales y no técnicas que expliquen su funcionamiento. Esto genera que frecuentemente el eventual comprador de un seguro sea sometido a tomar una decisión que implica asignar una cantidad de recursos a un bien intangible que él mismo no percibirá y cuyas características técnicas lo exceden, lo cual puede frustrar la compra. 
2 - Desconfianza: Hacia las Compañías aseguradoras y al marco legislativo que las regula, comprendiendo a su vez al organismo de contralor que es la superintendencia de Seguros de la Nación, dependiente del Ministerio de Economía de la Nación. La actividad de los seguros se encuentra regulada por la Ley $\mathrm{N}^{\circ} 17.418$ y las aseguradoras que desarrollan su actividad dentro del país por la Ley $\mathrm{N}^{\circ} 20.091$. Al tratarse el seguro de vida de un bien intangible y cuya cobertura se contrata a largo plazo, adicionando que los beneficios de la cobertura principal no serán percibidos por el contratante con vida; la confianza tanto en el contrato (póliza) como en la aseguradora donde se lleva a cabo, así como la que se tenga en el asesor que intervino y en el ente regulador que los controle, juega un rol a considerar dentro del presente análisis.

3 - Desinformación: Hace referencia al desconocimiento por parte de la población en general sobre la existencia de este tipo de productos de seguros de vida individual. A su vez se ignora el alcance de las coberturas, las exclusiones, la continuidad y permanencia, etc. Con frecuencia se confunden a los seguros de vida con los de accidentes personales y hasta con la cobertura que brindan las Aseguradoras del Riesgo del Trabajo (ART). El hecho que el estudio de la consultora D'Alessio IROL haya identificado que solo el $12 \%$ de los encuestados pudo proporcionar una definición apropiada para los seguros de vida, brindan la pauta para asumir que la falta de información apropiada debe ser considerado como uno de los determinantes a tener en cuenta en el estudio.

4 - Desinterés: A diferencia de lo que pueda hacerse referencia en las variables 3 y 7 , el presente determinante tiene que ver con aquellos asegurados que poseen un conocimiento (al menos básico), sobre la existencia del riesgo, de las coberturas de vida que pueden ampararlo y de los productos que ofrecen las aseguradoras, pero que de todas formas no se interesan en cubrirse del mismo, ya sea por cuestiones relacionadas con el propio egoísmo, por que no poseen allegados a quienes amparar o sencillamente por que no están dispuestos a sacrificar consumos inmediatos por previsiones futuras.

5 - Falta Incentivos Fiscales: Se encuentra relacionado con que la posibilidad de realizar deducciones en los impuestos a las ganancias constituye un importante motor en otros países para incentivar el ahorro y la prevención. La falta de incentivos fiscales hace alusión a que a la fecha de elaboración del presente estudio el importe límite para deducir los seguros de vida en los impuestos a las ganancias está fijado en \$ 996,23 al año (según el inciso "b" del artículo $\mathrm{N}^{\circ} 81$ de la ley 20.628), lo cual en la actualidad representa un estímulo fiscal de dudosa eficacia o al menos, insuficiente.

6 - Inestabilidad Económica: Independientemente que el seguro de vida contenga un componente de ahorro o no, la decisión de contratar un seguro de vida se encuentra influida por esta variable; dado que las coberturas se comercializan por lo general en la moneda de uso legal (y aunque no fuera así, la última devaluación demostró que la moneda extranjera en contratos particulares puede ser modificada por el Estado), y teniendo en cuenta que se tratan de productos que se contratan a largo plazo, la evolución de la economía, la inflación y otras inestabilidades de la economía del país inciden negativamente en la contratación de las coberturas de vida. También la pérdida del poder adquisitivo de la moneda juega un rol importante al no poder ajustar por inflación las sumas aseguradas oportunamente contratadas, a la vez que para incrementar los capitales asegurados las compañías exigen nuevos requisitos de salud, lo cual no siempre es posible y/o deseable por los asegurados.

7 - No Percepción del Riesgo: Se refiere a la incapacidad de la población en condiciones de contratar una o más coberturas de los seguros de vida para poder identificar el riesgo 
inherente que existe en todo ser humano que se encuentre con vida. Las argumentaciones en este sentido van desde declaraciones como: "soy joven, lo puedo contratar más adelante", hasta "si soy una persona sana". Las cuestiones relacionadas con los fallecimientos, enfermedades o incapacidades resultan temas difíciles de abordar en la mayoría de las personas por tratarse de temas dolorosos y que pueden conllevar a especulaciones, lo cual fomenta la falta de habilidad para percibir el riesgo y por consiguiente desalientan la contratación.

8 - Orientación a Otros Productos Financieros: Hace alusión a la preferencia que el eventual tomador de un seguro de vida realiza optando por productos financieros que tener un fondo como componente de ahorro o representar una inversión de la cuál el titular estima que ante un eventual fallecimiento podrán luego los herederos legales disponer del mismo, se inclinan a elegir productos financieros como fondos comunes de inversión, plazos fijos, etc. los cuales entienden que amparan el riesgo de vida. Esta confusión tiene su origen en la existencia de determinados productos de vida con ahorro, con lo cual el decidor compara erróneamente las coberturas de vida con otros productos financieros ignorando las eventualidades que puedan hacer variar a éstos últimos, en especial lo relacionado con el plazo para su disponibilidad, la libre elección de los destinatarios, la rentabilidad y su consecuente conformación de ese fondo.

9 - Preferencia Seguros Off Shore: Se encuentra relacionado con la predilección de los asegurables por un producto contratada en una aseguradora con origen y residencia en el extranjero y cuyas condiciones contractuales no se encuentran bajo la legislación argentina. Al momento de contratar un seguro de vida con o sin capitalización, los habitantes de países con economías poco estables suelen tener dudas sobre la evolución de sus fondos y frecuentemente son tentados por productos off shore sin conocer sobre su ilegalidad ni interiorizarse plenamente sobre los alcances de esa decisión. Más allá de las penalidades que pudieran corresponder por contratar un seguro ilegal, (como las establecidas en los Decretos del P.E.N. $\mathrm{N}^{\circ}$ 560/09 y $\mathrm{N}^{\circ} 726 / 10$ ), el tomador de un seguro off shore pierde toda posibilidad de defensa en un juicio bajo la legislación argentina, debiendo someterse a las normas del país dónde la aseguradora posee su domicilio legal. Tampoco puede acudir a la Superintendencia de Seguros de la Nación ni a las asociaciones de defensa al consumidor que pudiera necesitar, en especial ante condiciones contractuales redactadas en idioma extranjero, con lenguaje técnico y dónde frecuentemente se hace alusión a cláusulas ambiguas o abusivas. No obstante todo ello, la proliferación de este tipo de coberturas ilegales generan una competencia al mercado nacional como para ser considerado un determinante a tener en cuenta.

\subsubsection{Clasificación de las Variables}

Las variables seleccionadas pueden agruparse conforme a si representan factores endógenos o exógenos al mercado y si en este último caso el mercado puede ejercer algún grado de influencia.

Variables Endógenas del Mercado Asegurador:

- Complejidad de los Productos

- Desconfianza (Aseguradoras y Marco Regulatorio) 
Variables Exógenas al Mercado Asegurador:

- Orientación a Otros Productos Financieros

- Falta Incentivos Fiscales

- Inestabilidad Económica

Variables en dónde el Mercado Asegurador puede ejerce influencia:

- Desinformación

- Desinterés

- No Percepción del Riesgo

- Preferencia Seguros Off Shore

Es de destacar que a las variables anteriormente citadas, a los efectos de este estudio, se consideran "determinantes", toda vez que ejercen algún tipo de influencia en el efecto observado, en forma independiente del tipo de condicionamiento, que ejercen en el mismo.

Dicho condicionamiento es considerado como: "necesario" cuando no resulte posible que se produzca el efecto observado sin que una determinada variable se encuentre presente; "suficiente" cuando la sola presentación del determinante basta para producirlo (aunque no sea necesario que esté presente); "contribuyente" al favorecer el evento en forma decisiva y en general producirlo (aunque no alcanza un determinismo que pueda considerarse necesario o suficiente); o clasificado como "contingente" al tratarse de circunstancias que pudiendo favorecer el hecho observado, se presentan sólo eventualmente, (siendo posible que estén por completo ausentes en la mayoría de los casos).

En tal sentido y a los efectos del presente estudio se consideran "necesarios" aquellos determinantes que siempre están presentes, es decir que nunca tengan un "cero" como puntuación asignada por los especialistas.

Asimismo se considera que cumplen con la condición de "suficientes" aquellos determinantes cuya puntuación media superare el promedio de los puntos máximos posibles otorgados por los expertos.

También a los fines de la presente investigación se establece que será atribuible una condicionalidad "contribuyente" a aquellos determinantes que obtengan una puntuación promedio cercana a la media de los puntos posibles, que no posean una correlación negativa significativa y que obtengan cero puntos en al menos una oportunidad.

Por su parte se asigna la condición de "contingente" a los determinantes que a la vez de obtener una puntuación media inferior al promedio de los puntos posibles otorgados por los especialistas, no reciban puntos en al menos una oportunidad y que posean correlaciones negativas con al menos otros dos determinantes.

Se señala que solamente en aquellos casos en que se pueda sostener que un determinante cumple con las condiciones de necesario y suficiente a la vez, representa una causa para ese efecto. 


\section{Metodología de la Investigación}

\subsection{Población y Muestra}

Teniendo en cuenta que ninguno de los estudios realizados hasta el momento hace hincapié en la participación relativa de cada una de las variables como limitantes al crecimiento de los seguros de vida en la República Argentina y que el estudio sobre la relación entre la población y el seguro de vida y retiro realizado por la consultora D'Alessio IROL no indaga específicamente la problemática abordada por el presente estudio, a la vez que refleja un desconocimiento considerable de la temática en cuestión por parte de la población en general, se optó por anteponer la calidad ante la cantidad de los datos, procurando obtener la opinión de especialistas en el tema.

En este sentido las conclusiones a las que se arriban son válidas para la población asegurable en su conjunto para las coberturas que brinda una póliza de seguro de vida sin capitalización en la República Argentina, siempre y cuando las condiciones del contexto y antecedentes sean similares a las de la actualidad.

Asimismo, toda vez que dichas condiciones se mantengan y que se recurra a especialistas con perfiles y experiencia sean de similares características a los expertos que se seleccionarán, el presente estudio podrá ser replicado.

Se tuvieron en cuenta algunas características esenciales al seleccionar la población bajo estudio. Entre éstas se pueden contar los siguientes:

- Homogeneidad: Todos los consultados debían contar con similares conocimientos del mercado, más de 5 años de experiencia específica cada uno y encontrarse en plena vigencia del desarrollo de sus actividades, independientemente de la distribución de los perfiles que se realizará con el objeto de restringir una visión parcializada ya sea desde un punto de vista comercial, uno técnico, etc.

- Tiempo: El estudio corresponde a las circunstancias del momento presente.

- Espacio: El estudio refiere a especialistas de todo el país, siendo que se trata de un mercado no distribuido equitativamente en toda la Argentina, se hizo hincapié en las zonas de la Ciudad Autónoma de Buenos Aires, en el Gran Buenos Aires, en la Provincia de Buenos Aires y en la Provincia de Santa Fé, por contar con varias aseguradoras representativas del sector.

- Cantidad: El tamaño de la población de los especialistas a consultar se limitó a diez que brindaron respuesta positiva, es decir que comprendieron la metodología y consigna propuesta y respondieron todas las consultas con responsabilidad. 


\subsection{Tipo de Investigación}

Teniendo en cuenta que la objetividad en las ciencias sociales está definida como la intersubjetividad de los especialistas de una determinada temática, se consultó a personas destacadas en la actividad de los seguros de vida de la República Argentina.

Es por ello que se decidió recurrir como técnica de investigación a un Panel de Expertos o Especialistas profesionales ${ }^{1}$, el cual está formado por un grupo de personas expertas en una materia determinada, con un gran bagaje profesional en el tema en cuestión.

Con el objeto de contar con información confiable a un costo mucho menor que el de herramientas de investigación de mercados tradicionales, se recurrió a diez especialistas del sector que brindaron respuesta positiva, los cuales debían poseer tanto trayectoria como vigencia dentro del mercado de los seguros de vida.

Las principales ventajas de recurrir a un Panel de Especialistas sobre los métodos de investigación de mercados tradicionales son:

- Ahorro de costos,

- Superación de barreras geográficas, pudiendo reunir en una sesión a personas de diferentes ciudades,

- Lograr una mayor desinhibición de los participantes, lo que provoca que las opiniones vertidas sean más sinceras y arriesgadas,

- Posibilidad de recopilación inmediata de las opiniones nada más finalizar la misma, y

- Mayor individualidad en las respuestas frente a técnicas alternativas como el Focus Group, en el que la presión del grupo puede llevar a ciertos participantes a cambiar de opinión y por ende "contaminar" los resultados

\subsubsection{Perfiles de los Expertos}

Con el objeto de contar con una visión equitativa del problema, se han seleccionado especialistas del seguro de vida que participan en diferentes áreas dentro del mercado. En este sentido se han elegido un total de diez expertos con desempeño distribuido entre las siguientes tres áreas:

Área Actuarial

Conformada por actuarios, es la actividad profesional expresamente habilitada para el desarrollo de los planes de seguros de vida y coberturas, para lo que emplean cálculos actuariales y tablas de mortalidad. Desempeñando su rol generalmente dentro de Estudios Profesionales o Consultoras Externas, interactúan entre los requerimientos de los funcionarios del las gerencias técnicas y de producción de las empresas aseguradoras y las restricciones establecidas en la Superintendencia de Seguros de la Nación. A su vez, por sus conocimientos técnicos e información privilegiada que gestionan, frecuentemente son los encargados de asesorar a las gerencias y directivos de las empresas aseguradoras sobre las perspectivas de las diferentes unidades de negocios y oportunidades que se presentan.

\footnotetext{
${ }^{1}$ Los estudios que se realizan utilizando un "Panel de Expertos" tienen por finalidad obtener ideas o confirmar planteamientos por la experiencia de las personas seleccionadas representando más bien una consulta o una técnica proyectiva que una investigación cuantitativa de mercados propiamente dicha.
} 


\section{Área Técnico Comercial y Producción en Empresas}

Compuesto por funcionarios de diferentes empresas aseguradoras, son los que poseen una visión global sobre la evolución del negocio, recibiendo información tanto de los clientes como de los productores asesores de seguros, a la vez que son los que desarrollan los productos a comercializar, encargando el desarrollo de los planes a los actuarios, haciendo presentaciones en el organismo de control y monitoreando la rentabilidad y el crecimiento del sector en general y de los diferentes productos en particular ante el los cambios en las necesidades y preferencias de la población asegurable.

\section{Área Comercial}

La comercialización de los seguros en general y de los seguros de vida en particular es desarrollada exclusivamente por Productores Asesores de Seguros con matrícula habilitante otorgada por la Superintendencia de Seguros de la Nación. Los especialistas referentes del área comercial son los que proveen la percepción al encontrarse día a día con los clientes, al tener que manejar las objeciones que exponen los asegurables y al poder medir los argumentos que definen o no los cierres de una venta.

A su vez, algunos de los especialistas mencionados se han desempeñado oportunamente como funcionarios del organismo de contralor de la actividad que es la Superintendencia de Seguros de la Nación o como representantes de empresas de reaseguro internacional en el área específica de vida, enriqueciendo la visión que se proporciona de la problemática abordada. Asimismo, es válido destacar que uno de los especialistas desarrolla un rol adicional como editor y director del principal newsletter específico del sector, portal de Internet y organizador de varios seminarios y workshops orientados al desarrollo comercial de los seguros de vida.

Véase su composición en el anexo 12.2.

\subsection{Técnica de Recolección de Datos}

Con el fin de limitar la subjetividad inherente que posee cada uno de los expertos seleccionados, se buscó brindarles una herramienta que facilite la comparación entre las diferentes causas y su posterior posicionamiento, peso específico y participación relativa de cada uno de los determinantes en la problemática planteada.

Para ello, entre los días 1 y 10 de Septiembre de 2010, se les hizo llegar a cada uno de los especialistas una planilla de cálculo donde cada uno de los nueve determinantes seleccionados se comparaba con cada uno de los restantes en conjunto de a dos. Esta comparación "de a pares", facilita la evaluación que cada experto pueda realizar, a la vez que disminuye la subjetividad y permite mensurar la participación relativa de cada determinante como limitante al crecimiento de los seguros de vida en la argentina.

\subsubsection{Tabla de Ponderación Relativa}

Los nueve determinantes se comparan unos con otros entre sí, en grupos de a dos a la vez teniendo diez puntos para repartir entre ambos, representando dicho valor la participación relativa que cada uno de los dos determinantes posee como limitante al crecimiento de los seguros de vida. 


\begin{tabular}{|l|c|l|c|}
\hline \multicolumn{2}{|c|}{ Causa 1 } & \multicolumn{2}{c|}{ Causa 2 } \\
\hline Complejidad de Productos & 5 & Desconfianza & $\mathbf{5}$ \\
\hline Complejidad de Productos & 5 & Desinformación & $\mathbf{5}$ \\
\hline Complejidad de Productos & 5 & Desinterés & $\mathbf{5}$ \\
\hline Complejidad de Productos & 5 & Falta Incentivos Fiscales & $\mathbf{5}$ \\
\hline Complejidad de Productos & 5 & Inestabilidad Económica & $\mathbf{5}$ \\
\hline Complejidad de Productos & 5 & No Percepción Riesgo & $\mathbf{5}$ \\
\hline Complejidad de Productos & 5 & Ot. Productos Financieros & $\mathbf{5}$ \\
\hline Complejidad de Productos & 5 & Preferencia Off Shore & $\mathbf{5}$ \\
\hline Desconfianza & 5 & Desinformación & $\mathbf{5}$ \\
\hline Desconfianza & 5 & Desinterés & $\mathbf{5}$ \\
\hline Desconfianza & 5 & Falta Incentivos Fiscales & $\mathbf{5}$ \\
\hline Desconfianza & 5 & Inestabilidad Económica & $\mathbf{5}$ \\
\hline Desconfianza & 5 & No Percepción Riesgo & $\mathbf{5}$ \\
\hline Desconfianza & 5 & Ot. Productos Financieros & $\mathbf{5}$ \\
\hline Desconfianza & 5 & Preferencia Off Shore & $\mathbf{5}$ \\
\hline Desinformación & 5 & Desinterés & $\mathbf{5}$ \\
\hline Desinformación & 5 & Falta Incentivos Fiscales & $\mathbf{5}$ \\
\hline Desinformación & 5 & Inestabilidad Económica & $\mathbf{5}$ \\
\hline
\end{tabular}

\begin{tabular}{|l|c|l|l|}
\hline \multicolumn{2}{|c|}{ Causa 1 } & \multicolumn{2}{c|}{ Causa 2 } \\
\hline Desinformación & $\mathbf{5}$ & No Percepción Riesgo & $\mathbf{5}$ \\
\hline Desinformación & 5 & Ot. Productos Financieros & $\mathbf{5}$ \\
\hline Desinformación & $\mathbf{5}$ & Preferencia Off Shore & $\mathbf{5}$ \\
\hline Desinterés & 5 & Falta Incentivos Fiscales & $\mathbf{5}$ \\
\hline Desinterés & 5 & Inestabilidad Económica & $\mathbf{5}$ \\
\hline Desinterés & 5 & No Percepción Riesgo & $\mathbf{5}$ \\
\hline Desinterés & 5 & Ot. Productos Financieros & $\mathbf{5}$ \\
\hline Desinterés & 5 & Preferencia Off Shore & $\mathbf{5}$ \\
\hline Falta Incentivos Fiscales & 5 & Inestabilidad Económica & $\mathbf{5}$ \\
\hline Falta Incentivos Fiscales & 5 & No Percepción Riesgo & $\mathbf{5}$ \\
\hline Falta Incentivos Fiscales & 5 & Ot. Productos Financieros & $\mathbf{5}$ \\
\hline Falta Incentivos Fiscales & $\mathbf{5}$ & Preferencia Off Shore & $\mathbf{5}$ \\
\hline Inestabilidad Económica & 5 & No Percepción Riesgo & $\mathbf{5}$ \\
\hline Inestabilidad Económica & 5 & Ot. Productos Financieros & $\mathbf{5}$ \\
\hline Inestabilidad Económica & 5 & Preferencia Off Shore & $\mathbf{5}$ \\
\hline No Percepción Riesgo & $\mathbf{5}$ & Ot. Productos Financieros & $\mathbf{5}$ \\
\hline No Percepción Riesgo & 5 & Preferencia Off Shore & $\mathbf{5}$ \\
\hline Ot. Productos Financieros & 5 & Preferencia Off Shore & $\mathbf{5}$ \\
\hline
\end{tabular}

Por ejemplo cuando el par de determinantes examinado ejerce para el experto igual importancia como limitante, el especialista le asignará "cinco puntos" a cada uno de las variables. Si por el contrario uno de ellos es considerado por el experto como absolutamente superior en importancia relativa con relación al otro, le asignará un "diez" al primero y un "cero" al segundo. En el caso que el especialista que analiza cada caso entienda que no se presenta ninguno de los casos anteriores, procederá a indicar valores intermedios, siendo la totalidad de las alternativas posibles las siguientes: $0-10,1-9,2-8,3-7,4-6,5-5,6-4,7-3,8-2,9-1$ y $10-0$ en cada par de comparaciones.

\begin{tabular}{|l|c|l|c|}
\hline \multicolumn{2}{|c|}{ Causa 1 } & \multicolumn{2}{c|}{ Causa 2 } \\
\hline Complejidad de Productos & 0 & Desconfianza & $\mathbf{1 0}$ \\
\hline Complejidad de Productos & 1 & Desinformación & $\mathbf{9}$ \\
\hline Complejidad de Productos & 2 & Desinterés & $\mathbf{8}$ \\
\hline Complejidad de Productos & 3 & Falta Incentivos Fiscales & $\mathbf{7}$ \\
\hline Complejidad de Productos & 4 & Inestabilidad Económica & $\mathbf{6}$ \\
\hline Complejidad de Productos & 5 & No Percepción Riesgo & $\mathbf{5}$ \\
\hline Complejidad de Productos & 6 & Ot. Productos Financieros & $\mathbf{4}$ \\
\hline Complejidad de Productos & 7 & Preferencia Off Shore & $\mathbf{3}$ \\
\hline Desconfianza & 8 & Desinformación & $\mathbf{2}$ \\
\hline Desconfianza & 9 & Desinterés & $\mathbf{1}$ \\
\hline Desconfianza & 10 & Falta Incentivos Fiscales & $\mathbf{0}$ \\
\hline Desconfianza & 0 & Inestabilidad Económica & $\mathbf{1 0}$ \\
\hline Desconfianza & 1 & No Percepción Riesgo & $\mathbf{9}$ \\
\hline Desconfianza & 2 & Ot. Productos Financieros & $\mathbf{8}$ \\
\hline Desconfianza & 3 & Preferencia Off Shore & $\mathbf{7}$ \\
\hline Desinformación & 4 & Desinterés & $\mathbf{6}$ \\
\hline Desinformación & 5 & Falta Incentivos Fiscales & $\mathbf{5}$ \\
\hline Desinformación & 6 & Inestabilidad Económica & $\mathbf{4}$ \\
\hline
\end{tabular}

\begin{tabular}{|c|c|c|c|}
\hline \multicolumn{2}{|l|}{ Causa 1} & \multicolumn{2}{|l|}{ Causa 2} \\
\hline Desinformación & 7 & No Percepción Riesgo & 3 \\
\hline Desinformación & 8 & Ot. Productos Financieros & 2 \\
\hline Desinformación & 9 & Preferencia Off Shore & 1 \\
\hline Desinterés & 10 & Falta Incentivos Fiscales & 0 \\
\hline Desinterés & 0 & Inestabilidad Económica & 10 \\
\hline Desinterés & 1 & No Percepción Riesgo & 9 \\
\hline Desinterés & 2 & Ot. Productos Financieros & 8 \\
\hline Desinterés & 3 & Preferencia Off Shore & 7 \\
\hline Falta Incentivos Fiscales & 4 & Inestabilidad Económica & 6 \\
\hline Falta Incentivos Fiscales & 5 & No Percepción Riesgo & 5 \\
\hline Falta Incentivos Fiscales & 6 & Ot. Productos Financieros & 4 \\
\hline Falta Incentivos Fiscales & 7 & Preferencia Off Shore & 3 \\
\hline Inestabilidad Económica & 8 & No Percepción Riesgo & 2 \\
\hline Inestabilidad Económica & 9 & Ot. Productos Financieros & 1 \\
\hline Inestabilidad Económica & 10 & Preferencia Off Shore & 0 \\
\hline No Percepción Riesgo & 0 & Ot. Productos Financieros & 10 \\
\hline No Percepción Riesgo & 1 & Preferencia Off Shore & 9 \\
\hline Ot. Productos Financieros & 2 & Preferencia Off Shore & 8 \\
\hline
\end{tabular}

Al finalizar, cada uno de los especialistas puede observar los resultados de sus propias respuestas, pudiendo comentar sobre si esperaban lo obtenido y si se encontraban de acuerdo con el resultado. 


\subsection{Técnicas de Análisis}

Al tratarse de nueve variables que interactúan entre sí, se contaron 36 comparaciones en cada caso. Al procurarse la respuesta de diez especialistas los resultados fueron 360 en total.

Cada determinante anualizado fue considerado y posicionado conforme a la mayor cantidad de puntos relativos que poseía, lo cual representó un porcentaje relativo de incidencia como limitante al crecimiento del mercado de los seguros de vida en la argentina, pudiéndose realizar análisis univariado sobre cada uno de ellos y obtener datos estadísticos como el promedio, mediana, moda, desvío estándar, etc.

A su vez el análisis a través del coeficiente de correlación permitió fundamentar relaciones lógicas existentes entre determinantes.

Para ello, el principal instrumento de análisis empleado fue la planilla de cálculo y la aplicación de gráficos, fórmulas y funciones que el Microsoft Excel (Copyright $®$ Microsoft Corporation) provee. 


\section{Resultados de la Investigación}

\subsection{Resultados Obtenidos}

El $100 \%$ de las fichas enviadas fueron respondidas positivamente y las planillas fueron contestadas en su totalidad, sin encontrar en las respuestas comparaciones en blanco, sin valor 0 con valores no válidos conforme a las consignas establecidas.

Esto representa 80 valores cuantitativos asignados a cada uno de los nueve determinantes seleccionados con valores entre cero y diez puntos en cada caso, totalizando 3.600 puntos en total efectivamente asignados a las variables cualitativas.

En relación con los comentarios y observaciones adicionales de cada resultados obtenidos por los especialistas, el $40 \%$ de ellos no se esperaba las ponderaciones resultantes obtenidas, pero todos ellos estuvieron de acuerdo con el resultado final mismo.

\subsubsection{Resultados de la Tabla de Participación Relativa}

Considerando la sumatoria de puntos asignados a cada determinante por los especialistas consultados, resulta factible darles un orden de atención y prioridad a cada restricción a la vez que puede establecerse su importancia relativa como limitante al crecimiento de los seguros de vida, conforme se detalla en la siguiente tabla:

\begin{tabular}{|l|r|r|r|r|}
\hline Causas & TOTAL & Orden & \multicolumn{1}{c|}{$\%$} & \% Acumulado \\
\hline Inestabilidad Económica & 477 & $1^{\circ}$ & $13,25 \%$ & $13,25 \%$ \\
\hline Desinformación & 458 & $2^{\circ}$ & $12,72 \%$ & $25,97 \%$ \\
\hline No Percepción Riesgo & 450 & $3^{\circ}$ & $12,50 \%$ & $38,47 \%$ \\
\hline Desconfianza & 445 & $4^{\circ}$ & $12,36 \%$ & $50,83 \%$ \\
\hline Desinterés & 419 & $5^{\circ}$ & $11,64 \%$ & $62,47 \%$ \\
\hline Falta Incentivos Fiscales & 401 & $6^{\circ}$ & $11,14 \%$ & $73,61 \%$ \\
\hline Ot. Productos Financieros & 336 & $7^{\circ}$ & $9,33 \%$ & $82,94 \%$ \\
\hline Complejidad de Productos & 318 & $8^{\circ}$ & $8,83 \%$ & $91,78 \%$ \\
\hline Preferencia Off Shore & 296 & $9^{\circ}$ & $8,22 \%$ & $100,00 \%$ \\
\hline Total & 3.600 & - & $100,00 \%$ & - \\
\hline
\end{tabular}

Se destaca a la Inestabilidad Económica (13,25\%), como la principal restricción al crecimiento del mercado de los seguros de vida en la República Argentina seguidos por la Desinformación $(12,72 \%)$, la No Percepción del Riesgo $(12,50 \%)$ y en el cuarto lugar por la Desconfianza $(12,36 \%)$, acumulando estos cuatro determinantes más del $50 \%$ de participación relativa en el efecto observado..

Con el objeto de visualizar mejor la información relevada, se pueden observar los datos de la tabla anterior en el siguiente gráfico:

\section{Gráfico de Participación Relativa de los Determinantes Identificados}




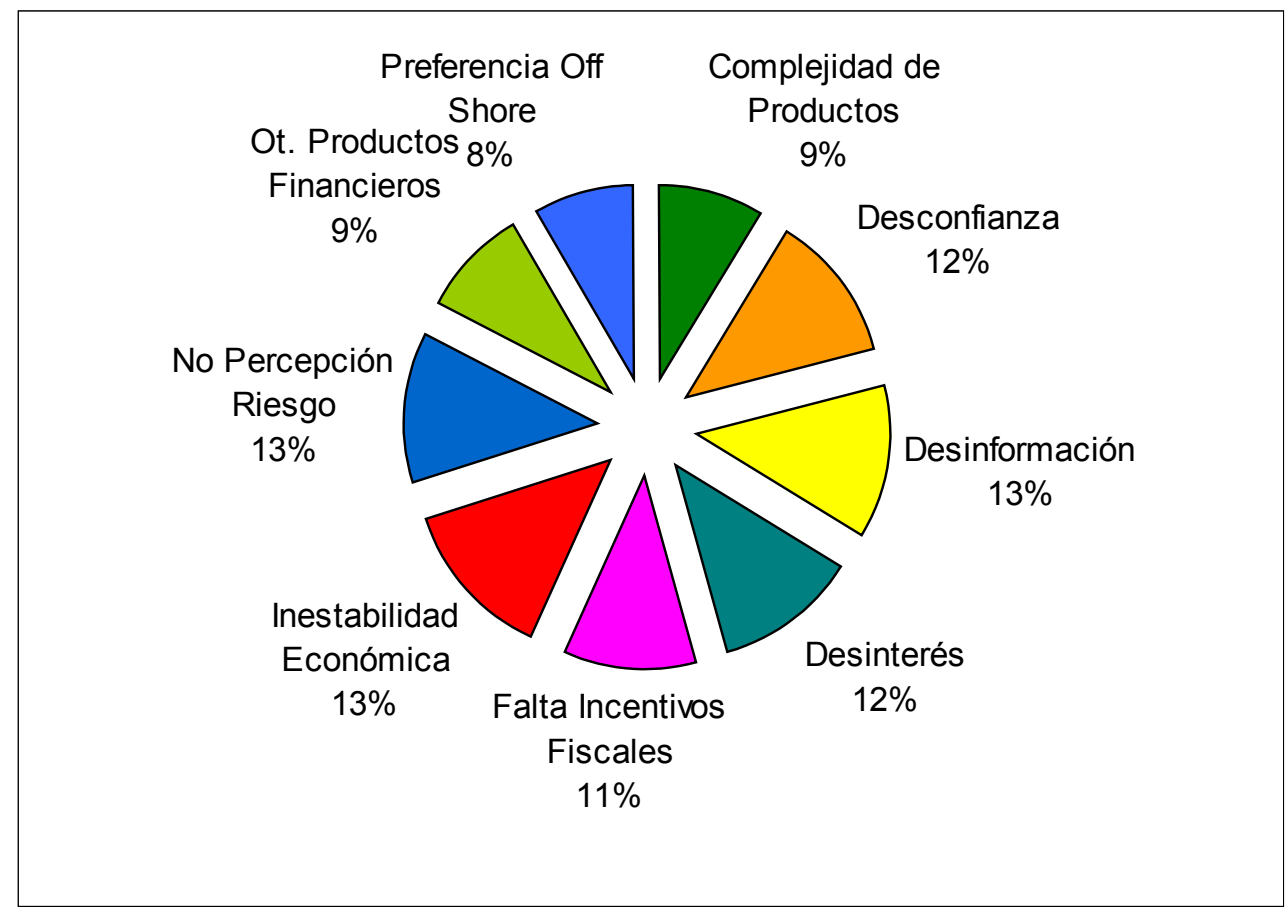

\subsubsection{Análisis Univariado de los Determinantes}

Resultados de la puntuación asignada por los especialistas a cada determinante y los principales estadísticos de cada una de las variables:

\begin{tabular}{|r|r|r|r|r|r|r|r|r|r|l|r|}
\hline \multicolumn{10}{|c|}{} \\
\hline \multicolumn{8}{|c|}{ Resultados Obtenidos } & \\
\hline 2 & 5 & 3 & 3 & 4 & 6 & 3 & 5 & 3 & 2 & Suma Total de Puntos & $\mathbf{3 1 8}$ \\
\hline 2 & 8 & 3 & 2 & 3 & 6 & 2 & 3 & 3 & 3 & Media (Promedio) & $\mathbf{3 , 9 8}$ \\
\hline 5 & 8 & 4 & 7 & 2 & 6 & 1 & 2 & 3 & 2 & Moda Estadística & $\mathbf{3}$ \\
\hline 5 & 8 & 7 & 0 & 2 & 6 & 5 & 3 & 2 & 5 & Mediana & $\mathbf{3}$ \\
\hline 1 & 1 & 2 & 0 & 3 & 6 & 3 & 2 & 2 & 1 & Valor Máximo & $\mathbf{8}$ \\
\hline 1 & 8 & 7 & 3 & 4 & 6 & 3 & 3 & 1 & 2 & Valor Mínimo & $\mathbf{0}$ \\
\hline 7 & 5 & 3 & 1 & 5 & 6 & 4 & 8 & 4 & 5 & Desvío Estándar & $\mathbf{2 , 1 4}$ \\
\hline 7 & 5 & 7 & 7 & 6 & 6 & 4 & 7 & 3 & 5 & Coeficiente de Variabilidad & $\mathbf{5 4 \%}$ \\
\hline
\end{tabular}

Sobre la base de los datos asignados a la Complejidad de los Productos como limitante al crecimiento de los seguros de vida, se observa una suma total de los puntos que representa un $39,75 \%$ de los puntos posibles, que en ningún caso se obtuvo la puntuación máxima (10) ni la siguiente (9), obteniendo un valor máximo asignado de 8 (en cinco oportunidades), coincidiendo la media y moda estadísticas y un valor mínimo de 0 (en dos oportunidades). Por su parte el desvío estándar supera las 2 unidades y el coeficiente de variabilidad excede el $50 \%$.

\begin{tabular}{|c|c|}
\hline \multicolumn{2}{|c|}{ Desconfianza } \\
\hline Resultados Obtenidos & Indicadores \\
\cline { 2 - 2 }
\end{tabular}




\begin{tabular}{|r|r|r|r|r|r|r|r|r|l|l|r|}
\hline 8 & 5 & 7 & 7 & 6 & 4 & 7 & 5 & 7 & 8 & Suma Total de Puntos & $\mathbf{4 4 5}$ \\
\hline 5 & 2 & 5 & 2 & 5 & 7 & 4 & 8 & 8 & 8 & Media (Promedio) & $\mathbf{5 , 5 6}$ \\
\hline 8 & 5 & 6 & 2 & 4 & 7 & 2 & 7 & 5 & 7 & Moda Estadística & $\mathbf{5}$ \\
\hline 10 & 8 & 7 & 1 & 4 & 7 & 5 & 7 & 4 & 5 & Mediana & $\mathbf{5}$ \\
\hline 5 & 2 & 4 & 1 & 5 & 7 & 4 & 5 & 5 & 6 & Valor Máximo & $\mathbf{1 0}$ \\
\hline 5 & 5 & 6 & 5 & 4 & 7 & 4 & 7 & 3 & 4 & Valor Mínimo & $\mathbf{1}$ \\
\hline 10 & 8 & 5 & 2 & 6 & 8 & 5 & 7 & 4 & 7 & Desvío Estándar & $\mathbf{1 , 9 9}$ \\
\hline 8 & 2 & 5 & 7 & 6 & 8 & 6 & 5 & 5 & 8 & Coeficiente de Variabilidad & $\mathbf{3 6 \%}$ \\
\hline
\end{tabular}

Se destaca en los datos asignados por los especialistas a la Desconfianza como participante en el efecto observado, una suma total de 445 puntos que representa el 55,63\% del total posibles, que en dos oportunidades se obtuvo la puntuación máxima (10), coincidiendo la media y moda estadísticas en un valor de 5 y un valor mínimo de 1 (no habiendo sido asignado el 0 en ninguna oportunidad). A su vez el desvío estándar resulta inferior a las 2 unidades, con un coeficiente de variabilidad inferior al $40 \%$.

\begin{tabular}{|r|r|r|r|r|r|l|l|l|l|l|r|}
\hline \multicolumn{10}{|c|}{ Desinformación } \\
\hline 8 & 2 & 7 & 8 & 7 & 4 & 8 & 7 & 7 & 7 & Suma Total de Puntos & $\mathbf{4 5 8}$ \\
\hline 5 & 8 & 5 & 8 & 5 & 3 & 6 & 2 & 2 & 2 & Media (Promedio) & $\mathbf{5 , 7 3}$ \\
\hline 9 & 2 & 5 & 5 & 4 & 8 & 3 & 4 & 5 & 7 & Moda Estadística & $\mathbf{5}$ \\
\hline 9 & 8 & 6 & 2 & 3 & 8 & 8 & 3 & 9 & 7 & Mediana & $\mathbf{6}$ \\
\hline 5 & 2 & 4 & 2 & 5 & 8 & 7 & 5 & 3 & 3 & Valor Máximo & $\mathbf{1 0}$ \\
\hline 5 & 5 & 5 & 5 & 4 & 8 & 6 & 6 & 5 & 6 & Valor Mínimo & $\mathbf{2}$ \\
\hline 10 & 8 & 5 & 3 & 6 & 8 & 6 & 6 & 5 & 5 & Desvío Estándar & $\mathbf{2 , 1 3}$ \\
\hline 10 & 8 & 6 & 8 & 4 & 8 & 7 & 7 & 5 & 8 & Coeficiente de Variabilidad & $\mathbf{3 7 \%}$ \\
\hline
\end{tabular}

De los datos asignados a la Desinformación, se destaca una suma total de 458 puntos que representa casi un $60 \%$ de los puntos posibles, que en ningún caso se obtuvo la puntuación mínima (0) ni la siguiente (1), obteniendo un valor máximo asignado de 10 (en dos oportunidades), coincidiendo la media y mediana estadísticas en un valor de 5 . El desvío estándar resulta superior a las 2 unidades y el coeficiente de variabilidad es inferior al $40 \%$.

\begin{tabular}{|r|r|l|l|l|l|l|l|l|l|l|r|}
\hline \multicolumn{10}{|c|}{ Desinterés } \\
\hline \multicolumn{10}{|c|}{ Resultados Obtenidos } & \multicolumn{4}{c|}{ Indicadores } \\
\hline 5 & 2 & 6 & 3 & 8 & 4 & 9 & 8 & 7 & 8 & Suma Total de Puntos & $\mathbf{4 1 9}$ \\
\hline 2 & 5 & 4 & 8 & 6 & 3 & 8 & 3 & 5 & 3 & Media (Promedio) & $\mathbf{5}$ \\
\hline 1 & 8 & 5 & 5 & 6 & 2 & 7 & 6 & 5 & 3 & Moda Estadística & $\mathbf{5}$ \\
\hline 5 & 8 & 8 & 0 & 5 & 6 & 10 & 4 & 4 & 4 & Mediana & $\mathbf{1 0}$ \\
\hline 2 & 2 & 6 & 0 & 7 & 6 & 9 & 4 & 9 & 3 & Valor Máximo & $\mathbf{0}$ \\
\hline 2 & 2 & 7 & 5 & 7 & 6 & 8 & 4 & 3 & 5 & Valor Mínimo & $\mathbf{2 , 2 8}$ \\
\hline 5 & 3 & 7 & 2 & 7 & 6 & 9 & 6 & 4 & 5 & Desvío Estándar & $\mathbf{4 4 \%}$ \\
\hline 5 & 5 & 8 & 5 & 6 & 6 & 9 & 5 & 3 & 7 & Coeficiente de Variabilidad & \\
\hline
\end{tabular}

Al observar los datos asignados al Desinterés como limitante al crecimiento de los seguros de vida, se observa una suma total de los puntos que representa un $52,38 \%$ de los puntos posibles (800), que en solo en una oportunidad se obtuvo la puntuación máxima (10), coincidiendo la media, la mediana y moda estadísticas y un valor mínimo de 0 (en dos oportunidades). Por su parte el desvío estándar supera las 2 unidades y el coeficiente de variabilidad resulta inferior al $50 \%$.

\section{Falta Incentivos Fiscales}




\begin{tabular}{|r|r|c|c|c|c|c|c|c|c|l|l|}
\multicolumn{8}{|c|}{ Resultados Obtenidos } & \multicolumn{4}{c|}{ Indicadores } \\
\hline 5 & 2 & 3 & 10 & 8 & 4 & 5 & 7 & 8 & 5 & Suma Total de Puntos & $\mathbf{4 0 1}$ \\
\hline 0 & 2 & 3 & 9 & 6 & 3 & 5 & 3 & 6 & 5 & Media (Promedio) & $\mathbf{5 , 0 1}$ \\
\hline 1 & 2 & 4 & 8 & 7 & 2 & 2 & 7 & 1 & 3 & Moda Estadística & $\mathbf{5}$ \\
\hline 5 & 2 & 2 & 10 & 5 & 4 & 0 & 6 & 6 & 6 & Mediana & $\mathbf{5}$ \\
\hline 2 & 5 & 3 & 5 & 7 & 8 & 5 & 8 & 3 & 5 & Valor Máximo & $\mathbf{1 0}$ \\
\hline 2 & 4 & 3 & 7 & 6 & 8 & 3 & 7 & 2 & 3 & Valor Mínimo & $\mathbf{0}$ \\
\hline 4 & 3 & 3 & 5 & 7 & 8 & 4 & 8 & 8 & 7 & Desvío Estándar & $\mathbf{2 , 4 6}$ \\
\hline 5 & 3 & 5 & 10 & 8 & 8 & 5 & 9 & 8 & 5 & Coeficiente de Variabilidad & $\mathbf{4 9 \%}$ \\
\hline
\end{tabular}

Con respecto a la Falta de Incentivos Fiscales como incidente en el efecto observado, se destaca una suma total de 401 puntos que representa el 50,13\% de los puntos posibles, que en una tres oportunidades se obtuvo la puntuación máxima (10), coincidiendo la media (promedio), la mediana y moda estadísticas y un valor mínimo de 0 (en dos oportunidades). Por su parte el desvío estándar se encuentra cercano a un índice del 2,50 y el coeficiente de variabilidad resulta levemente inferior al $50 \%$.

\begin{tabular}{|r|r|c|c|c|c|c|c|c|l|l|r|}
\hline \multicolumn{10}{|c|}{ Inestabilidad Económica } \\
\hline \multicolumn{8}{|c|}{ Resultados Obtenidos } & \multicolumn{4}{c|}{ Indicadores } \\
\hline 9 & 9 & 8 & 10 & 7 & 4 & 7 & 8 & 8 & 9 & Suma Total de Puntos & $\mathbf{4 7 7}$ \\
\hline 5 & 8 & 6 & 9 & 5 & 3 & 6 & 5 & 5 & 4 & Media (Promedio) \\
\hline 5 & 8 & 6 & 8 & 5 & 2 & 3 & 5 & 7 & 7 & Moda Estadística & $\mathbf{5}$ \\
\hline 8 & 8 & 4 & 10 & 3 & 4 & 1 & 6 & 1 & 7 & Mediana & $\mathbf{6}$ \\
\hline 8 & 5 & 7 & 5 & 3 & 2 & 5 & 2 & 7 & 5 & Valor Máximo & $\mathbf{1 0}$ \\
\hline 5 & 9 & 8 & 5 & 5 & 7 & 4 & 7 & 3 & 4 & Valor Mínimo & $\mathbf{1}$ \\
\hline 9 & 9 & 7 & 8 & 4 & 7 & 5 & 7 & 5 & 6 & Desvío Estándar & $\mathbf{2 , 1 9}$ \\
\hline 9 & 9 & 7 & 5 & 6 & 7 & 6 & 2 & 3 & 7 & Coeficiente de Variabilidad & $\mathbf{3 7 \%}$ \\
\hline
\end{tabular}

En cuanto a los datos asignados a Inestabilidad Económica, se destaca una suma total de 477 puntos que representa casi un $60 \%$ de los puntos posibles, que en ningún caso se obtuvo la puntuación mínima (0), obteniendo un valor máximo asignado de 10 (en dos oportunidades) por los especialistas consultados, coincidiendo la media y mediana estadísticas en un valor de 6 . El desvío estándar resulta superior a las 2 unidades y el coeficiente de variabilidad resulta inferior al $40 \%$.

\begin{tabular}{|r|r|l|l|l|l|l|l|l|l|l|r|}
\hline \multicolumn{10}{|c|}{ Resultados Obtenidos } & \multicolumn{2}{c|}{ Indicadores } \\
\hline 9 & 2 & 3 & 7 & 6 & 4 & 7 & 7 & 9 & 8 & Suma Total de Puntos & $\mathbf{4 5 0}$ \\
\hline 5 & 5 & 4 & 5 & 6 & 3 & 6 & 3 & 7 & 6 & Media (Promedio) & $\mathbf{5 3}$ \\
\hline 5 & 5 & 5 & 5 & 6 & 2 & 4 & 4 & 5 & 4 & Moda Estadística & $\mathbf{6}$ \\
\hline 8 & 8 & 3 & 5 & 3 & 4 & 2 & 6 & 7 & 5 & Mediana & $\mathbf{6}$ \\
\hline 8 & 6 & 7 & 3 & 4 & 2 & 7 & 3 & 8 & 7 & Valor Máximo & $\mathbf{1}$ \\
\hline 5 & 1 & 2 & 5 & 5 & 3 & 6 & 3 & 7 & 6 & Valor Mínimo & $\mathbf{1 , 9 9}$ \\
\hline 9 & 8 & 7 & 5 & 7 & 7 & 7 & 6 & 7 & 7 & Desvío Estándar & $\mathbf{3 5 \%}$ \\
\hline 9 & 6 & 7 & 10 & 7 & 7 & 7 & 6 & 7 & 8 & Coeficiente de Variabilidad & \\
\hline
\end{tabular}

Al considerar los datos asignados al determinante No Percepción del Riesgo como, se observa una suma total de 450 puntos que representa un $56,25 \%$ de los puntos posibles (800), que en solo en una oportunidad se obtuvo la puntuación máxima (10), coincidiendo la media y moda estadísticas en un valor de 6 , repitiéndose la moda en veinte oportunidades con 7 puntos 
asignados y un valor mínimo de 1 ( $\sin$ que se haya registrado el 0). Por su parte el desvío estándar se encuentra cercano a las 2 unidades sin superarlas y el coeficiente de variabilidad resulta inferior al $50 \%$ en 15 puntos porcentuales.

\begin{tabular}{|r|r|l|l|l|l|l|l|l|l|l|r|}
\hline \multicolumn{10}{|c|}{ Ot. Productos Financieros } \\
\hline \multicolumn{2}{|c|}{ Resultados Obtenidos } & \multicolumn{2}{c|}{ Indicadores } \\
\hline 3 & 5 & 7 & 9 & 5 & 4 & 6 & 2 & 6 & 5 & Suma Total de Puntos & $\mathbf{3 3 6}$ \\
\hline 0 & 2 & 5 & 8 & 4 & 2 & 5 & 3 & 6 & 3 & Media (Promedio) & $\mathbf{4}$ \\
\hline 0 & 2 & 5 & 7 & 4 & 2 & 4 & 4 & 5 & 5 & Moda Estadística & $\mathbf{4}$ \\
\hline 5 & 7 & 3 & 8 & 3 & 4 & 1 & 4 & 6 & 5 & Mediana & $\mathbf{1 0}$ \\
\hline 6 & 7 & 7 & 5 & 3 & 2 & 6 & 2 & 2 & 3 & Valor Máximo & $\mathbf{0}$ \\
\hline 1 & 1 & 3 & 2 & 6 & 3 & 5 & 3 & 5 & 4 & Valor Mínimo & $\mathbf{2 , 0 5}$ \\
\hline 1 & 2 & 3 & 5 & 3 & 3 & 3 & 4 & 3 & 3 & Desvío Estándar & $\mathbf{4 9 \%}$ \\
\hline 3 & 5 & 6 & 10 & 4 & 7 & 6 & 4 & 8 & 3 & Coeficiente de Variabilidad & \\
\hline
\end{tabular}

Analizando los datos asignados a los Otros Productos Financieros como limitante al crecimiento de los seguros de vida, se observa una suma total de los puntos que representa un $42 \%$ de los puntos posibles (800), que en solo en una oportunidad se obtuvo la puntuación máxima (10), coincidiendo la media y la mediana estadísticas y un valor mínimo de 0 (en dos oportunidades). Por su parte el desvío estándar supera levemente las 2 unidades y el coeficiente de variabilidad resulta inferior al $50 \%$.

\begin{tabular}{|c|c|c|c|c|c|c|c|c|c|c|c|}
\hline \multicolumn{12}{|c|}{ Preferencia Off Shore } \\
\hline \multicolumn{10}{|c|}{ Resultados Obtenidos } & \multicolumn{2}{|c|}{ Indicadores } \\
\hline 3 & 5 & 3 & 3 & 4 & 4 & 6 & 3 & 7 & 5 & Suma Total de Puntos & 296 \\
\hline 2 & 8 & 5 & & 4 & 2 & 4 & 5 & 5 & 2 & Media (Promedio) & 3,70 \\
\hline 0 & 2 & 4 & & 6 & 2 & 3 & 3 & 5 & 2 & Moda Estadística & 3 \\
\hline 5 & 5 & 2 & 5 & 4 & 4 & 1 & 5 & 7 & 3 & Mediana & 4 \\
\hline 5 & 7 & 5 & 0 & 2 & 2 & 5 & 1 & 2 & 5 & Valor Máximo & 8 \\
\hline 1 & 1 & & & 4 & 3 & 4 & 8 & 7 & 3 & Valor Mínimo & 0 \\
\hline 1 & 4 & 3 & & 3 & 3 & 3 & 4 & 3 & 2 & Desvío Estándar & 1,90 \\
\hline 7 & 5 & 4 & 0 & 6 & 3 & 4 & 6 & 2 & 7 & Coeficiente de Variabilidad & $51 \%$ \\
\hline
\end{tabular}

De los datos asignados a la Preferencia Off Shore, se destaca una suma total de 296 puntos que representa un $37,00 \%$ de los puntos posibles, que en ningún caso se obtuvo la puntuación máxima (10) ni la siguiente (9), obteniendo un valor máximo asignado de 8 (en dos oportunidades), coincidiendo la mediana y moda estadísticas y un valor mínimo de 0 (en cuatro oportunidades). Por su parte el desvío estándar resulta inferior a las 2 unidades y el coeficiente de variabilidad excede en uno el $50 \%$.

De los datos anteriormente expuestos se desprende que, considerando las características de la población de especialistas consultados, los datos resultantes obtenidos se encuentran dentro de una dispersión aceptable para el alcance propuesto en el presente estudio.

\subsubsection{Tabla a Doble Entrada de Puntajes Promedio de los Determinantes}

A efectos de indagar sobre las relaciones entre las variables, se procedió a establecer el puntaje promedio para cada análisis por pares hecho por los expertos. 


\begin{tabular}{|c|c|c|c|c|c|c|c|c|c|}
\hline Puntaje promedio & 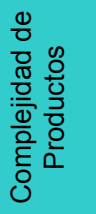 & 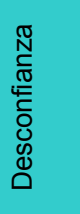 & 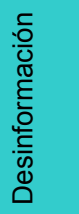 & 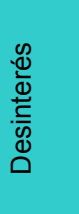 & 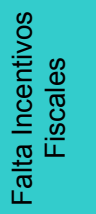 & 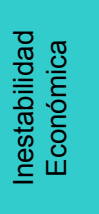 & 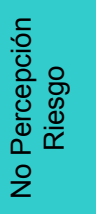 & 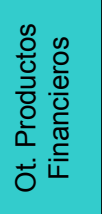 & 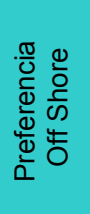 \\
\hline Complejidad de Productos & & 3,60 & 3,50 & 4,00 & 4,30 & 2,10 & 3,80 & 4,80 & 5,70 \\
\hline Desconfianza & 3,60 & & 5,40 & 5,30 & 5,80 & 4,40 & 5,00 & 6,20 & 6,00 \\
\hline Desinformación & 3,50 & 5,40 & & 5,20 & 6,30 & 4,40 & 5,50 & 6,20 & 7,10 \\
\hline Desinterés & 4,00 & 5,30 & 5,20 & & 5,40 & 4,80 & 4,90 & 5,40 & 5,90 \\
\hline Falta Incentivos Fiscales & 4,30 & 5,80 & 6,30 & 5,40 & & 5,10 & 4,50 & 5,70 & 6,60 \\
\hline Inestabilidad Económica & 2,10 & 4,40 & 4,40 & 4,80 & 5,10 & & 5,70 & 6,70 & 6,10 \\
\hline No Percepción Riesgo & 3,80 & 5,00 & 5,50 & 4,90 & 4,50 & 5,70 & & 7,00 & 7,40 \\
\hline Ot. Productos Financieros & 4,80 & 6,20 & 6,20 & 5,40 & 5,70 & 6,70 & 7,00 & & 5,60 \\
\hline Preferencia Off Shore & 5,70 & 6,00 & 7,10 & 5,90 & 6,60 & 6,10 & 7,40 & 5,60 & \\
\hline
\end{tabular}

\subsubsection{Coeficientes de Correlación de los Determinantes}

A continuación se detallan los coeficientes de correlación ${ }^{2}$ entre las variables:

\begin{tabular}{|c|c|c|c|c|c|c|c|c|c|}
\hline Coeficientes de Correlación & $\begin{array}{l}\frac{0}{0} \\
0 \\
\frac{0}{\pi} \\
\frac{\pi}{0} \\
: \frac{0}{0} \\
\frac{0}{0} \\
0 \\
\frac{0}{0} \\
0 \\
0 \\
0\end{array}$ & 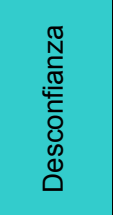 & 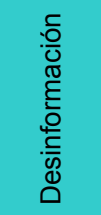 & 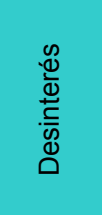 & 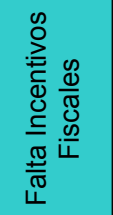 & 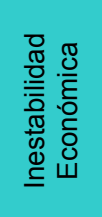 & 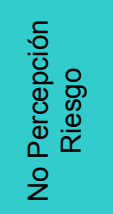 & 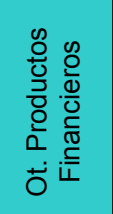 & 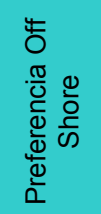 \\
\hline Complejidad de Productos & 1,0000 & --------- & --------- & --------- & -------- & --------- & --------- & --------- & --------- \\
\hline Desconfianza & 0,8990 & 1,0000 & 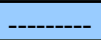 & $\begin{array}{ll}------- \\
--\end{array}$ & - -------- & $\begin{array}{l}------- \\
--\end{array}$ & $\begin{array}{ll}------- \\
\end{array}$ & 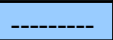 & --------- \\
\hline Desinformación & 0,9520 & 0,9478 & 1,0000 & --------- & -------- & -------- & -------- & $\begin{array}{ll}------- \\
\end{array}$ & -------- \\
\hline Desinterés & 0,8928 & 0,9398 & 0,9577 & 1,0000 & -------- & -------- & -------- & --------- & -------- \\
\hline Falta Incentivos Fiscales & 0,5293 & 0,7773 & 0,8201 & 0,8728 & 1,0000 & --------- & -------- & $\begin{array}{ll}------- \\
\end{array}$ & $\begin{array}{ll}------- \\
\end{array}$ \\
\hline Inestabilidad Económica & 0,7565 & 0,8994 & 0,8807 & 0,8059 & 0,4757 & 1,0000 & --------- & --------- & $\begin{array}{l}------- \\
--\end{array}$ \\
\hline No Percepción Riesgo & 0,5330 & 0,6735 & 0,6924 & 0,7234 & 0,7302 & 0,8462 & 1,0000 & $\begin{array}{ll}------- \\
-\end{array}$ & $\begin{array}{ll}------- \\
\end{array}$ \\
\hline Ot. Productos Financieros & $-0,6233$ & 0,1467 & 0,1504 & 0,2157 & $-0,0018$ & 0,5891 & 0,3854 & 1,0000 & $\begin{array}{ll}------- \\
\end{array}$ \\
\hline Preferencia Off Shore & $-0,1265$ & 0,1435 & 0,2940 & 0,2111 & 0,0296 & 0,1950 & $-0,0959$ & 0,6536 & 1,0000 \\
\hline
\end{tabular}

${ }^{2}$ El coeficiente de correlación de Pearson (introducido por Francis Galton), se obtiene dividiendo la covarianza de dos variables por el producto de sus desviaciones estándar, permite identificar la fuerza y la dirección de las relaciones entre dos variables del conjunto de determinantes seleccionados, sin que ello implique por sí solo una relación de causalidad o dependencia entre ambas variables. 


\section{Conclusiones}

\subsection{Conclusiones del Estudio Realizado}

Considerando la fuerza y el sentido de la correlación, se señala que presentan una elevada correlación positiva (cercana a la unidad), entre las variables los siguientes pares de determinantes:

1) Desinformación y Desinterés $(0,9577)$ : Corresponde asumir razonablemente que la población asegurable se encuentra desinformada sobre los productos de seguros de vida y sus coberturas, la misma no se encuentra interesado sobre su existencia y características. A la vez si las personas no están interesadas en los productos de protección personal, también será lógico asumir que abundará la desinformación en ellas, representando una sinergia positivamente correlacionada para desalentar la contratación de este tipo de seguros.

2) Complejidad de los Productos y la Desinformación (0,9520): Si a la complejidad de los productos se suma la desinformación y a su vez la falta de información confiable atenta contra la comprensión de los productos, estos determinantes en conjunto son críticos para la no contratación de los seguros de vida en la argentina.

3) Desinformación y Desconfianza (0,9478): Es comprensible una correlación significativamente positiva entre la desinformación y la desconfianza, toda vez que a menor información la confianza para contratar un seguro de vida disminuirá y a su vez un alto grado de desconfianza apartará a los asegurables de la información pertinente, actuando en ambos casos en forma conjunta y en la misma dirección como limitantes al crecimiento de los seguros de vida.

4) Inestabilidad Económica y Desconfianza (0,8994): Resulta lógico que la inestabilidad económica y la desconfianza se correlacionen positivamente, ya que con inestabilidad económica hay pocas certezas (alto grado de desconfianza) y así es sumamente dificultoso realizar una razonable previsión de futuro, lo cual actuaría como limitante al crecimiento de los seguros de vida.

5) Desinterés y Falta Incentivos Fiscales $(0,8728)$ : Conforme con los datos obtenidos, se puede afirmar que el desinterés de la población asegurable junto a la falta de incentivos fiscales (que representa la falta de motivación o desinterés por parte del Estado), se potencian positivamente como fuente de restricciones al crecimiento de estos seguros.

6) Inestabilidad Económica y No Percepción Riesgo $(0,8462)$ : La fuerte correlación positiva en este caso puede atribuirse a que la inestabilidad económica ha hecho que se haya perdido la capacidad de proyección a largo plazo, lo que conlleva a no contemplar los riesgos de este tipo, toda vez que lo urgente acapara la atención que le correspondería a lo importante.

Teniendo en cuenta la fuerza y el sentido de la correlación, se señala que presentan una correlación significativamente negativa (cercana a -1), entre las variables el siguiente par de determinantes, no presentando otro par de variables una correlación negativa significativa: 
1) Se destaca la correlación negativa $(-0,6233)$ entre la complejidad de los productos y la preferencia por otros productos financieros, lo que permite inferir-conforme a los resultados de la población de especialistas consultados-, que a mayor oferta y atractivo de otros productos financieros, menor debería ser la complejidad de los productos del mercado asegurador de vida y a mayor complejidad de los productos menor será la incidencia de la preferencia por otros productos financieros (los cuales pueden asociarse con su complejidad), como limitantes al crecimiento de los seguros de vida.

\subsubsection{Clasificación de los Determinantes Conforme con el Tipo de Condicionamiento}

Teniendo en cuenta el tipo de determinación que ejerce cada variable y conforme al tipo de condicionamiento que ejerce cada uno como limitante al crecimiento de los seguros de vida, puede establecerse que:

- Se puede señalar que la Desconfianza, la Desinformación, la Inestabilidad Económica y la No Percepción del Riesgo cumplen con la "condición de necesarios", es decir que de existir estabilidad económica, una clara percepción del riesgo, información completa sobre el sistema del seguro de vida y/o plena confianza por parte de la población asegurable en relación con el mismo, resulta imposible para los especialistas que se limite el crecimiento del mercado de los seguros de vida en la argentina.

- Por su parte se puede identificar a partir de las respuestas de los especialistas que determinantes como la Inestabilidad Económica, la Desinformación, la Desconfianza, el Desinterés y la No Percepción del Riesgo, los cuales cumplen con la "condición de suficientes", significando que la presentación de cualquiera de estas situaciones, basta para limitar el crecimiento de los seguros de vida (aunque no es imprescindible que estén presentes para restringirlo).

- A su vez se señala que, conforme a los expertos, la Falta Incentivos Fiscales cumple con una "condicionalidad contribuyente", es decir que favorece de una manera decisiva como limitante al crecimiento de los seguros de vida y que generalmente suele producir dicha restricción, aunque no alcanza lograr un determinismo que pueda considerarse necesario o suficiente.

- Finalmente, considerando que la preferencia por Otros Productos Financieros, la Complejidad de los Productos y la Preferencia Off Shore, resulta razonable identificar su determinación con una "condición contingente", es decir que para los especialistas consultados se trata de circunstancias que pueden favorecer las limitaciones al crecimiento de los seguros de vida, y se presentan sólo eventualmente, (encontrándose ausentes como restricciones en la mayoría de los casos). 


\begin{tabular}{|l|c|c|c|c|}
\hline \multicolumn{1}{|c|}{$\begin{array}{c}\text { Tipo de } \\
\text { Condicionamiento }\end{array}$} & Necesario & Suficiente & Contribuyente & Contingente \\
\hline Complejidad de Productos & & & & Sí \\
\hline Desconfianza & Sí & Sí & & \\
\hline Desinformación & Sí & Sí & & \\
\hline Desinterés & & Sí & & \\
\hline Falta Incentivos Fiscales & & & Sí & \\
\hline Inestabilidad Económica & Sí & Sí & & \\
\hline No Percepción Riesgo & Sí & Sí & & Sí \\
\hline Ot. Productos Financieros & & & & Sí \\
\hline Preferencia Off Shore & & & & \\
\hline
\end{tabular}

En base a lo anteriormente expuesto, es válido destacar que la Inestabilidad Económica, la Desconfianza, la Desinformación y la No Percepción del Riesgo conforman determinantes que representan una condición necesaria y suficiente a la vez, se puede afirmar que para los especialistas consultados en función del presente estudio, se puede establecer una relación causal entre estas variables y el efecto observado, es decir que los mismos representan por sí solos (en conjunto o en forma individual) una causa para la limitación en el crecimiento del mercado de los seguros de vida.

\subsection{Evaluación del Trabajo Futuro}

Si bien se asume que no resulta necesario realizar una investigación adicional al presente estudio, se destaca que el mismo se encuentra acotado al contexto en el cual fue realizado y por consiguiente, deberá ser actualizado necesariamente conforme el mismo se modifique.

El resultado de esta investigación sirve de inicio para la elaboración de una propuesta superadora de los limitantes identificados y de sus características, las cuales se encuentran en el siguiente capítulo.

Se señala que tal vez los próximos pasos a dar pueden provenir de la retroalimentación empírica que pueda obtenerse a partir de la eventual implementación de la mencionada propuesta. 


\section{Recomendaciones y Propuesta}

\subsection{Propuesta de Valor}

En función de los resultados obtenidos y asumiendo que para el mercado asegurador la Inestabilidad Económica es una variable no controlable, se hace hincapié en aquellos determinantes endógenos del mercado asegurador de vida y en aquellos donde el mismo puede ejercer su influencia.

En este sentido, se considera conveniente concentrarse en campañas de información sobre la existencia de los seguros de vida, sus características y beneficios, a la vez que se procure generar la confianza necesaria para que los esfuerzos realizados resulten productivos.

A su vez, se enfatiza la necesidad del desarrollo de pocos productos y fáciles de entender, dónde abunde la información y sean claros los beneficios de contar con una determinada cobertura de vida (y/o los perjuicios de no poseerla, facilitando la percepción del riesgo) e interesando / motivando a la población asegurable para que contrate seguros de vida.

Es por ello que en forma adicional a la investigación realizada, se elaboró una propuesta de solución que supere los limitantes identificados, a fin de proponer al menos una forma de impulsar el desarrollo de los seguros de vida en la argentina.

Se destaca que la presente propuesta posibilita a las Compañías aseguradoras que ofrecen coberturas de riesgos de vida para las personas, que logren una mayor penetración en el mercado y mejorar su gestión de riesgos, a partir de una mayor conciencia aseguradora y sobre la autogestión de la salud.

Es válido destacar que los beneficios de la propuesta necesariamente afectan al mercado en su conjunto, dado que la empresa que proponga y logre aprobar un producto, cobertura o cláusula innovadora, solo podrá lograr una ventaja temporal de seis meses hasta que el resto de las aseguradoras lo aprueben en la SSN (dado que la normativa permite luego de ese plazo la adhesión a un plan ya aprobado). Por consiguiente, la propuesta tiene como destinatarios en forma indistinta a una determinada empresa aseguradora, a un conjunto de estas, a la cámara que las agrupa o a la totalidad de las empresas que intervienen en este mercado.

Se considera apropiado desarrollar la presente propuesta dentro de un marco estratégico dado que las empresas que intervienen en el sector necesitan:

- Identificar y entender sus capacidades y cómo utilizarlas y aplicarlas para asegurarse una ventaja competitiva sobre sus rivales.

- Entender y responder a la dinámica de la complejidad de los negocios en los que opera.

- Asegurar que hay intención de focalizarse en aprovechar las energías creativas de la gente que trabaja en ellas.

Asimismo, todas las partes interesadas (stakeholders), y en particular los accionistas, se sienten mejor en una empresa con un equipo gerencial que comprende que tiene una dirección y que la está siguiendo. En este sentido, la estrategia provee una forma de monitorear el avance del 
plan original y sus desvíos de manera tal que se puedan tomar acciones relevantes y a tiempo para lograr las metas.

En este sentido, la propuesta de valor se basa en aumentar el aprovechamiento de la información existente y en la generación de nuevo conocimiento, a fin de agregar valor al negocio planteado, así como generar oportunidades en líneas de negocios conexos y/o complementarios al que tiene como centro el seguro de vida.

\subsection{Objetivos de la Propuesta}

A partir del grado de penetración de los seguros de vida en la Argentina ya mencionado, se procuró identificar al menos una alternativa que favorezca el incrementar la cantidad de seguros de vida en nuestro país.

1- El principal objetivo planteado, es elaborar una propuesta que permita aumentar el grado de penetración de la cobertura del riesgo de Vida dirigido a la población asegurable (es decir: económicamente activa, sin patologías graves), en un plazo de 12 meses desde su implementación.

2- A su vez, la propuesta tiene en cuenta que el aumento de las coberturas vendidas sin afectar el resultado técnico del negocio (que no incida negativamente en la siniestralidad del producto / cobertura a desarrollar), mejorando la rentabilidad (resultado técnico) en la cobertura del riesgo vida (siendo su cobertura principal la de fallecimiento por enfermedad o accidente), en un plazo promedio de 10 años (promedio de duración de los contratos de Vida).

Al aumentar la cantidad de personas que tengan coberturas del riesgo Vida, no solamente las Empresas Aseguradoras obtendrán una mayor utilidad (además de poder reducir los riesgos de anti-selección), sino que también se procurará cumplir con una función social al procurarse un mayor nivel de cobertura en la sociedad argentina, que le permita a las personas que sufran una incapacidad y/o a sus herederos de una mayor independencia económica, a la vez que se reduce la necesidad del asistencialismo estatal.

\subsubsection{Criterios de Evaluación y Factores Críticos de Éxito}

Cabe señalar que los factores del éxito de la propuesta radica principalmente en:

- Que permita aumentar la comercialización de los productos de Vida

- Que no promueva la antiselección y no descuide los aspectos técnicos del seguro, es decir que mantenga o reduzca la probabilidad de ocurrencia del siniestro

- Que el beneficio que produzca se perciba claramente por parte del tomador del seguro

- Que cumpla con un rol social, beneficiando a las personas, a la comunidad y a las aseguradoras. 


\subsection{Propuesta de Solución}

La propuesta de solución al problema planteado consta de una estrategia de diferenciación, basada en una mejor información sobre el riesgo que se denomina "Riesgos Custodiados" y que se encuadra dentro del marco de una cláusula.

Dicha cláusula prevé que la presentación periódica de los requisitos médicos solicitados por la aseguradora, conforme a los distintos factores de riesgo a los que se vea expuesto el asegurado (género, edad, hábitos, etc.), le repercutirá en un descuento en la prima de su seguro de vida. La mencionada reducción en los costos de su seguro, serán aplicables a la tarifa técnica de un seguro de vida anual renovable o en los gastos de un seguro de vida con vigencia mayor a un año (Entera / Universal / Temporario).

El descuento debe proveerse siempre que el asegurado cumplimente los requisitos médicos solicitados por la aseguradora, ya sea que los mismos sean con resultados positivos o no; dado que la aseguradora debe beneficiar al asegurado por llevar un adecuado control de su salud, hecho que finalmente repercutirá en la mejora en cuanto a las expectativas de sobrevida, disminuyendo la probabilidad de que el siniestro se concrete.

Se señala el empleo del Benchmarking ${ }^{3}$ como técnica para potenciar las mejores prácticas de otras unidades de negocios del sector asegurador, pero aplicables al riesgo "vida" se tuvieron en cuenta las experiencias de las bonificaciones que se promueven en el ramo automotores (como el descuento por alarma, rastreadores satelitales, conducción correcta o "scoring", etc.) y el cumplimiento de las medidas preventivas establecidos por las aseguradoras del riesgo del trabajo, a fin de elaborar la presente propuesta.

La viabilidad y pertinencia de la propuesta quedan manifiestas al considerar las causas de muerte en la Argentina y el beneficio por diagnóstico anticipado que señalan las opiniones especializadas, los cuales se encuentran en el anexo 12.3 sobre Datos la detección temprana de enfermedades mortales en Argentina y las Tablas estadísticas y censales en el anexo 12.4.

\subsection{Evaluación Cualitativa y Cuantitativa}

Se destaca que el principal beneficio radica en el hecho de una relación ganar-ganar que implica satisfacer el interés común de la aseguradora y del asegurado en que éste conserve su buena salud y que en el caso de que se presente alguna patología de riesgo de vida, la misma sea detectada tempranamente a fin de que se realice el tratamiento adecuado en tiempo de procurar un mayor porcentaje de recuperación de la enfermedad.

\footnotetext{
${ }^{3}$ El Benchmarking busca imitar las prácticas de aquellas compañías y organizaciones que representan la excelencia e implica un estudio cuyo fin es identificar las características de los productos de la competencia, así como las prácticas y procedimientos que las empresas más competitivas (sean o no competidores) utilizan para serlo. Sus objetivos fundamentales son: conocer las características de los mejores productos y servicios; identificar los mejores procesos productivos y administrativos que puedan ser incorporados a la empresa para hacerla más competitiva; y establecer medidas de desempeño para incorporarlas en las metas $y$ objetivos de la empresa o sector.
} 


\subsubsection{Ventajas de la Propuesta}

Ventaja para el Asegurado

- Beneficio económico claro que percibe el asegurado al obtener el descuento

- Detección de una eventual patología "a tiempo"

- Propone un "juego justo" dónde el beneficio esperado que se percibe resulta superior a la prima a pagar por el seguro

- Cuenta con una guía de los controles médicos pertinentes conforme a sus características de edad, sexo, hábitos, etc.

Ventajas para la Compañía de Seguros

- Reducción de la probabilidad de ocurrencia del siniestro

- Gestiona el Riesgo Moral y desalienta la Selección Adversa

- Posibilidad de disminuir el costo sin atentar contra el resultado técnico

- Conlleva un beneficio adicional por mantener el cliente mayor cantidad de años abonando la prima del seguro

- Mayor fidelización del cliente, dado que el cliente que eventualmente se le detecte una patología no estará motivado a abandonar su cobertura

- Al poder incrementar la cantidad de pólizas vigentes (por mayor adhesión y permanencia), se favorece a la ley de los grandes números en los que se basan las tablas de mortalidad (se disminuye la antiselección

\section{Ventajas para la Sociedad}

- Se propenden a la mejora en los hábitos y condiciones de salud del sector de la sociedad que cuente con un producto de vida con esta cláusula.

- Se genera una sinergia positiva en la conducta de los asegurados que se extenderá al resto del núcleo familiar.

\subsubsection{Ejemplo del Beneficio}

Sin dejar de tener en cuenta que la cláusula propuesta debe ser diseñada y redactada por actuarios con el apoyo de profesionales de la medicina, se realizará una simplificación para mostrar el funcionamiento numérico del mecanismo propuesto para la cobertura de muerte:

1. Identificar dentro de las causas de muerte la participación relativa de las patologías con mejoras significativas en la expectativa de vida por diagnóstico anticipado.

$100 \%=$ Enf. $1(10 \%)+$ Enf. $2(6 \%)+\ldots . . .+$ Enf. n (2\%)+ OT. Enf. $2(17 \%)+$ Externas $(7 \%)+$ Resto $(17 \%)$

2. Mesurar la disminución de la probabilidad de muerte por diagnóstico precoz de cada enfermedad.

Enf.1 (70\%); Enf. 2 (50\%); \%); Enf. 3 (90\%); \%); Enf. 4 (100\%);\%); Enf. 5 (80\%);....; Enf. n (60\%)

3. Sumarizar el beneficio ponderando la sumatoria de la disminución de la probabilidad de muerte por la participación relativa de cada patología.

Beneficio $=(0,1 \times 0,80)+(0,6 \times 0,7)+(0,5 \times 0,90)+(0,3 \times 1)+(0,2 \times 0,80)+\ldots+(0,05 \times 0,6)=0,30$ 
4. Calcular el descuento a aplicar en el costo total del seguro, ponderando el beneficio en la cobertura de muerte en el total de las coberturas del producto.

Descuento Total $=0,30$ (Beneficio) $\times 0,90$ (Part. Muerte en el Cto. del producto $)=27 \%$

\subsection{Riesgos de la Propuesta a Considerar}

Dentro de la investigación realizada y con el objeto de prever con anticipación las cuestiones que pudieran presentarse en contraposición con el desarrollo de la propuesta realizada, se detectaron principalmente nueve riesgos relevantes, los cuales se han segmentados en la Matriz de Tolerancia que abajo se grafica, la que clasifica cada una de las eventualidades que se pudieran presentar en la implementación de la propuesta, conforme a la probabilidad subjetiva de ocurrencia y al grado de impacto (estimados por el investigador en base a la frecuencia histórica de cada riesgo), que implicaría en el caso en que se concrete cada uno de los riesgos detectados.

\begin{tabular}{|c|c|c|c|c|c|c|c|}
\hline \multirow{7}{*}{ 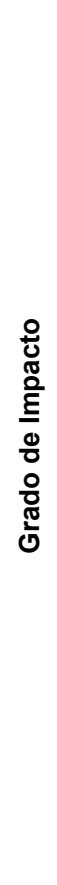 } & 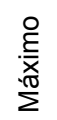 & $100 \%$ & $\begin{array}{l}\text { Divulgación } \\
\text { Factores } \\
\text { Genéticos }\end{array}$ & & & & \\
\hline & $\frac{9}{\frac{1}{2}}$ & $80 \%$ & $\begin{array}{c}\text { Baja } \\
\text { Rentabilidad }\end{array}$ & & & & \\
\hline & $\frac{\stackrel{\circ}{\overline{0}}}{\frac{0}{2}}$ & $60 \%$ & $\begin{array}{l}\text { Aumento Costos } \\
\text { de } \\
\text { Implementación }\end{array}$ & $\begin{array}{l}\text { Antiselección } \\
\text { (fraude) }\end{array}$ & $\begin{array}{l}\text { Inseguridad } \\
\text { Jurídica }\end{array}$ & & \\
\hline & $\frac{0}{\sqrt[\pi]{\pi}}$ & $40 \%$ & $\begin{array}{l}\text { Epidemias / } \\
\text { Guerras }\end{array}$ & $\begin{array}{l}\text { Cambios en la } \\
\text { Normativa }\end{array}$ & $\begin{array}{l}\text { Cambio Política } \\
\text { Económica }\end{array}$ & & \\
\hline & 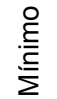 & $20 \%$ & $\begin{array}{l}\text { Inestabilidad } \\
\text { Institucional }\end{array}$ & $\begin{array}{c}\text { Baja } \\
\text { Comercialización }\end{array}$ & & & \\
\hline & & & $20 \%$ & $40 \%$ & $60 \%$ & $80 \%$ & $100 \%$ \\
\hline & & & Mínima & Baja & Media & Alta & Máxima \\
\hline
\end{tabular}

A su vez, estos riesgos detectados, se han clasificado y ordenados por prioridad, a fin de establecer qué medidas de contingencia deberán preverse en cada caso:

\begin{tabular}{|l|c|c|c|c|c|c|l|}
\hline Riesgos Identificados & Ocurrencia & $\%$ & Impacto & $\%$ & Prioridad & Orden & \multicolumn{1}{|c|}{ Medidas de Contingencia } \\
\hline Inseguridad Jurídica & Medio & $60 \%$ & Medio & $60 \%$ & $36 \%$ & 1 & Monitorear fallos emergentes \\
\hline Cambio Política Económica & Media & $60 \%$ & Bajo & $40 \%$ & $24 \%$ & 2 & Operar con monedas alternativas \\
\hline Antiselección (fraude) & Baja & $40 \%$ & Medio & $60 \%$ & $24 \%$ & 3 & Correcta suscripción \\
\hline Divulgación Factores Genéticos & Mínima & $20 \%$ & Máximo & $100 \%$ & $20 \%$ & 4 & Prever estimar dichos factores \\
\hline Cambios en la Normativa & Baja & $40 \%$ & Bajo & $40 \%$ & $16 \%$ & 5 & Lograr apoyo político \\
\hline Baja Rentabilidad & Mínima & $20 \%$ & Alto & $80 \%$ & $16 \%$ & 6 & Emplear márgenes de seguridad \\
\hline Aumento Costos de Implementación & Mínima & $20 \%$ & Medio & $60 \%$ & $12 \%$ & 7 & Evaluar correctamente los egresos \\
\hline Baja Comercialización & Baja & $40 \%$ & Mínimo & $20 \%$ & $8 \%$ & 8 & Adecuado lanzamiento comercial \\
\hline Epidemias / Guerras & Mínima & $20 \%$ & Bajo & $40 \%$ & $8 \%$ & 9 & Contemplar en exclusiones \\
\hline Inestabilidad Institucional & Mínima & $20 \%$ & Mínimo & $20 \%$ & $4 \%$ & 10 & Difundir los beneficios sociales \\
\hline
\end{tabular}




\subsection{Requerimientos Adicionales a la Propuesta}

- Adicionalmente, se puede evaluar financiar todo o un porcentaje del costo de los análisis y demás requisitos médicos (siempre o solo cuando el asegurado no posea cobertura de la obra social). El costo de los mismos se financiaría con un aumento en el costo de la premio del seguro (aumento en los gastos), y/o con una disminución en el beneficio por presentar los estudios requeridos.

- A su vez, se debe considerar el costo adicional de horas hombre en la auditoria médica por analizar los exámenes que se realicen los asegurados.

- Ante la detección de una patología, se puede combinar con las coberturas de segunda opinión médica, "long time care" y/o de anticipos de enfermedades graves, o proveer un seguimiento adicional al tratamiento que el asegurado escoja para resguardar su salud.

- Ante riesgos preferentes (por estados de salud, hábitos, conductas, etc.), se le pueden ofrecer ampliar las sumas aseguradas o coberturas.

- A fin de lograr una mejor identificación de las potencialidades comerciales que representa cada cliente, a la vez de aportar un mayor seguimiento y atención de cada asegurado, se recomienda la importancia de complementar el desarrollo de esta propuesta con la implementación de una estrategia de CRM, en la cual además de implementar un software que administre la relación con cada cliente se debe acompañar con el desarrollo de un área de "contact center" a fin de optimizar la utilidad de la herramienta.

- Se destaca la conveniencia de la instrumentación de un proceso de Mejora Continua, toda vez que la operatoria propuesta es perfectible de ser mejorada y necesariamente debe encontrarse en sintonía con las necesidades que el mercado demande; en procura de optimizar la operatoria a la vez de no quedar desactualizada ante los requerimientos cambiantes de asegurables y asegurados.

\subsection{Recomendación Final}

A partir del estudio realizado, se recomienda implementar la alternativa elegida, dado que además de cumplir con el objetivo planteado, posee los siguientes beneficios adicionales:

- Se trata de una cláusula innovadora en el mercado argentino de seguros de vida.

- En la Superintendencia de Seguros de la Nación existen antecedentes de aprobación de cláusulas de descuento con respaldo técnico para otros ramos (por ejemplo el descuento por alarma, rastreadores satelitales y conducción correcta "scoring"4 en automotores).

- A su vez las Aseguradoras ampliarán la función social que desarrollan, ya que no solo se proveen el instrumento que proporciona un resarcimiento económico a los beneficiarios o herederos legales ante la pérdida de generación de ingresos que trae aparejado el fallecimiento prematuro del jefe de familia (rol que desempeñan todas las aseguradoras que ofrecen coberturas de vida), sino que además promueven un mayor cuidado de la salud de la población.

\footnotetext{
${ }^{4}$ Con "scoring" se hace alusión al programa de bonificaciones y recargos que realiza el sector de seguros para el automotor en función de las conductas de manejo. Se destaca que conforme a lo publicado en el N ${ }^{\circ} 180$ de la Revista Nuevos Bancos y Seguros de Septiembre de 2010, se señala que se prevé que en los próximos años se generalice el uso de mecanismos más eficientes de contratación más eficientes basados en técnicas de "scoring".
} 


\section{Bibliografía}

\subsection{Fuentes Bibliográfías}

- Alberto M. Ballvé (2008) “Tablero de Comando", $1^{\circ}$ Edición, Editorial Emecé, Argentina.

- Darwin, Charles (2010) "La Origen de las Especies" $1^{\circ}$ Edición, Editorial Aguilar, Argentina.

- Davidson Frame, J. (2005) "La Nueva Dirección de Proyectos", $1^{\circ}$ Edición, Editorial Granica, Argentina.

- Facal, Carlos José María (2007) “El Seguro de Vida en la Argentina”, $1^{\circ}$ Edición, Editorial Lexis Nexis Argentina S.A., Argentina.

- Gómez Vieites / Suarez Rey (2007) "Sistemas de Información", 1 Edición, Editorial Alfaomega, Argentina.

- Hammer, Michael (2005) "La Agenda" $1^{\circ}$ Edición, Editorial Deusto, Argentina.

- Levin, Richard I. (1988) "Estadística para Administradores", $2^{\circ}$ Edición, Editorial Prentice-Hall Hispanoamericana S.A., México.

- Mecca, Roberto (1995) "Manual Profesional del Seguro", 4 Edición, Editor Roberto Mecca, Argentina.

- Perucci, Héctor (2006) "Todo Seguro", $1^{\circ}$ Edición, Editorial Comunicación y Proyectos S.A., Argentina.

- Porter, Michael E. (2005) "Estrategia y Ventaja Competitiva" $1^{\circ}$ Edición, Editorial Deusto, Argentina.

- Ribeiro, Lair (1998) “Comunicación Eficaz", $1^{\circ}$ Edición, Editorial Urano, España.

- Sabino, Carlos A. (1996) "El Proceso de Investigación”, $4^{\circ}$ Edición, Editorial Lumen, Argentina.

\subsection{Publicaciones Específicas de Seguros}

- Revista "Estrategas", № 109, Directores: Raúl Veiga / Graciela Sasbon, Le Journal de L'Assurance de Francia, Argentina

- Revista "Gerencia de Riesgos y Seguros", № 104 y 105 , Director: José Luis Ibáñez Götzens, Fundación Mapfre, España

- Revista "Mercado Asegurador", № 328 y 329 , Director: Pedro Zournadian, Ediseg S.R.L.

- Revista "Nuevos Bancos y Seguros" No 180, Director: Silvia I Fichman, Grupo Sol Comunicaciones S.A., Argentina

- Revista "Todo Riesgo", N 140,150 y 156, Directores: Horacio Levy / Horacio Lachman, Comunicación y Proyectos S.R.L., Argentina

\subsection{Páginas Web Consultadas}

- www.aacsra.org.ar

- www.avira.org.ar

- www.buenafuente.com.ar

- www.goseguros.com

- www.indec.gob.ar

- www.revistaestrategas.com.ar

- www.revistatodoriesgo.com.ar

- www.sellingpoint.com.ar

- www.ssn.gob.ar

- www.wikipedia.com 


\section{Glosario de Términos de Seguros}

(FUENTE: Superintendencia de Seguros de la Nación).

Accidente: Es el acontecimiento inesperado, repentino e involuntario que pueda ser causa de daños a las personas o a las cosas independientemente de su voluntad.

Actuario: Profesional titulado especializado en cálculos matemáticos y conocimientos estadísticos, económicos, jurídicos y financieros cuya función primordial es el asesoramiento a las Entidades Aseguradoras en todas aquellas materias de índole técnica, esenciales para la determinación de las tarifas, primas del seguro, cálculo de reservas, etc.

Agravación del Riesgo: modificación o alteración posterior a la celebración del contrato que, aumentando la posibilidad de un evento, afecta a un determinado riesgo. El tomador del seguro o Asegurado deberá, durante el curso del contrato, comunicar al Asegurador, todas las circunstancias que agraven el riesgo. Solo se debe denunciar la agravación del riesgo que obedezca a motivos específicamente previstos en el contrato.

Arbitraje: Es el sistema mediante el cual en aquellas pólizas en las que existe disparidad en la valorización de un siniestro, se acude a peritos imparciales para determinar el valor de los daños, y cuya decisión suele ser vinculante con las partes.

Asegurable: Persona o bien que reúne las características predeterminadas para poder ser objeto de la cobertura del seguro.

Asegurado: Es la persona, titular del interés sobre cuyo riesgo se toma el seguro. En el sentido estricto, es la persona sobre la cual recae la cobertura del seguro.

Asegurador: Es la empresa que asume la cobertura del riesgo, previamente autorizadas a operar como tales por la Superintendencia de Seguros de la Nación.

Beneficiario: Persona a cuyo favor se constituye un seguro. Técnicamente se denomina así a la persona que ostenta el derecho de percibir la prestación indemnizatoria del Asegurador.

Capital Asegurado: Se llama así al monto pagadero en caso de siniestro previamente estipulado en las condiciones de póliza.

Carencia: período durante el cual el Asegurado paga primas pero no recibe la cobertura prevista en la póliza. Se extiende desde la fecha de inicio del contrato hasta una fecha posterior determinada. Solo se aplica en los Seguros de Vida y enfermedades para evitar posibles fraudes y antiselección.

Certificado Individual de Seguro: Es el documento por el cual se prueba la existencia de una póliza de seguro colectivo, y en el que deben figurar los elementos que la identifican, como ser: suma asegurada, vigencia, datos personales del Asegurado, beneficiarios, etc.

Contrato de Seguro: Hay contrato de seguro cuando el Asegurador se obliga mediante el pago de una prima o cotización a resarcir un daño o cumplir la prestación convenida si ocurre el evento previsto. 
Edad Límite: Es la máxima o mínima edad necesaria para poder estar Asegurado en determinados seguros. Así, en los Seguros de Vida la edad mínima es de 14 años (determinada por Ley), y la máxima depende de cada Entidad Aseguradora, pero generalmente oscila entre los 60 o 65 años.

Esperanza de Vida: Es el promedio de años de vida restantes para un grupo de personas de cierta edad según una tabla particular de mortalidad

Exclusión de Riesgos: La Entidad Aseguradora cubre únicamente los riesgos previstos en el contrato.

Franquicia: Es el monto que se encuentra a cargo del Asegurado en caso de producirse el siniestro.

Indemnización: Es la contraprestación a cargo del Asegurador en caso de producirse el siniestro.

Interés Asegurable: Es el interés económico, legal y substancial de quien desee contratar una póliza a los fines de cubrir un riesgo. Es el objeto del contrato.

Interés Técnico: Porcentaje mínimo de rentabilidad que un Asegurador garantiza en las bases técnicas de cada modalidad del Seguro de Vida.

Participación en Utilidades: Característico de los Seguros de Vida. Reconoce al Asegurado una participación en los beneficios de la Entidad Aseguradora obtenidos en un determinado período.

Plazo de Gracia: Período durante el cual están en vigor las coberturas de la póliza, aunque no se hayan pagado las primas correspondientes, por lo general es de un mes a partir de la fecha de vencimiento de pago de la prima.

Póliza: Es el instrumento probatorio por excelencia del contrato celebrado entre el Asegurado y el Asegurador. Es aconsejable antes de celebrarlo, leer todas las cláusulas contenidas en el mismo, para tener una información completa de sus términos y condiciones. En él se reflejan las normas que de forma general, particular o especial regulan la relación contractual convenida entre el Asegurador y el Asegurado.

Premio: Está compuesto por la Prima Pura, más una suma determinada para gastos y utilidad del Asegurador, gastos especiales de emisión y administración (derecho de emisión y recargos administrativos), coeficientes de financiación del pago del premio, comisión del productor y los importes destinados al pago de tasas, impuestos y contribuciones que gravan al contrato y a la operación de seguros.

Prima de Riesgo: En los Seguros de Vida es aquella parte de la prima que está destinada a cubrir exclusivamente la posibilidad de muerte del Asegurado.

Prima Nivelada O Constante: En los Seguros de Vida es la que permanece inalterable durante toda la vigencia del contrato.

Prima Pura: Es el costo real del riesgo asumido, sin incluir gastos de gestión externa ni interna. 
Prima Única: Es aquella cuyo importe se satisface de una sola vez y por adelantado. Es una de las variantes de los Seguros de Vida.

Propuesta/Solicitud de Seguro: Es el documento donde se determina la naturaleza del riesgo a asegurar, sus características, el importe que se desea asegurar, etc. A través de éste, el Asegurador aceptará o rechazará el riesgo tras un estudio de dicha propuesta.

Productor-Asesor de Seguros: Es la persona, habilitada por la Superintendencia de Seguros, que realiza la intermediación entre quien quiere comprar una póliza de seguros y la Entidad Aseguradora. Es el que ejerce la actividad de intermediación promoviendo la concertación de contratos de seguros, asesorando a Asegurados y Asegurables.

Ramo: Se entiende por Ramo a la modalidad o conjunto de modalidades de seguros relativas a riesgos de características o naturaleza semejante (Ramo Vida, Ramo Automóviles, etc.). Debe tenerse en cuenta que para operar en un determinado ramo las Entidades Aseguradoras deberán estar previamente autorizadas por la Superintendencia de Seguros de la Nación.

Recargo: Aumento de la prima que se cobra al Asegurado para poder asumir riesgos mayores de lo normal (riesgo agravado).

Rehabilitación: Para el Seguro de Vida. Es el derecho del Asegurado a poner de nuevo en vigor una póliza que caducó por falta de pago.

Renovación Automática: Acuerdo entre las partes por el cual el seguro se prorroga tácitamente por un nuevo período de vigencia.

Renta Financiera: Es una sucesión de un número determinado de pagos constantes, ciertos y pagaderos al fin o al inicio de cada período, calculados teniendo en cuenta una cierta tasa de interés.

Rescisión: Finalización del contrato en una fecha distinta a la prevista en el mismo.

Reservas: Es la provisión constituida por las Entidades Aseguradoras para atender las obligaciones contraídas con sus Asegurados.

Reticencia: Toda declaración falsa o toda reticencia de circunstancias conocidas por el Asegurado, aún hechas de buena fe, que a juicio de peritos hubiese impedido el contrato o modificado sus condiciones si el Asegurador hubiese sido cerciorado del verdadero estado del riesgo, hace nulo el contrato.

Riesgo: Es la probabilidad de ocurrencia de un siniestro. Es la posibilidad de que la persona asegurada sufra el siniestro previsto en las condiciones de póliza.

Riesgos No Asegurables: Son aquellos que quedan fuera de la cobertura general por parte de las Aseguradoras, por ser opuestos a la Ley.

Seguro: Jurídicamente hablando es un instituto por el cual el Asegurador se obliga, mediante el cobro de una prima a abonar, dentro de los límites pactados, un Capital u otras prestaciones convenidas, en caso de que se produzca el evento cuyo riesgo es objeto de cobertura. El seguro brinda protección frente a un daño inevitable e imprevisto, tratando de reparar materialmente, en 
parte o en su totalidad sus consecuencias. El seguro no evita el riesgo, resarce al Asegurado, en la medida de lo convenido, de los efectos dañosos que el siniestro provoca.

Seguro Colectivo/Grupal: Es aquel contrato que reúne a un grupo de personas unidas por un vínculo o interés común previo a la adhesión del seguro, pero diferente a la motivación de contratar el seguro, que cumple las condiciones de asegurabilidad y cuya cobertura se realiza mediante contrato único suscrito por el Asegurador y el Contratante.

Seguros Obligatorios: Son aquellos que son impuestos por el Estado, tales como los de Seguridad Social, Seguro de Vida Obligatorio, Seguro colectivo para el Personal del Estado, etc.

Seguro Por Cuenta Ajena: Se denomina así a aquellos seguros en los que el Asegurado no es el tomador del seguro, sino un tercero determinado o indeterminado que adquiere los derechos derivados del contrato.

Siniestro: Es la concreción del riesgo tal como ha sido previsto en el contrato, cuyo acaecimiento genera la obligación de indemnizar en el Asegurador.

Sobreprima: Recargo a la prima cuando se trata de riesgos agravados o tarados.

Subrogación: Los derechos que correspondan al Asegurado contra un tercero, en razón del siniestro, se transfieren al Asegurador hasta el monto de la indemnización abonada. El Asegurado es responsable de todo acto que perjudique este derecho del Asegurador. La subrogación es inaplicable en los seguros de personas.

Tablas de Morbilidad: Tablas estadísticas que reflejan la incidencia de las enfermedades en un determinado grupo de personas.

Tablas de Mortalidad: Tablas estadísticas que reflejan la probabilidad de fallecimiento de las personas en función de sus edades.

Tomador: Es la persona que contrata el seguro con el Asegurador. Generalmente en los seguros individuales el tomador contrata el seguro por cuenta propia, uniéndose así en una persona dos figuras (Tomador o Contratante y Asegurado). Por el contrario el seguro es por cuenta ajena cuando el Tomador es distinto del Asegurado; esta situación es típica en los seguros colectivos.

Valores Garantizados: Aplicable a los Seguros de Vida Individual. Transcurridos 3 años desde la celebración del contrato y hallándose el Asegurado al día en el pago de las primas, podrá en cualquier momento exigir, de acuerdo con los planes técnicamente aprobados por la autoridad de contralor:

Seguro Saldado: convertir el seguro en otro saldado por una suma reducida o de plazo menor.

Rescate: se rescinde la póliza, percibiendo el Asegurado, el importe de la reserva matemática constituida sobre el riesgo, con las deducciones que correspondan.

Vencimiento de Póliza: Es la fecha pactada en el contrato para la finalización del mismo.

Vigencia del Seguro: Es el plazo durante el cual el contrato está en vigor y el Asegurado se encuentra cubierto. 


\section{Referencias y Anexos}

\subsection{Tablas del Estudio sobre la Relación de la Población y el Seguro de Vida}

Corresponden al trabajo realizado durante los meses de Junio y Julio de 2009 por la consultora D'Alessio IROL (Certificación en encuestas online norma ISO 9001:2000) para la Asociación de Aseguradoras de Vida y Retiro (AVIRA), sobre una muestra de 1.667 casos, en un universo de personas de entre 25 y 54 años de nivel socioeconómico C1, C2, C3 y parte de D1, mediante la técnica Cuantitativa de Encuestas On Line, en todo el país (33\% Capital Federal, 33\% Gran Buenos Aires y $34 \%$ Resto del País).

\subsubsection{Encuestas sobre el Proyectos y Ahorros Familiares}

¿Cuáles son los proyectos principales que tiene actualmente con su familia?

\begin{tabular}{|c|c|c|c|c|c|c|c|c|c|}
\hline \multirow[b]{2}{*}{ Respuestas } & \multirow[b]{2}{*}{ Total } & \multicolumn{2}{|c|}{ Sexo } & \multicolumn{3}{|c|}{ Edad } & \multicolumn{3}{|c|}{ Nivel Socioeconómico } \\
\hline & & Hombre & Mujer & $\begin{array}{c}\text { Menor de } \\
34 \text { años }\end{array}$ & $\begin{array}{c}\text { Entre } 35 \\
\text { y } 44 \text { años }\end{array}$ & $\begin{array}{c}\text { Mayor de } \\
45 \text { años }\end{array}$ & Alto & Medio & Bajo \\
\hline Arreglos en la casa & 45 & 42 & 47 & 41 & 47 & 45 & 43 & 48 & 45 \\
\hline Hacer un viaje & 40 & 41 & 40 & 36 & 38 & 49 & 44 & 34 & 24 \\
\hline Cambiar el auto & 28 & 32 & 24 & 24 & 30 & 28 & 32 & 20 & 6 \\
\hline Comprar una vivienda & 26 & 29 & 24 & 34 & 26 & 19 & 26 & 26 & 36 \\
\hline Renovar los electrodomésticos & 22 & 23 & 22 & 18 & 25 & 24 & 22 & 23 & 12 \\
\hline Redecorar la casa & 20 & 18 & 21 & 19 & 20 & 21 & 20 & 19 & 12 \\
\hline Comprar una computadora & 11 & 12 & 9 & 10 & 12 & 8 & 10 & 12 & 12 \\
\hline Casamiento & 5 & 5 & 5 & 12 & 2 & 2 & 5 & 6 & - \\
\hline Compra de la vivienda de hijos & 5 & 5 & 5 & 0 & 3 & 13 & 5 & 4 & 6 \\
\hline Jubilación & 2 & 2 & 3 & 1 & 1 & 5 & 3 & 2 & - \\
\hline Otros & 9 & 8 & 10 & 10 & 10 & 7 & 9 & 11 & 3 \\
\hline Prefiero no responder & 3 & 3 & 2 & 4 & 2 & 3 & 2 & 3 & 9 \\
\hline Promedio de respuestas & 2,1 & 2,2 & 2,1 & 2,0 & 2,1 & 2,2 & 2,2 & 2,0 & 1,6 \\
\hline Casos & 1667 & 800 & 866 & 507 & 686 & 472 & 1057 & 572 & 33 \\
\hline
\end{tabular}

¿Qué porcentaje del ingreso de su hogar se ahorra por mes?

\begin{tabular}{|c|c|c|c|c|c|c|c|c|c|}
\hline \multirow[b]{2}{*}{ Respuestas } & \multirow[b]{2}{*}{ Total } & \multicolumn{2}{|c|}{ Sexo } & \multicolumn{3}{|c|}{ Edad } & \multicolumn{3}{|c|}{ Nivel Socioeconómico } \\
\hline & & Hombre & Mujer & $\begin{array}{c}\text { Menor de } \\
34 \text { años }\end{array}$ & $\begin{array}{l}\text { Entre } 35 \\
\text { y } 44 \text { años }\end{array}$ & $\begin{array}{l}\text { Mayor de } \\
45 \text { años }\end{array}$ & Alto & Medio & Bajo \\
\hline Nada & 23 & 20 & 26 & 17 & 24 & 27 & 17 & 33 & 35 \\
\hline Menos del $5 \%$ & 22 & 19 & 25 & 23 & 24 & 19 & 19 & 28 & 19 \\
\hline Entre 6 y $10 \%$ & 23 & 25 & 20 & 24 & 22 & 22 & 25 & 18 & 19 \\
\hline Entre 11 y $15 \%$ & 13 & 13 & 12 & 15 & 11 & 13 & 14 & 10 & 4 \\
\hline Entre 16 y $20 \%$ & 9 & 10 & 8 & 8 & 9 & 10 & 11 & 5 & 8 \\
\hline Más del $20 \%$ & 11 & 14 & 9 & 14 & 11 & 9 & 13 & 6 & 15 \\
\hline Casos & 1555 & 749 & 805 & 465 & 648 & 440 & 996 & 528 & 26 \\
\hline
\end{tabular}

\subsubsection{Encuestas sobre Información y Contratación de Seguros de Vida}


¿Escuchó hablar o leyó sobre seguros de vida?

\begin{tabular}{|c|c|c|c|c|c|c|c|c|c|}
\hline \multirow[b]{2}{*}{ Respuestas } & \multirow[b]{2}{*}{ Total } & \multicolumn{2}{|c|}{ Sexo } & \multicolumn{3}{|c|}{ Edad } & \multicolumn{3}{|c|}{ Nivel Socioeconómico } \\
\hline & & Hombre & Mujer & $\begin{array}{l}\text { Menor de } \\
34 \text { años }\end{array}$ & $\begin{array}{l}\text { Entre } 35 \\
\text { y } 44 \text { años }\end{array}$ & $\begin{array}{c}\text { Mayor de } \\
45 \text { años }\end{array}$ & Alto & Medio & Bajo \\
\hline $\mathrm{Si}$ & 88 & 89 & 88 & 86 & 91 & 87 & 90 & 87 & 67 \\
\hline No & 12 & 11 & 12 & 14 & 9 & 13 & 10 & 13 & 33 \\
\hline Casos & 1667 & 800 & 866 & 507 & 686 & 472 & 1057 & 572 & 33 \\
\hline
\end{tabular}

¿Tiene o tuvo un seguro de vida?

\begin{tabular}{|c|c|c|c|c|c|c|c|c|c|}
\hline \multirow[b]{2}{*}{ Respuestas } & \multirow[b]{2}{*}{ Total } & \multicolumn{2}{|c|}{ Sexo } & \multicolumn{3}{|c|}{ Edad } & \multicolumn{3}{|c|}{ Nivel Socioeconómico } \\
\hline & & Hombre & Mujer & $\begin{array}{l}\text { Menor de } \\
34 \text { años }\end{array}$ & $\begin{array}{c}\text { Entre } 35 \\
\text { y } 44 \text { años }\end{array}$ & $\begin{array}{c}\text { Mayor de } \\
45 \text { años }\end{array}$ & Alto & Medio & Bajo \\
\hline Sí, tengo por la Empresa & 39 & 39 & 39 & 35 & 40 & 41 & 40 & 38 & 36 \\
\hline Sí, tengo contratado por mí & 18 & 21 & 16 & 14 & 20 & 21 & 22 & 12 & 6 \\
\hline Sí, tuve pero ya no lo poseo & 14 & 14 & 14 & 11 & 14 & 17 & 12 & 17 & 12 \\
\hline No, nunca tuve & 29 & 26 & 32 & 40 & 26 & 21 & 26 & 33 & 45 \\
\hline Casos & 1667 & 800 & 866 & 507 & 686 & 472 & 1057 & 572 & 33 \\
\hline
\end{tabular}

\subsubsection{Encuestas sobre Intereses y Motivación a los de Seguros de Vida}

¿Qué lo llevaría a interesase en un seguro de vida?

\begin{tabular}{|c|c|c|c|c|c|c|c|c|c|}
\hline \multirow[b]{2}{*}{ Respuestas } & \multirow[b]{2}{*}{ Total } & \multicolumn{2}{|c|}{ Sexo } & \multicolumn{3}{|c|}{ Edad } & \multicolumn{3}{|c|}{ Nivel Socioeconómico } \\
\hline & & Hombre & Mujer & $\begin{array}{l}\text { Menor de } \\
34 \text { años }\end{array}$ & $\begin{array}{l}\text { Entre } 35 \\
\text { y } 44 \text { años }\end{array}$ & $\begin{array}{c}\text { Mayor de } \\
45 \text { años }\end{array}$ & Alto & Medio & Bajo \\
\hline La seguridad a la familia & 47 & 41 & 52 & 57 & 45 & 37 & 42 & 53 & 58 \\
\hline Monto accesible a pagar por mes & 45 & 38 & 51 & 47 & 49 & 37 & 43 & 49 & 32 \\
\hline Cobertura & 31 & 27 & 33 & 33 & 31 & 28 & 30 & 33 & 21 \\
\hline Trayectoria de la Aseguradora & 21 & 20 & 21 & 21 & 21 & 20 & 24 & 16 & 16 \\
\hline La prima contratada & 10 & 11 & 9 & 12 & 8 & 10 & 10 & 10 & 5 \\
\hline Recomendación de amigos & 9 & 9 & 9 & 10 & 9 & 9 & 11 & 7 & 5 \\
\hline No burocracia de la aseguradora & 9 & 9 & 9 & 11 & 9 & 6 & 7 & 11 & 21 \\
\hline Un asesor que me explique bien & 9 & 10 & 8 & 10 & 8 & 9 & 10 & 6 & 16 \\
\hline Información permanente & 8 & 8 & 8 & 10 & 8 & 6 & 7 & 9 & 5 \\
\hline Resúmenes claros & 8 & 7 & 8 & 8 & 9 & 6 & 8 & 8 & 5 \\
\hline Que tenga descarga fiscal & 6 & 8 & 4 & 5 & 7 & 4 & 7 & 4 & - \\
\hline La calidad de la atención & 3 & 3 & 3 & 5 & 3 & 2 & 3 & 2 & 11 \\
\hline Otros & 8 & 11 & 6 & 5 & 9 & 12 & 10 & 7 & - \\
\hline Prefiero no responder & 15 & 17 & 13 & 10 & 16 & 21 & 16 & 13 & 21 \\
\hline Promedio de respuestas & 2,1 & 2,0 & 2,2 & 2,3 & 2,1 & 1,9 & 2,1 & 2,2 & 1,9 \\
\hline Casos & 711 & 316 & 395 & 258 & 275 & 178 & 403 & 286 & 19 \\
\hline
\end{tabular}

Contratando un Seguro de Vida usted aseguraría que su familia no enfrente problemas financieros frente a la desaparición imprevista del sostén del hogar. ¿Estaría interesado en comprar ese seguro?

\begin{tabular}{|c|c|c|c|c|c|c|c|c|c|}
\hline \multirow[b]{2}{*}{ Respuestas } & \multirow[b]{2}{*}{ Total } & \multicolumn{2}{|c|}{ Sexo } & \multicolumn{3}{|c|}{ Edad } & \multicolumn{3}{|c|}{ Nivel Socioeconómico } \\
\hline & & Hombre & Mujer & $\begin{array}{l}\text { Menor de } \\
34 \text { años }\end{array}$ & $\begin{array}{l}\text { Entre } 35 \\
\text { y } 44 \text { años }\end{array}$ & $\begin{array}{l}\text { Mayor de } \\
45 \text { años }\end{array}$ & Alto & Medio & Bajo \\
\hline Sí, seguramente & 23 & 26 & 18 & 23 & 22 & 24 & 22 & 23 & 22 \\
\hline Sí, posiblemente & 40 & 37 & 43 & 42 & 39 & 38 & 45 & 39 & 28 \\
\hline No creo & 24 & 24 & 24 & 23 & 28 & 22 & 20 & 26 & 30 \\
\hline No, seguro & 10 & 10 & 11 & 12 & 8 & 11 & 11 & 10 & 13 \\
\hline Prefiero no responder & 3 & 2 & 4 & 1 & 4 & 4 & 2 & 3 & 7 \\
\hline Casos & 516 & 294 & 221 & 172 & 186 & 157 & 168 & 302 & 46 \\
\hline
\end{tabular}


¿Si pudiera deducir de sus impuestos una parte del costo de este seguro de vida, ¿estaría interesado?

\begin{tabular}{|c|c|c|c|c|c|c|c|c|c|}
\hline \multirow[b]{2}{*}{ Respuestas } & \multirow[b]{2}{*}{ Total } & \multicolumn{2}{|c|}{ Sexo } & \multicolumn{3}{|c|}{ Edad } & \multicolumn{3}{|c|}{ Nivel Socioeconómico } \\
\hline & & Hombre & Mujer & $\begin{array}{l}\text { Menor } \\
\text { de } 34 \\
\text { años }\end{array}$ & $\begin{array}{c}\text { Entre } 35 \\
\text { y } 44 \\
\text { años }\end{array}$ & $\begin{array}{l}\text { Mayor } \\
\text { de } 45 \\
\text { años }\end{array}$ & Alto & Medio & Bajo \\
\hline Sí, seguramente & 27 & 30 & 21 & 27 & 25 & 27 & 29 & 27 & 17 \\
\hline Sí, posiblemente & 41 & 39 & 43 & 45 & 40 & 36 & 42 & 41 & 30 \\
\hline No creo & 21 & 21 & 21 & 18 & 21 & 24 & 18 & 21 & 35 \\
\hline No, seguro & 8 & 7 & 10 & 9 & 9 & 6 & 9 & 7 & 13 \\
\hline Prefiero no responder & 4 & 3 & 5 & 1 & 4 & 6 & 2 & 5 & 4 \\
\hline Casos & 516 & 294 & 221 & 172 & 186 & 157 & 168 & 302 & 46 \\
\hline
\end{tabular}

¿Qué significa un seguro de vida para usted?

\begin{tabular}{|c|c|c|c|c|c|c|c|c|c|}
\hline \multirow[b]{2}{*}{ Respuestas } & \multirow[b]{2}{*}{ Total } & \multicolumn{2}{|c|}{ Sexo } & \multicolumn{3}{|c|}{ Edad } & \multicolumn{3}{|c|}{ Nivel Socioeconómico } \\
\hline & & Hombre & Mujer & $\begin{array}{l}\text { Menor de } \\
34 \text { años }\end{array}$ & $\begin{array}{c}\text { Entre } 35 \\
\text { y } 44 \text { años }\end{array}$ & $\begin{array}{l}\text { Mayor de } \\
45 \text { años }\end{array}$ & Alto & Medio & Bajo \\
\hline Seguridad & 39 & 39 & 38 & 42 & 38 & 36 & 40 & 37 & 18 \\
\hline Las dos cosas & 30 & 27 & 33 & 29 & 32 & 29 & 30 & 30 & 33 \\
\hline Ahorro/Inversión a futuro & 8 & 9 & 8 & 7 & 9 & 10 & 8 & 10 & 9 \\
\hline Prefiero no responder & 23 & 25 & 21 & 21 & 22 & 25 & 22 & 23 & 39 \\
\hline Casos & 1667 & 800 & 866 & 507 & 686 & 472 & 1057 & 572 & 33 \\
\hline
\end{tabular}

\subsection{Panel de Expertos Seleccionados}

\section{Ficha de Expertos del Área Actuarial de Vida}

Apellido y Nombres: Zubiri, María Gabriela

Antigüedad en el Rubro: $\quad$ Desde 1991

Cargo:

Empresa/s:

Actuario

Estudio Moar \& Asociados / Ex Funcionaria de la Gerencia Técnica

Zona:

de la Superintendencia de Seguros de la Nación

Ciudad Autónoma de Buenos Aires

Apellido y Nombres:

Guaita, Diego Carlos

Antigüedad en el Rubro:

Desde 1995

Cargo:

Empresa/s:

Actuario

Zona:

Tower Watson

Gran Buenos Aires

Apellido y Nombres:

Moar, Pablo

Antigüedad en el Rubro:

Cargo:

Empresa/s:

Desde 1990

Actuario

Estudio AR Noesis - Ex Representante de General Cologne Re (Reasegurador de Vida y Salud)

Zona:

Ciudad Autónoma de Buenos Aires 
Ficha de Expertos del Área Suscripción Técnica - Comercial de Vida

Apellido y Nombres:

González Pardo, Sebastián

Antigüedad en el Rubro:

Desde 2003

Cargo:

Empresa/s:

Zona:

Gerente Comercial

Prudencial Seguros S.A.

Ciudad Autónoma de Buenos Aires

Apellido y Nombres:

Cabrini, Fabián Raúl

Antigüedad en el Rubro:

Cargo:

Empresa/s:

Zona:

Desde 1994

Jefe Sección

Sancor Seguros

Provincia de Santa Fe

Apellido y Nombres:

Manfría, Carlos

Antigüedad en el Rubro:

Desde 1977

Cargo:

Jefe Sección

Empresa/s:

Federación Patronal Seguros S.A.

Zona:

Provincia de Buenos Aires

Apellido y Nombres: Vila, Miguel Ángel

Antigüedad en el Rubro: $\quad$ Desde 1989

Cargo:

Empresa/s:

Jefe Sección

Zona:

La Segunda Cía. de Seguros de Personas S.A.

Provincia de Santa Fe

\section{Ficha de Expertos del Área Comercial de Vida}

Apellido y Nombres: de Olazábal, Nicolás

Antigüedad en el Rubro: Desde 1988

Cargo:

Empresa/s:

Productor de Seguros

Eagle Star / Zurich / CNP y Editor / Director del Newsletter y Sitio de Internet: "SellingPoint"

Zona: $\quad$ Ciudad Autónoma de Buenos Aires

Apellido y Nombres: Redín, Patricia Liliana

Antigüedad en el Rubro: Desde 1998

Cargo:

Empresa/s:

Zona:

Productor Asesor de Seguros

Federación Patronal Seguros S.A.

Gran Buenos Aires

Apellido y Nombres: Straini, Luis Alberto

Antigüedad en el Rubro: Desde 2000

Cargo:

Productor Asesor de Seguros 
$\begin{array}{ll}\text { Empresa/s: } & \text { ING Insurance } \\ \text { Zona: } & \text { Provincia de Buenos Aires }\end{array}$

Al reconocimiento y trayectoria de cada uno de los diez especialistas seleccionados, los cuales presentan un promedio de 18 años de experiencia en el mercado argentino de seguros de vida, se debe destacar que los mismos poseen actualmente una participación activa en el sector, desempeñándose como funcionarios en puestos clave dentro de diferentes aseguradoras, agentes comerciales en pleno desarrollo de su actividad o asesores externos y/o consultores.

\subsection{Datos la Detección Temprana de Enfermedades Mortales}

\subsubsection{Causas de Muerte en la Argentina}

A Diciembre de 2006, el Instituto Nacional de Estadística y Censos (INDEC) clasifica los motivos que originan fallecimientos en todo el país, de la siguiente manera:

- Enfermedades del sistema circulatorio

$30,7 \%$

- Tumores malignos

$19,5 \%$

- Enfermedades del sistema respiratorio

$13,8 \%$

- Causas externas (accidentes y otros)

$6,5 \%$

- Enfermedades infecciosas y parasitarias

$5,0 \%$

- Enfermedades del sistema urinario

$2,9 \%$

- Diabetes Mellitus

$2,8 \%$

- Ciertas afecciones originadas en el período perinatal $1,5 \%$

- Resto de las causas

$17,3 \%$

Considerando que la $3^{\circ}$ causa se relaciona principalmente con un mal hábito (conducta cuya corrección excede el alcance del presente) y que la $4^{\circ}$ se encuentra vinculada a causas externas; se relevaron algunas opiniones de expertos sobre las dos primeras "Grandes Causas", las cuales explican más del $50 \%$ del total de los fallecimientos en la Argentina, y los beneficios del diagnóstico anticipado.

\subsubsection{Opiniones Especializadas sobre la Detección Temprana de Enfermedades}

En cuanto a las enfermedades del sistema circulatorio, la revista "Insuficiencia Cardíaca" ya en su editorial destaca que, la insuficiencia cardíaca es la cardiopatía con mayor incidencia y prevalencia, y que más internaciones y gastos produce a los sistemas de salud en el mundo occidental. Si bien el diagnóstico y tratamiento de dicha enfermedad ha asistido a significativos progresos en los últimos años, su morbimortalidad sigue siendo muy elevada, con altas tasas de hospitalizaciones y elevado costo económico. Según recientes estudios, se encuentra asociada a una tasa anual de mortalidad de un 10\%, además de ser la principal causa de hospitalización en personas mayores de 65 años. También se señala que la hipertensión pulmonar es una enfermedad crónica e invalidante de difícil terapéutica. Aún cuando datos recientes indican una mejora en la sobrevida gracias a las numerosas investigaciones que se realizan para el desarrollo de nuevos tratamientos médicos; sin un diagnóstico precoz y preciso, su pronóstico es malo. Debe 
ser detectada en sus etapas tempranas, pudiendo así aplicar el correcto tratamiento, evitando de este modo una progresión hacia un posible cuadro de insuficiencia cardíaca, o incluso, de muerte.

Según un estudio que publica BMC Geriatrics, en agosto del 2009, cuando se les pidió que nombraran los factores de riesgo más comunes del ACV, alrededor de tres cuartos de los participantes mencionaron correctamente la hipertensión, en cambio el $40 \%$ o menos sabía que el colesterol alto y el tabaquismo también elevan el riesgo de padecerlo y sólo cerca del 20 por ciento de las personas consultadas sabía que la diabetes y el consumo de alcohol eran otros factores que podían provocar un accidente cerebrovascular. Dado que este tipo de accidente cerebral requiere una detección e intervención médica inmediata, por lo que se sugiere la necesidad de mejorar la educación pública sobre la prevención de los ACV.

A su vez, un trabajo presentado por José Kawazoe Lazzoli en el X Congreso Argentino de Medicina del Deporte sobre la Epidemiología de la Actividad Física en la Prevención de las enfermedades Cardiovasculares; abandonar el sedentarismo, el tabaquismo, el stress o la misma obesidad, constituyen el mejor control para disminuir los factores de riesgo de que se produzca un ACV y reducir la mortalidad por esta patología.

La conclusión del Primer Consenso Latinoamericano en Cáncer Gástrico es que no solo el cáncer es la principal causa de muerte en el mundo, y el cáncer gástrico en particular ocupa el segundo lugar como causa de muerte por cáncer en Latinoamérica, sino que en cuando se detecta el cáncer gástrico en su etapa incipiente, se recurre a la cirugía y existe un pronóstico de sobrevida a cinco años cercana al $100 \%$, mientras que en estado avanzado extenso o irresecable, solo se puede aplicar la quimioterapia y menos del $10 \%$ de estos pacientes tienen una sobrevida mayor a los dos años.

En la Guía de Recomendaciones para la Prevención del Cáncer Colorrectal (del Ministerio de Salud y Ambiente de la Nación), se destaca que en la Argentina el cáncer colorrectal ha experimentado un notable incremento en las últimas décadas, ocupando el segundo lugar tras el cáncer de pulmón. Entre las mujeres ocupa el segundo lugar detrás del cáncer de mama como causa de muerte, y en el hombre, el tercero, detrás del cáncer de próstata y de pulmón. En relación con los sexos, se puede encontrar una ligera prevalencia de tumores de colon en la mujer y de recto en el hombre. En general, es un tumor bastante raro en personas con edades inferiores a los cuarenta años, siendo la edad media de diagnóstico entre 50 y 60 años. Se recomienda realizarse exámenes periódicos, dado más del $70 \%$ de los pacientes se presentan con la enfermedad avanzada (metástasis) al momento del diagnóstico inicial (mientras que en países más desarrollados es del $45 \%$ ), con índices de sobrevida a los 5 años del $50 \%$ al $60 \%$ lo cual puede elevarse al $90 \%$ cuando se lo diagnostica en forma temprana. Asimismo, no se aconseja la ingesta de mucho alcohol, sobretodo si la persona fuma ya que dicha combinación resulta sumamente peligrosa.

No se debe dejarse vencer por el miedo de saber que puede ser algo grave ya que tomado a tiempo el cáncer colorectal tiene un alto porcentaje de curación y de reincorporación del paciente a la vida normal con muy buena calidad de vida, según señala en su informe el Dr. Norberto Smurra del Hospital de Oncología "María Curie".

En un estudio de la Fundación Dr. J.R. Villavicencio sobre los cánceres renales tumorales, se afirma que los cánceres hereditarios son típicamente multifocales y bilaterales, y es común que sea el radiólogo el que primero sospeche la causa hereditaria. Es importante estar familiarizado 
con la creciente lista de enfermedades que predisponen al cáncer (por ejemplo el renal), para alcanzar un diagnóstico más temprano en el paciente y en sus familiares de riesgo.

Para casos como el cáncer de cuello uterino y el de mama, la detección temprana mejora de manera importante los efectos de tratamiento. La valoración racional del impacto potencial que sobre la salud pública tendría la detección temprana identifica a la prevención como la primera prioridad.

En el informe de Federación Argentina de Urología sobre el Consenso Urológico Nacional sobre pautas para el diagnóstico y tratamiento del cáncer de próstata (2003), se deja en claro que para mejorar la supervivencia de los pacientes con cáncer de próstata es preciso efectuar un diagnóstico precoz de la enfermedad. Así, los pacientes con tumores confinados a la glándula y que son tratados con prostatectomía radical tienen una supervivencia equiparable a la de los individuos sanos de igual edad.

El cáncer bucal representa un $6 \%$ del total del cáncer del organismo y 7 de cada 10 personas con esta patología fallecen. Aproximadamente el $80 \%$ de las personas con cáncer bucal tienen más de 40 años de edad y los varones resultan más afectados que las mujeres (los porcentajes se acercan al 80-90\%). Como los anteriores, dependiendo del tipo de cáncer y del tiempo de evolución; mientras más tarde se hace el diagnóstico, más avanzado y grave será, ya que el cáncer que recién se inicia se cura con mayor probabilidad. Generalmente es sencillo de presumir el diagnóstico con el examen clínico y luego se certifica realizando una biopsia.

En un programa de concientización sobre el cáncer (realizado en Kerala-India, del que participaron 130.000 voluntarios, y relevado por un artículo de Jones, Sinead, "Cancer in the developing world: a call to action"), fue unido a otro de educación de los profesionales de la salud y al establecimiento de centros de detección temprana, obteniendo sustanciales mejoras en los índices de: Incidencia del cáncer, Mortalidad, Sobrevida, Estado de presentación de la enfermedad al momento de la consulta y Prevalencia del uso de tabaco. Los datos preliminares mostraron una marcada disminución en el número de personas que se presentaron con cáncer en estado terminal.

También se destaca un proyecto de ley en la provincia de Corrientes sobre la detección temprana y atención del cáncer de ovario, que procura que los habitantes de esa provincia tengan acceso gratuito a los recursos terapéuticos y a los protocolos de diagnóstico precoz y tratamiento según estándares de calidad para los establecimientos hospitalarios públicos provinciales y para los establecimientos de Atención Primaria.

El tabaco representa una de cada 10 muertes en el mundo y podría terminar con 5,5 millones de vidas sólo este año", añadió el escrito. Si la tendencia actual se mantiene, en el 2020 la cifra crecerá a alrededor de 7 millones y llegará a 8 millones en el 2030 . El riesgo de morir por cáncer de pulmón es más de 23 veces mayor en los hombres y 13 veces superior en las mujeres fumadoras, comparado con las personas que no consumen tabaco. En el siglo XX, 100 millones de personas fueron asesinadas por el tabaco. A menos que se implementen medidas efectivas para prevenir que los jóvenes fumen y para ayudar a los actuales fumadores a abandonar (el hábito), el tabaco producirá la muerte de 1.000 millones de personas en el siglo XXI", sentenció el informe de la Sociedad Estadounidense del Cáncer.

Como se puede observar los especialistas en cada patología, señalan que el diagnóstico precoz es el principal factor crítico para sobrevivir a una enfermedad, ya que sin él no se logrará 
disminuir la mortalidad por más que avance la medicina. Seguidamente se considerarán algunos datos en relación al cuidado de la salud en la República Argentina.

\subsubsection{Datos de Atención y Cuidados de la Salud}

Según datos del INDEC relevados en el censo de 2001, el 48,1\% del total de la población no poseía cobertura de Obra Social, aunque esto varía sustancialmente según el distrito, siendo la Ciudad Autónoma de Buenos Aires la de mayor cobertura en todo el país con un $26,2 \%$ de la población amparada. 2007.

De las personas cubiertas, el $63 \%$ corresponde a obras sociales sindicales a Diciembre de

A su vez, el Instituto Nacional de Estadística y Censos brinda los siguientes datos en la población de 18 años y más a Junio de 2005 en localidades de más de 5.000 habitantes, a nivel país:

- Dentro de la población femenina, el 36,9\% y el 25,0\% nunca se han realizado los exámenes de Mamografías y de Papanicolau respectivamente.

- Solo el 10,45\% de la población realizan un nivel intenso de actividad física, un 45,1\% un nivel moderado y un $44,5 \%$ un bajo nivel de actividad.

- El 31,6\% manifieste sobrepeso (conforme a su peso corporal y talla), y el $13,4 \%$ de todo el país sufra de obesidad.

- El 34,5\% sufre de hipertensión arterial, el $27,8 \%$ de hipercolesterolemia y el $8,4 \%$ de diabetes.

- El consumo de tabaco asciende al $54,4 \%$ que lo realiza con prevalencia de vida, el $30 \%$ consume actualmente, el $36,6 \%$ es ex fumador y el 42,6 consume pasivamente.

- El consumo regular del riesgo de alcohol llega al 19,5\% del total con preponderancia de los mayores de 50 años y hasta los 64 años que lo realizan en un 27,7\% y segmentando por nivel de instrucción el mayor registro se encuentra en los que no han completado la primaria con un $25,8 \%$ del total.

\subsection{Tablas Estadísticas y Censales}

Los siguientes cuadros estadísticos pertenecen al Ministerio de Salud de la Nación Dirección de Estadísticas e Información de Salud (DEIS), publicados en la base de datos del Instituto Nacional de Estadísticas y Censos (INDEC), en todo el país, difiriendo los períodos de las consultas realizadas.

\subsubsection{Tablas sobre la Mortalidad en La Argentina}

\begin{tabular}{|l|r|r|r|r|r|r|}
\hline Tasa de mortalidad por mil habitantes según grupos de edad y sexo. Total de país. Años 1980/2006 \\
\hline \multirow{2}{*}{ Grupo de edad y sexo } & \multicolumn{7}{|c|}{ Años } \\
\cline { 2 - 7 } & 1980 & 1990 & 2000 & 2004 & 2005 & 2006 \\
\hline Total del país & $\mathbf{8 , 6}$ & $\mathbf{8 , 0}$ & $\mathbf{7 , 5}$ & $\mathbf{7 , 7}$ & $\mathbf{7 , 6}$ & $\mathbf{7 , 5}$ \\
\hline Varones & 10,0 & 8,9 & 8,3 & 8,3 & 8,2 & 8,1 \\
\hline Mujeres & 7,3 & 6,9 & 6,9 & 7,1 & 7,0 & 6,9 \\
\hline
\end{tabular}




\begin{tabular}{|c|c|c|c|c|c|c|}
\hline Menores de 1 año & 33,2 & 25,6 & 16,6 & 14,4 & 13,3 & 12,9 \\
\hline Varones & 36,7 & 28,2 & 18,3 & 15,7 & 14,8 & 14,1 \\
\hline Mujeres & 29,6 & 22,8 & 14,7 & 12,9 & 11,8 & 11,7 \\
\hline 1 a 4 años & 1,5 & 1,1 & 0,7 & 0,6 & 0,6 & 0,6 \\
\hline Varones & 1,6 & 1,2 & 0,7 & 0,7 & 0,6 & 0,6 \\
\hline Mujeres & 1,5 & 1,0 & 0,6 & 0,6 & 0,6 & 0,5 \\
\hline 5 a 14 años & 0,5 & 0,3 & 0,3 & 0,3 & 0,3 & 0,3 \\
\hline Varones & 0,5 & 0,4 & 0,3 & 0,3 & 0,3 & $\overline{0,3}$ \\
\hline Mujeres & 0,4 & 0,3 & 0,2 & 0,2 & 0,2 & $\overline{0,2}$ \\
\hline 15 a 24 años & 1,0 & 0,9 & 0,9 & 0,8 & 0,8 & $\overline{0,8}$ \\
\hline Varones & 1,3 & 1,1 & 1,3 & 1,1 & 1,2 & 1,2 \\
\hline Mujeres & 0,7 & 0,6 & 0,4 & 0,4 & 0,5 & 0,5 \\
\hline 25 a 34 años & 1,5 & 1,2 & 1,2 & 1,0 & 1,0 & 1,0 \\
\hline Varones & 1,8 & 1,5 & 1,7 & 1,4 & 1,4 & 1,4 \\
\hline Mujeres & 1,2 & 0,9 & 0,8 & 0,7 & 0,6 & 0,7 \\
\hline 35 a 44 años & 3,1 & 2,5 & 2,2 & 1,9 & 1,9 & 1,9 \\
\hline Varones & 3,9 & 3,1 & 2,8 & 2,4 & 2,4 & 2,4 \\
\hline Mujeres & 2,3 & 1,8 & 1,6 & 1,5 & 1,4 & $\overline{1,4}$ \\
\hline 45 a 54 años & 7,1 & 6,0 & 5,2 & 4,9 & 4,8 & 4,7 \\
\hline Varones & 9,7 & 8,0 & 7,0 & 6,4 & 6,4 & 6,2 \\
\hline Mujeres & 4,6 & 3,9 & 3,8 & 3,5 & 3,4 & 3,3 \\
\hline 55 a 64 años & 15,2 & 13,8 & 11,9 & 11,7 & 11,5 & 11,4 \\
\hline Varones & 21,1 & 19,3 & 16,5 & 15,9 & 15,8 & 15,5 \\
\hline Mujeres & 9,8 & 8,7 & 8,6 & 7,8 & 7,5 & 7,7 \\
\hline 65 a 74 años & 34,6 & 29,5 & 26,5 & 26,2 & 25,7 & 24,8 \\
\hline Varones & 46,8 & 40,6 & 37,3 & 36,8 & 36,3 & 34,8 \\
\hline Mujeres & 24,6 & 20,4 & 23,4 & 18,0 & 17,4 & 17,0 \\
\hline 75 años y más & 102,8 & 100,8 & 91,5 & 91,6 & 90,0 & 88,0 \\
\hline Varones & 120,8 & 117,5 & 109,6 & 108,7 & 106,5 & 104,5 \\
\hline Mujeres & 91,0 & 88,9 & 81,1 & 81,9 & 80,6 & 78,7 \\
\hline
\end{tabular}

Nota: los datos de población utilizados en el cálculo de las tasas de los años 2004 a 2006 corresponden a la revisión de las proyecciones de población en base a resultados definitivos del Censo 2001.

En consecuencia, se presentan fluctuaciones en las tasas que se deben fundamentalmente al cambio de denominador.

Fuente: Ministerio de Salud de la Nación. Dirección de Estadísticas e Información de Salud (DEIS).

\begin{tabular}{|c|c|c|c|}
\hline \multicolumn{4}{|c|}{ Tasa de mortalidad por 100.000 habitantes, según principales causas de muerte y sexo. Total del país. Año 2006} \\
\hline \multirow[b]{2}{*}{ Principales causas de muerte } & \multicolumn{3}{|c|}{2006} \\
\hline & Defunciones & $\begin{array}{l}\text { Tasa de } \\
\text { mortalidad }\end{array}$ & $\begin{array}{l}\text { Distribución } \\
\text { porcentual }\end{array}$ \\
\hline Total & $\begin{array}{c}292.3 \\
13 \\
\end{array}$ & 750,1 & 100,0 \\
\hline Enfermedades del sistema circulatorio: & $\begin{array}{l}89.6 \\
49 \\
\end{array}$ & 230,0 & 30,7 \\
\hline Enfermedades cerebrovasculares & $\begin{array}{l}20.1 \\
36 \\
\end{array}$ & 51,7 & 6,9 \\
\hline Resto & $\begin{array}{l}69.5 \\
13 \\
\end{array}$ & 178,4 & 23,8 \\
\hline Tumores malignos & $\begin{array}{l}56.8 \\
81 \\
\end{array}$ & 146,0 & 19,5 \\
\hline Enfermedades del sistema respiratorio: & $\begin{array}{l}40.2 \\
13 \\
\end{array}$ & 103,2 & 13,8 \\
\hline Neumonía e influenza & $\begin{array}{l}15.5 \\
00 \\
\end{array}$ & 39,8 & 5,3 \\
\hline
\end{tabular}




\begin{tabular}{|c|c|c|c|}
\hline Resto & $\begin{array}{l}24.7 \\
13 \\
\end{array}$ & 63,4 & 8,5 \\
\hline Causas externas: & $\begin{array}{l}19.0 \\
38\end{array}$ & 48,9 & 6,5 \\
\hline Accidentes & $\begin{array}{l}10.8 \\
85\end{array}$ & 27,9 & 3,7 \\
\hline Resto & $\begin{array}{c}8.1 \\
53 \\
\end{array}$ & 20,9 & 2,8 \\
\hline Enfermedades infecciosas y parasitarias: & $\begin{array}{l}14.7 \\
01 \\
\end{array}$ & 37,7 & 5,0 \\
\hline Septicemia & $\begin{array}{l}11.1 \\
51 \\
\end{array}$ & 28,6 & 3,8 \\
\hline Resto & $\begin{array}{c}3.5 \\
50\end{array}$ & 9,1 & 1,2 \\
\hline Diabetes Mellitus & \begin{tabular}{|c|}
8.3 \\
19 \\
\end{tabular} & 21,3 & 2,8 \\
\hline Enfermedades del sistema urinario & $\begin{array}{c}8.4 \\
70\end{array}$ & 21,7 & 2,9 \\
\hline Ciertas afecciones originadas en el período perinatal & $\begin{array}{l}4.4 \\
02\end{array}$ & 11,3 & 1,5 \\
\hline Resto de las causas & $\begin{array}{l}50.6 \\
40 \\
\end{array}$ & 129,9 & 17,3 \\
\hline Varones & $\begin{array}{c}154.4 \\
79 \\
\end{array}$ & 809,5 & 100,0 \\
\hline Enfermedades del sistema circulatorio: & $\begin{array}{l}45.0 \\
21 \\
\end{array}$ & 235,9 & 29,1 \\
\hline Enfermedades cerebrovasculares & $\begin{array}{c}9.7 \\
30\end{array}$ & 51,0 & 6,3 \\
\hline Resto & $\begin{array}{l}35.2 \\
91\end{array}$ & 184,9 & 22,8 \\
\hline Tumores malignos & $\begin{array}{l}31.9 \\
06 \\
\end{array}$ & 167,2 & 20,7 \\
\hline Enfermedades del sistema respiratorio: & $\begin{array}{l}20.1 \\
15\end{array}$ & 105,4 & 13,0 \\
\hline Neumonía e influenza & $\begin{array}{l}7.3 \\
93\end{array}$ & 38,7 & 4,8 \\
\hline Resto & $\begin{array}{l}12.7 \\
22 \\
\end{array}$ & 66,7 & 8,2 \\
\hline Causas externas: & $\begin{array}{l}14.0 \\
65 \\
\end{array}$ & 73,7 & 9,1 \\
\hline Accidentes & $\begin{array}{l}7.7 \\
95 \\
\end{array}$ & 40,8 & 5,0 \\
\hline Resto & $\begin{array}{c}6.2 \\
70 \\
\end{array}$ & 32,9 & 4,1 \\
\hline Enfermedades infecciosas y parasitarias: & $\begin{array}{c}7.4 \\
10 \\
\end{array}$ & 38,8 & 4,8 \\
\hline Septicemia & $\begin{array}{c}5.1 \\
68\end{array}$ & 27,1 & 3,3 \\
\hline Resto & $\begin{array}{l}2.2 \\
42 \\
\end{array}$ & 11,7 & 1,5 \\
\hline Diabetes Mellitus & $\begin{array}{l}4.2 \\
60 \\
\end{array}$ & 22,3 & 2,8 \\
\hline Enfermedades del sistema urinario & $\begin{array}{c}4.2 \\
66 \\
\end{array}$ & 22,4 & 2,8 \\
\hline Ciertas afecciones originadas en el período perinatal & $\begin{array}{c}2.5 \\
53 \\
\end{array}$ & 13,4 & 1,7 \\
\hline Resto de las causas & $\begin{array}{l}24.8 \\
83\end{array}$ & 130,4 & 16,1 \\
\hline Mujeres & $\begin{array}{c}137.6 \\
47\end{array}$ & 692,2 & 100,0 \\
\hline Enfermedades del sistema circulatorio: & $\begin{array}{l}44.5 \\
82 \\
\end{array}$ & 224,2 & 32,4 \\
\hline Enfermedades cerebrovasculares & $\begin{array}{l}10.3 \\
95 \\
\end{array}$ & 52,3 & 7,6 \\
\hline Resto & \begin{tabular}{|l|}
34.1 \\
87 \\
\end{tabular} & 171,9 & 24,8 \\
\hline Tumores malignos & $\begin{array}{l}27.2 \\
35 \\
\end{array}$ & 137,0 & 19,8 \\
\hline
\end{tabular}




\begin{tabular}{|c|c|c|c|}
\hline Enfermedades del sistema respiratorio: & $\begin{array}{l}20.0 \\
86\end{array}$ & 101,0 & 14,6 \\
\hline Neumonía e influenza & $\begin{array}{l}8.1 \\
05 \\
\end{array}$ & 40,8 & 5,9 \\
\hline Resto & $\begin{array}{l}11.9 \\
81\end{array}$ & 60,2 & 8,7 \\
\hline Causas externas: & $\begin{array}{c}4.9 \\
54\end{array}$ & 24,9 & 3,6 \\
\hline Accidentes & $\begin{array}{l}3.0 \\
79\end{array}$ & 15,5 & 2,2 \\
\hline Resto & $\begin{array}{l}1.8 \\
75\end{array}$ & 9,4 & 1,4 \\
\hline Enfermedades infecciosas y parasitarias: & $\begin{array}{l}7.2 \\
86 \\
\end{array}$ & 36,6 & 5,3 \\
\hline Septicemia & $\begin{array}{l}5.9 \\
80 \\
\end{array}$ & 30,1 & 4,3 \\
\hline Resto & $\begin{array}{l}1.3 \\
06\end{array}$ & 6,6 & 0,9 \\
\hline Diabetes Mellitus & $\begin{array}{l}4.0 \\
52 \\
\end{array}$ & 20,4 & 2,9 \\
\hline Enfermedades del sistema urinario & $\begin{array}{l}4.2 \\
00\end{array}$ & 21,1 & 3,1 \\
\hline Ciertas afecciones originadas en el período perinatal & $\begin{array}{l}1.8 \\
48 \\
\end{array}$ & 9,3 & 1,3 \\
\hline Resto de las causas & $\begin{array}{l}23.4 \\
04\end{array}$ & 117,7 & 17,0 \\
\hline
\end{tabular}

Fuente: Ministerio de Salud de la Nación. Dirección de Estadísticas e Información de Salud (DEIS).

\subsubsection{Tablas sobre la Cobertura de Obra Social en La Argentina}

\begin{tabular}{|c|c|c|c|c|}
\hline \multirow{3}{*}{ Naturaleza de la obra social } & \multicolumn{4}{|c|}{2007} \\
\hline & \multirow{2}{*}{$\begin{array}{c}\text { Obras } \\
\text { sociales }\end{array}$} & \multicolumn{3}{|c|}{ Beneficiarios } \\
\hline & & Total & Titulares & Familiares \\
\hline Total & 288 & 15.943 .256 & 9.449 .934 & 6.493 .322 \\
\hline Sindicales & 205 & 10.074 .014 & 5.218 .281 & 4.855 .733 \\
\hline Personal de dirección & 27 & 952.103 & 485.927 & 466.176 \\
\hline Administración mixta & 2 & 3.789 .726 & 3.110 .980 & 678.746 \\
\hline Resto & 53 & 1.127 .413 & 634.746 & 492.667 \\
\hline
\end{tabular}

Fuente: Ministerio de Salud de la Nación. Superintendencia de Servicios de Salud.

\begin{tabular}{|l|r|r|}
\hline \multirow{2}{*}{$\begin{array}{c}\text { Población sin cobertura de obra social, plan médico o mutual por grupo } \\
\text { Pe edad y sexo, según provincia. Año } 2001\end{array}$} \\
\cline { 2 - 3 } & \multicolumn{1}{c|}{ Población } \\
\cline { 2 - 3 } & \multicolumn{1}{c|}{ Total } & $\begin{array}{c}\text { Sin cobertura de } \\
\text { obra social }\end{array}$ \\
\hline Total del país & $\mathbf{3 6 . 2 6 0 . 1 3 0}$ & $\mathbf{4 8 , 1}$ \\
\hline Ciudad de Buenos Aires & 2.776 .138 & 26,2 \\
\hline Buenos Aires & 13.827 .203 & 48,8 \\
\hline Catamarca & 334.568 & 45,0 \\
\hline Chaco & 3.066 .801 & 45,8 \\
\hline Chubut & 930.991 & 62,1 \\
\hline Córdoba & 984.446 & 65,5 \\
\hline Corrientes & 413.237 & 39,5 \\
\hline Entre Ríos & 1.158 .147 & 48,7 \\
\hline Formosa & 486.559 & 65,8 \\
\hline
\end{tabular}




\begin{tabular}{|l|r|r|} 
Jujuy & 611.888 & 54,2 \\
\hline La Pampa & 299.294 & 45,5 \\
\hline La Rioja & 289.983 & 40,8 \\
\hline Mendoza & 1.579 .651 & 50,6 \\
\hline Misiones & 965.522 & 57,8 \\
\hline Neuquén & 474.155 & 48,7 \\
\hline Río Negro & 552.822 & 49,9 \\
\hline Salta & 1.079 .051 & 60,4 \\
\hline San Juan & 620.023 & 53,0 \\
\hline San Luis & 367.933 & 51,6 \\
\hline Santa Cruz & 196.958 & 29,2 \\
\hline Santa Fe & 3.000 .701 & 42,0 \\
\hline Santiago del Estero & 804.457 & 63,7 \\
\hline Tierra del Fuego & 101.079 & 30,1 \\
\hline Tucumán & 1.338 .523 & 48,2 \\
\hline Fuente: INDEC, Censo Nacional & & \\
\hline
\end{tabular}

Fuente: INDEC, Censo Nacional de Población, Hogares y Viviendas 2001.

\section{Beneficiarios de obras sociales por naturaleza institucional. Total del país. Años 2003-2007}

\begin{tabular}{|c|c|c|c|c|c|}
\hline \multirow{2}{*}{ Naturaleza de la obra social } & \multicolumn{5}{|c|}{ Beneficiarios de obras sociales } \\
\hline & 2003 & 2004 & 2005 & 2006 & 2007 \\
\hline Total & 14.175 .892 & 14.882.140 & 15.514.299 & 15.502 .139 & 15.943.256 \\
\hline Sindicales & 9.422 .020 & 10.247.704 & 10.916.326 & 10.558.787 & 10.074 .014 \\
\hline Estatales & 31.078 & 27.804 & 27.694 & 22.390 & 16.438 \\
\hline Por convenio & 54.756 & 22.727 & 67.541 & 58.080 & 42.729 \\
\hline Personal de dirección & 748.386 & 916.015 & 922.595 & 979.900 & 952.103 \\
\hline Administración mixta (1) & 2.986 .915 & 2.727 .367 & 2.566 .352 & 2.821 .863 & 3.789 .726 \\
\hline Por adhesión (2) & 23.942 & 25.420 & 28.407 & 29.714 & 28.750 \\
\hline Ley $N^{\circ} 21.476(3)$ & 19.014 & 18.179 & 17.339 & 16.716 & 15.341 \\
\hline De empresas (4) & 6.276 & 6.450 & 6.874 & 9.516 & 11.049 \\
\hline De otra naturaleza & 883.505 & 890.474 & 961.171 & 1.005 .173 & 1.013 .106 \\
\hline
\end{tabular}

(1) Creadas por ley y cuya conducción es ejercida por un organismo integrado por empresas del Estado, beneficiarios y empleadores. Incluye PAMI y otras menores.

(2) Exceptuadas de la Ley de Obras Sociales que no obstante se adhieren.

(3) De empresas estatales creadas por una disposición especial (Atanor, Papel Misionero, etc.).

(4) Corresponde a una sola empresa.

Fuente: Ministerio de Salud de la Nación. Superintendencia de Servicios de Salud.

\subsubsection{Tablas sobre la realización de Estudios de Prevención para la Salud}

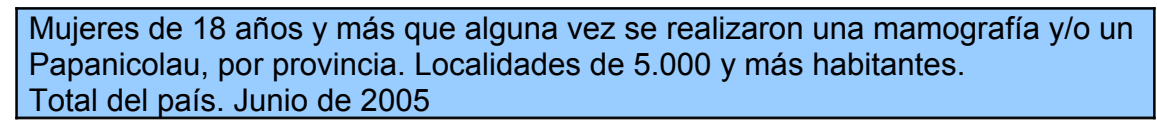

\begin{tabular}{|l|r|r|r|r|r|}
\hline \multirow{2}{*}{ Provincia } & \multicolumn{4}{|c|}{ \% Mujeres que se realizaron } \\
\cline { 2 - 3 } & \multicolumn{2}{|c|}{ Mamografía (1) } & & \multicolumn{2}{c|}{ Papanicolau (2) } \\
\cline { 2 - 3 } \cline { 5 - 6 } & \multicolumn{1}{|c|}{ Sín } & No & \multicolumn{1}{c|}{ Sí } & \multicolumn{1}{c|}{ No } \\
\hline Total del país & $\mathbf{6 2 , 3}$ & $\mathbf{3 6 , 9}$ & & $\mathbf{7 4 , 4}$ & $\mathbf{2 5 , 0}$ \\
\hline Ciudad de Buenos Aires & 81,9 & 18,1 & & 85,3 & 14,7 \\
\hline Buenos Aires & 66,3 & 32,3 & & 77,4 & 21,7 \\
\hline Catamarca & 55,1 & 44,9 & & 63,0 & 36,9 \\
\hline
\end{tabular}




\begin{tabular}{|c|c|c|c|c|}
\hline Chaco & 46,8 & 53,1 & 68,9 & 30,8 \\
\hline Chubut & 60,7 & 37,9 & 76,2 & 23,2 \\
\hline Córdoba & 57,8 & 41,6 & 76,2 & 23,3 \\
\hline Corrientes & 38,0 & 61,9 & 54,3 & 45,5 \\
\hline Entre Ríos & 53,0 & 47,0 & 64,5 & 35,5 \\
\hline Formosa & 29,2 & 69,2 & 58,7 & 40,4 \\
\hline Jujuy & 46,7 & 52,3 & 73,0 & 26,4 \\
\hline La Pampa & 61,5 & 37,7 & 81,4 & 17,6 \\
\hline La Rioja & 53,9 & 45,3 & 68,1 & 31,6 \\
\hline Mendoza & 52,5 & 47,4 & 72,0 & 27,9 \\
\hline Misiones & 48,6 & 51,4 & 57,0 & 43,0 \\
\hline Neuquén & 64,4 & 34,7 & 83,5 & 16,4 \\
\hline Río Negro & 56,1 & 43,2 & 74,6 & 24,8 \\
\hline Salta & 36,4 & 63,4 & 59,6 & 40,2 \\
\hline San Juan & 50,9 & 48,7 & 70,4 & 29,5 \\
\hline San Luís & 54,3 & 45,4 & 72,8 & 26,9 \\
\hline Santa Cruz & 55,8 & 43,3 & 78,0 & 21,7 \\
\hline Santa Fe & 64,9 & 34,8 & 75,2 & 24,7 \\
\hline Santiago del Estero & 38,7 & 60,9 & 55,3 & 44,4 \\
\hline Tierra del Fuego & 76,3 & 23,0 & 85,3 & 14,5 \\
\hline Tucumán & 40,2 & 59,5 & 54,2 & 45,6 \\
\hline
\end{tabular}

(1) Se toma como población de referencia a mujeres de 40 años y más que alguna vez se realizaron por lo menos una mamografía.

(2) Se toma como población de referencia a mujeres de 18 años y más que alguna vez se realizaron por lo menos un Papanicolau.

Nota: la suma de los parciales no corresponde al $100 \%$ de la población encuestada, ya que se omite la presentación de la categoría "Ns/Nc".

Fuente: "Programa de Vigilancia de la Salud y Control de Enfermedades" VIGI+A e

INDEC, Encuesta Nacional de Factores de Riesgo 2005.

\begin{tabular}{|c|c|c|c|c|c|c|c|c|c|}
\hline \multirow{4}{*}{ Provincia } & $\begin{array}{l}\text { ción d } \\
\text { más, }\end{array}$ & $\begin{array}{l}\text { hipertens } \\
\text { según sex }\end{array}$ & $\begin{array}{l}\text { ón arteria } \\
\text { por pro }\end{array}$ & $\begin{array}{l}\text {, hiper } \\
\text { incia. }\end{array}$ & $\begin{array}{l}\text { olesterol } \\
\text { otal del p }\end{array}$ & $\begin{array}{l}\text { mia y dial } \\
\text { is. Junio }\end{array}$ & $\begin{array}{l}\text { tes. Pob } \\
2005\end{array}$ & ción de 18 & años y \\
\hline & \multicolumn{9}{|c|}{ Prevalencia de detección } \\
\hline & \multicolumn{3}{|c|}{ Hipertensión arterial } & \multicolumn{3}{|c|}{ Hipercolesterolemia } & \multicolumn{3}{|c|}{ Diabetes } \\
\hline & Total & Varones & Mujeres & Total & Varones & Mujeres & Total & Varones & Mujeres \\
\hline Total del país & 34,5 & 31,6 & 36,8 & 27,8 & 27,7 & 27,8 & 8,4 & 8,8 & 7,9 \\
\hline Ciudad de Buenos Aires & 29,7 & 29,5 & 29,9 & 32,4 & 32,0 & 32,7 & 8,0 & 6,7 & 9,6 \\
\hline Buenos Aires & 34,8 & 32,9 & 36,4 & 25,0 & 24,4 & 25,5 & 8,6 & 9,2 & 7,9 \\
\hline Catamarca & 36,5 & 32,4 & 39,8 & 34,4 & 37,7 & 31,7 & 8,9 & 11,1 & 6,5 \\
\hline Chaco & 39,1 & 35,1 & 42,3 & 27,9 & 26,2 & 29,1 & 8,7 & 10,9 & 6,4 \\
\hline Chubut & 29,9 & 24,8 & 34,2 & 27,5 & 26,0 & 28,8 & 9,4 & 10,8 & 7,8 \\
\hline Córdoba & 35,4 & 31,9 & 38,3 & 28,9 & 30,4 & 27,7 & 10,2 & 10,8 & 9,6 \\
\hline Corrientes & 35,1 & 28,2 & 40,5 & 30,2 & 31,2 & 29,5 & 7,9 & 8,5 & 7,2 \\
\hline Entre Ríos & 34,4 & 30,0 & 38,0 & 29,9 & 29,8 & 29,9 & 8,0 & 8,9 & 7,1 \\
\hline Formosa & 37,1 & 30,6 & 41,9 & 25,1 & 25,3 & 24,9 & 8,3 & 10,4 & 5,8 \\
\hline Jujuy & 30,5 & 28,1 & 32,6 & 32,8 & 37,6 & 28,6 & 4,1 & 3,7 & 4,5 \\
\hline La Pampa & 34,9 & 29,5 & 39,0 & 30,1 & 32,0 & 28,7 & 7,4 & 8,9 & 5,8 \\
\hline La Rioja & 41,4 & 41,1 & 41,6 & 36,3 & 39,4 & 33,7 & 9,4 & 11,9 & 6,8 \\
\hline Mendoza & 35,9 & 30,4 & 40,3 & 26,4 & 27,8 & 25,1 & 6,6 & 6,6 & 6,8 \\
\hline Misiones & 34,8 & 26,7 & 41,2 & 26,5 & 25,2 & 27,5 & 8,0 & 9,0 & 6,8 \\
\hline Neuquén & 35,2 & 31,1 & 38,6 & 29,5 & 31,1 & 28,2 & 9,2 & 9,9 & 8,4 \\
\hline Río Negro & 37,4 & 30,0 & 43,9 & 31,1 & 31,7 & 30,7 & 10,0 & 11,6 & 8,2 \\
\hline
\end{tabular}




\begin{tabular}{|l|r|r|r|r|r|r|r|r|r|} 
Salta & 27,7 & 22,3 & 31,9 & 29,0 & 34,2 & 25,2 & 4,2 & 5,1 & 3,3 \\
\hline San Juan & 38,5 & 33,8 & 42,3 & 27,9 & 31,5 & 25,1 & 9,3 & 10,7 & 7,7 \\
\hline San Luís & 31,6 & 26,9 & 35,4 & 25,9 & 26,1 & 25,8 & 9,8 & 11,8 & 7,6 \\
\hline Santa Cruz & 36,4 & 32,3 & 40,1 & 37,6 & 41,5 & 34,4 & 8,3 & 9,5 & 7,1 \\
\hline Santa Fe & 34,8 & 31,1 & 38,0 & 27,1 & 26,2 & 27,7 & 8,7 & 7,7 & 9,7 \\
\hline Santiago del Estero & 36,4 & 33,4 & 38,8 & 28,2 & 28,6 & 28,0 & 9,3 & 8,5 & 10,2 \\
\hline Tierra del Fuego & 39,3 & 36,9 & 41,1 & 37,3 & 35,3 & 38,7 & 9,5 & 12,6 & 6,2 \\
\hline Tucumán & 35,9 & 31,4 & 39,8 & 30,9 & 33,6 & 28,4 & 6,9 & 8,8 & 4,8 \\
\hline
\end{tabular}

Nota: "Prevalencia de detección": proporción de personas de 18 años y más que detectó mediante estudios médicos alguna de las siguientes enfermedades en su vida respecto del total de personas del mismo grupo etario.

Fuente: "Programa de Vigilancia de la Salud y Control de Enfermedades" VIGI+A e INDEC, Encuesta Nacional de Factores de Riesgo 2005.

\subsubsection{Tablas sobre Estado de Salud de la Población}

Estado de salud general de la población de 18 años y más por sexo según provincia. Localidades de 5.000 y más habitantes. Total del país. Junio de 2005

\begin{tabular}{|c|c|c|c|c|c|}
\hline \multirow{2}{*}{ Provincia } & \multicolumn{5}{|c|}{ Estado de salud general de la población } \\
\hline & Excelente & Muy bueno & Bueno & Regular & Malo \\
\hline Total del país & 9,2 & 25,3 & 45,5 & 17,3 & 2,6 \\
\hline Ciudad de Buenos Aires & 13,9 & 33,0 & 37,8 & 13,3 & 2,0 \\
\hline Buenos Aires & 8,6 & 22,8 & 50,2 & 15,6 & 2,8 \\
\hline Catamarca & 7,7 & 23,8 & 44,7 & 21,5 & 2,3 \\
\hline Chaco & 8,5 & 23,6 & 47,4 & 18,3 & 2,3 \\
\hline Chubut & 11,1 & 28,0 & 44,8 & 13,5 & 2,5 \\
\hline Córdoba & 9,4 & 31,1 & 37,7 & 18,7 & 3,1 \\
\hline Corrientes & 7,0 & 27,9 & 44,3 & 8,2 & 1,3 \\
\hline Entre Ríos & 10,2 & 30,8 & 39,4 & 18,6 & 1,1 \\
\hline Formosa & 5,7 & 13,1 & 51,9 & 26,6 & 2,7 \\
\hline Jujuy & 5,5 & 14,2 & 44,6 & 33,6 & 2,2 \\
\hline La Pampa & 13,4 & 27,6 & 44,8 & 12,2 & 2,1 \\
\hline La Rioja & 7,6 & 19,8 & 47,4 & 22,8 & 2,4 \\
\hline Mendoza & 11,6 & 32,5 & 38,1 & 14,8 & 2,9 \\
\hline Misiones & 8,7 & 25,9 & 41,7 & 21,2 & 2,4 \\
\hline Neuquén & 7,0 & 22,3 & 46,8 & 19,8 & 4,1 \\
\hline Río Negro & 8,2 & 23,7 & 45,8 & 20,0 & 2,3 \\
\hline Salta & 4,0 & 18,6 & 48,2 & 25,2 & 4,0 \\
\hline San Juan & 9,0 & 23,2 & 43,3 & 22,0 & 2,5 \\
\hline San Luís & 10,1 & 24,5 & 41,8 & 21,1 & 2,5 \\
\hline Santa Cruz & 9,5 & 24,9 & 44,7 & 17,4 & 3,5 \\
\hline Santa Fe & 8,9 & 25,4 & 47,4 & 16,4 & 1,9 \\
\hline Santiago del Estero & 7,7 & 21,5 & 44,2 & 24,2 & 2,4 \\
\hline Tierra del Fuego & 24,8 & 53,9 & 92,4 & 31,2 & 2,5 \\
\hline Tucumán & 10,4 & 22,8 & 39,2 & 24,3 & 3,3 \\
\hline
\end{tabular}

Nota: el "Estado de salud general" hace referencia a la percepción del encuestado acerca del mismo.

Fuente: "Programa de Vigilancia de la Salud y Control de Enfermedades" VIGI+A e INDEC, Encuesta Nacional de Factores de Riesgo

Prevalencia de vida, prevalencia de consumo actual, prevalencia de ex consumo y prevalencia de consumo pasivo de tabaco de la población de 18 años y más por sexo, grupo de edad, nivel de instrucción y provincia. Localidades de 5.000 y más habitantes. Total del país. Junio de 2005 


\begin{tabular}{|c|c|c|c|c|}
\hline \multirow{2}{*}{ Población de 18 años y más } & \multicolumn{4}{|c|}{ Prevalencia de } \\
\hline & Vida & Consumo actual & Ex consumo & Consumo pasivo \\
\hline \multicolumn{5}{|l|}{ Sexo } \\
\hline Total & 54,4 & 30,0 & 36,6 & 42,6 \\
\hline Varón & 65,0 & 35,4 & 38,5 & 45,3 \\
\hline Mujer & 44,8 & 25,0 & 33,8 & 40,4 \\
\hline \multicolumn{5}{|l|}{ Grupo de edad } \\
\hline Total & 54,4 & 30,0 & 36,6 & 42,6 \\
\hline 18 a 24 años & 54,2 & 36,2 & 16,7 & 64,2 \\
\hline 25 a 34 años & 53,0 & 34,7 & 24,9 & 49,4 \\
\hline 35 a 49 años & 59,1 & 36,0 & 32,1 & 40,3 \\
\hline 50 a 64 años & 59,1 & 27,2 & 48,7 & 38,4 \\
\hline 65 años y más & 41,8 & 9,2 & 73,7 & 25,3 \\
\hline \multicolumn{5}{|l|}{ Nivel de instrucción } \\
\hline Total & 54,4 & 30,0 & 36,6 & 42,6 \\
\hline Hasta primario incompleto & 48,8 & 24,1 & 43,9 & 37,6 \\
\hline Primario completo - Secundario incompleto & 56,2 & 31,6 & 35,4 & 41,7 \\
\hline Secundario completo & 55,4 & 32,2 & 34,1 & 40,4 \\
\hline Terciario o universitario incompleto y más & 53,5 & 28,6 & 37,5 & 48,8 \\
\hline \multicolumn{5}{|l|}{ Provincia } \\
\hline Total del país & 54,4 & 30,0 & 36,6 & 42,6 \\
\hline Ciudad de Buenos Aires & 61,4 & 27,8 & 46,1 & 43,9 \\
\hline Buenos Aires & 53,9 & 29,8 & 36,2 & 40,2 \\
\hline Catamarca & 54,5 & 34,6 & 27,7 & 54,4 \\
\hline Chaco & 50,4 & 28,0 & 34,7 & 46,2 \\
\hline Chubut & 60,3 & 35,5 & 35,4 & 49,6 \\
\hline Córdoba & 54,6 & 31,3 & 35,5 & 44,8 \\
\hline Corrientes & 46,8 & 29,3 & 28,9 & 43,1 \\
\hline Entre Ríos & 47,3 & 28,1 & 35,1 & 36,5 \\
\hline Formosa & 35,9 & 22,8 & 29,0 & 33,9 \\
\hline Jujuy & 56,5 & 27,5 & 33,7 & 31,9 \\
\hline La Pampa & 55,5 & 35,7 & 30,3 & 40,9 \\
\hline La Rioja & 56,1 & 32,9 & 34,7 & 53,9 \\
\hline Mendoza & 55,5 & 31,8 & 33,3 & 48,5 \\
\hline Misiones & 44,9 & 27,5 & 33,6 & 48,9 \\
\hline Neuquén & 55,9 & 35,5 & 30,6 & 38,9 \\
\hline Río Negro & 63,4 & 32,6 & 40,6 & 42,6 \\
\hline Salta & 57,3 & 32,2 & 30,5 & 39,8 \\
\hline San Juan & 53,0 & 32,0 & 33,8 & 49,6 \\
\hline San Luís & 52,4 & 34,7 & 25,3 & 47,2 \\
\hline Santa Cruz & 70,0 & 41,3 & 33,5 & 52,1 \\
\hline Santa Fe & 52,0 & 27,3 & 41,3 & 44,0 \\
\hline Santiago del Estero & 49,0 & 28,3 & 34,1 & 45,7 \\
\hline Tierra del Fuego & 65,4 & 38,1 & 35,4 & 53,7 \\
\hline Tucumán & 57,1 & 34,3 & 29,5 & 50,1 \\
\hline
\end{tabular}

Nota:

Prevalencia de vida: proporción de personas de 18 años y más que fumó cigarrillos alguna vez en su vida respecto del total de personas del mismo grupo etario.

Prevalencia de consumo actual: proporción de personas de 18 años y más que fuman todos o algunos días en la actualidad y que a lo largo de su vida han fumado al menos 100 cigarrillos respecto del total de personas del mismo grupo etario.

Prevalencia de ex consumo: proporción de personas de 18 años y más que alguna vez en su vida fumaron al menos 100 cigarrillos y no fuman actualmente respecto del total de personas del mismo grupo etario. 
Evolución del Mercado de Seguros de Vida en Argentina - Restricciones para el Crecimiento

Prevalencia de consumo pasivo: proporción de personas de 18 años y más que no fuman en la actualidad y que habitualmente están expuestas, en su entorno, a personas que fuman respecto del total de personas del mismo grupo etario.

Fuente: "Programa de Vigilancia de la Salud y Control de Enfermedades" VIGI+A e INDEC, Encuesta Nacional de Factores de Riesgo 2005. 